Nelzair Araujo Vianna

\title{
Poluição do ar em Salvador, Bahia : uma abordagem para a tomada de decisão baseada em análise de riscos
}

Tese apresentada à Faculdade de Medicina da Universidade de São Paulo para obtenção do título de Doutor em Ciências

Programa de Pós-graduação em Patologia

Orientador: Prof. Dr. Paulo Hilário Nascimento Saldiva

São Paulo

2014 


\section{Dados Internacionais de Catalogação na Publicação (CIP)}

Preparada pela Biblioteca da

Faculdade de Medicina da Universidade de São Paulo

Creprodução autorizada pelo autor

\section{Vianna, Nelzair Araujo}

Poluição do ar em Salvador, Bahia : uma abordagem para a tomada de decisão baseada em análise de riscos / Nelzair Araujo Vianna. -- São Paulo, 2014.

Tese(doutorado)--Faculdade de Medicina da Universidade de São Paulo.

Programa de Patologia.

Orientador: Paulo Hilário Nascimento Saldiva.

Descritores: 1.Poluição do ar 2.Tomada de decisões 3.Qualidade do ar 4.Vigilância em saúde ambiental 5.Análise de risco 6.Monitoramento ambiental 7.Microscopia eletrônica 8.Poluentes do ar 9.Espectrofotometria atômica 10.Saúde ambiental

USP/FM/DBD-252/14 


\section{DEDICATÓRIA}

Aos meus filhos Alice, Rafael e Julia, que sejam inspirados infinitamente no aprender para ser.

Aos meus Pais e Família que são a fonte inesgotável de amor na minha vida. 


\section{AGRADECIMENTOS}

Agradecer em primeiro lugar a Deus por permitir todas as condições necessárias para a realização deste trabalho.

A inspiração é algo fundamental para que os nossos objetivos estejam sempre firmes e que possamos superar todos os obstáculos na realização de um sonho. Sem dúvida, sinto-me privilegiada pela orientação do Prof. Paulo Saldiva, que desde o primeiro contato, manteve acesa em mim a chama do entusiasmo, alimentada constantemente pela fonte de inspiração de sua magnífica pessoa e admirável vida acadêmica. Agradeço ao Professor pela confiança, por aceitar uma iniciante pesquisadora em seu grupo de pesquisa, pela oportunidade de participar da coordenação de dois projetos do Edital 18-CNPq, acreditando na capacitação profissional em serviço de Vigilância em Saúde Ambiental. Pela sede de aprender, nossos encontros talvez não tenham sido em número de vezes que eu havia idealizado, mas certamente em todos eles pude ter a honra de aprender, crescer e principalmente conviver com tão humilde pessoa, podendo assimilar um pouco desse grande exemplo e poder incorporar em minha conduta profissional. Nessas pequenas ocasiões agradeço pelo prazer de recebe-lo em Salvador, seja para fazer nossas reuniões no trajeto do aeroporto até seu compromisso, nos intervalos das suas apresentações, especialmente recebê-lo em minha casa e poder apresenta-lo aos meus filhos, naquele almoço improvisado. Todos esses momentos serão inesquecíveis em minha mente.

Delimitar o tempo de início desta tese para agradecer pessoas que fizeram parte em algum momento seria impreciso, pois algumas delas, muito antes, já estariam permanentemente nos influenciando, especialmente por ter acreditado em nossa capacidade e em nossos sonhos. Algumas delas mesmo não podendo estar lado a lado, 
no dia a dia, em cada troca de filtro, em cada experimento, no aprendizado de corredores, em todo o período dessa tese, mesmo assim conseguiu fazer parte de todas as etapas simplesmente pelo que representou antes de iniciar este trabalho e ainda pelo que representa em todos os momentos, de alguma forma se fazendo presente como fonte inesgotável de energia. O meu especial agradecimento ao Prof. Dr. Leonardo Rodrigues de Andrade, da Universidade Federal do Rio de Janeiro, pelos seus sólidos ensinamentos profissionais e de caráter, pelo envolvimento e discussão ainda no delineamento do estudo, pela coleta de dados utilizados nesta tese, pelos compromissos assumidos e cumpridos.

À competente Secretária Liduvina pelas orientações no processo de seleção e inscrição no Doutorado.

Ao Prof. Dr. Luis Alfésio por me receber na Pós-graduação e pelas discussões iniciais do projeto de doutorado.

Ao Núcleo de Epidemiologia Ambiental da FMUSP, em especial Profa. Dra. Lourdes Martins e Prof. Dr. Luiz Alberto Amador pelas discussões enriquecedoras de alinhamento da pesquisa e análises estatísticas.

À colega Samya de Lara Pinheiro pela convivência harmoniosa e recepção calorosa nas minhas estadias em São Paulo. Por estar sempre disponível e compartilhar experiências.

À toda equipe do LPAE que facilitou o empréstimo de equipamentos e processamento de análises.

Ao Prof. Dr. Raymundo Azevedo pela disponibilidade, pelos skypes e convivência, ainda que virtual, mas muito presente na resolução de todos os encaminhamentos necessários para a realização deste doutorado. 
Ao Thiago Rezende por toda atenção, esclarecendo de maneira sempre cordial as minhas intermináveis dúvidas sobre as normas, disciplinas, formato de tese, créditos, matrícula, etc., durante todo o curso.

Às Secretárias Fátima e Rosana, sempre atenciosas, facilitando o acesso à tão concorrida agenda do Professor e eficiência no encaminhamento de toda documentação necessária.

À Profa. Dra. Luciana Gatti, pelo apoio e incentivo no início das pesquisas, disponibilizando o Laboratório de Química Atmosférica do IPEN.

Ao Prof. Dr. Olaf Malm da Universidade Federal do Rio de Janeiro, pela disponibilidade do Laboratório de Radioisótopos e sua equipe técnica, Adan e Ricardo, pelo apoio nas análises.

Ao Dr. Vinicius Antão, da ATSDR -Agency Toxic Substances and Disease Registry, pelo convite para o curso Mapping Public Health Data using GIS, oferecido pelo Geospatial Research, Analysis, and Services Program (GRASP), e sua pronta colaboração.

À Secretaria Municipal de Saúde de Salvador, por concordar na elaboração desta tese e realização com o apoio institucional.

Aos colegas da VISAMB - Vigilância em Saúde Ambiental de Salvador: Lumaria, Lourenço, Lídice, Marcio, Flavia, Barbara, Adriana, Elizangela, Antônio Raimundo, Patrícia, Sonia, Janete, Aline, Gilvan e Herbert, pessoas que presenciaram todas as fases dessa tese, testemunhando os momentos de glória e os outros nem tão gloriosos assim, momentos onde tive que superar muitos obstáculos ou até mudar estratégias. Tive a certeza de poder contar com a compreensão de pessoas maravilhosas que tem o privilégio de compartilhar um ambiente de trabalho muito mais que especial. À vocês colegas, obrigada pela paciência com a minha persistência, e muitas vezes 
insistência nas abordagens. Desculpe se em algum momento tive que ser firme e defender veemente meus ideais e pontos de vista, e que de forma não intencional possa ter exaurido todos vocês.

À Secretaria Estadual de Meio Ambiente, pelo apoio institucional, financeiro e investimento na discussão deste tema em Salvador.

Ao ProAR - Programa de Asma e Rinite, da Universidade Federal da Bahia, agradecimento especial ao Prof. Dr. Álvaro Cruz e ao Prof. Dr. Adelmir Machado, pelo constante incentivo e oportunidade de colaboração.

Aos colegas do Departamento de Medicina Preventiva da Universidade Federal da Bahia, em especial ao Prof. Dr. Marco Antônio Rêgo Vasconcelos, onde recebi apoio, na ocasião como Professora Substituta, para desenvolver esta tese.

À Profa. Dra. Sandra Hacon, pelo seu carisma, atenção e exemplo a ser seguido na pesquisa aplicada, com envolvimento da comunidade e socialização de métodos, por atender inúmeras vezes aos nossos convites em workshops para construção da rede de pesquisa em saúde ambiental na Bahia.

À Profa. Dra Simone Miraglia, também pela disponibilidade em atender aos nossos encontros para desenvolvimento da pesquisa na Bahia e pelo colaboração nos resultados desta tese.

A Dra. Priscila Novaes pela colaboração no estudo de avaliação à saúde dos trabalhadores no carnaval de Salvador.

Aos voluntários que participaram do estudo.

Aos colegas que se reuniam semanalmente pelo grupo do INCT-CITECS, no Instituto de Saúde Coletiva da Universidade Federal da Bahia, pelo momento que acreditaram na formação do Núcleo e da estruturação da nossa rede de pesquisa. Ao 
INCT/CITECS especialmente pelo apoio para o organização do curso sobre comunicação de riscos com a Profa. Ana Rosa Moreno, que muito contribuiu para nortear um dos capítulos desta tese.

Aos colegas do LEMB-Laboratório de Epidemiologia Molecular e Bioestatística, da Fundação Oswaldo Cruz, Bahia, em especial ao Dr. Edson Duarte Moreira Junior, que permitiu a minha dedicação à etapa final de construção desta tese, além de revisar os manuscritos auxiliando na formatação final.

Às colegas doutorandas contemporâneas de outros programas, em especial Laíse Campos, pela ajuda na revisão de resultados.

À minha família por entender os momentos de privação em muitos dos nossos fins de semana, feriado e tantos momentos de lazer que foram substituídos pelo objetivo de realização deste trabalho.

À Capes pelo auxílio da bolsa de Doutorado.

Aos amigos e amigas que atentamente me escuta em todos os momentos de angústia e comemoram a cada pequena vitória alcançada com este trabalho.

Sou grata não somente a tantos encontros, como também aos desencontros, porque todos eles foram essenciais para o meu crescimento pessoal e profissional. 
"Cada um que passa em nossa vida, passa sozinho, pois cada pessoa é única e nenhuma substitui outra.

Cada um que passa em nossa vida, passa sozinho, mas não vai só nem nos deixa sós.

Leva um pouco de nós mesmos, deixa um pouco de si mesmo.

Há os que levam muito, mas há os que não levam nada. Essa é a maior responsabilidade de nossa vida, e a prova de que duas almas não se encontram ao acaso. " 
...e ainda que tivesse o dom da profecia, e conhecesse todos os mistérios e toda a ciência, e ainda que tivesse toda a fé, de maneira tal que transportasse os montes, $e$ não tivesse Amor, nada seria... Tudo tolera, tudo crê, tudo espera e tudo suporta. O Amor nunca falha..." 


\section{NORMATIZAÇÃO ADOTADA}

Esta tese está de acordo com as seguintes normas, em vigor no momento desta publicação:

Referências: adaptado de International Committee of Medical Journals Editors (Vancouver)

Universidade de São Paulo. Faculdade de Medicina. Serviço de Biblioteca e Documentação. Guia de Apresentação de dissertações, teses e monografias. Elaborado por Annelise Carneiro da Cunha, Maria Julia de A. L. Freddi, Maria F. Crestana, Marinalva de Souza Aragão, Suely Campos Cardoso, Valéria Vilhena. 3a ed. São Paulo: Serviço de biblioteca e Documentação; 2011.

Abreviaturas dos títulos dos periódicos de acordo com List of Journals Indexed in Index Medicus. 


\section{SUMÁRIO}

Lista de siglas

Lista de símbolos

Lista de figuras

Lista de tabelas

Resumo

Summary

1 INTRODUÇÃO......................................................................................... 1

1.1 Poluição do ar e efeitos sobre a saúde...........................................................4

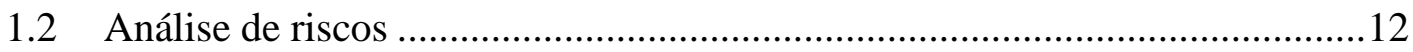

1.2.1 Abordagens em Análise de Riscos e Política Pública...................... 13

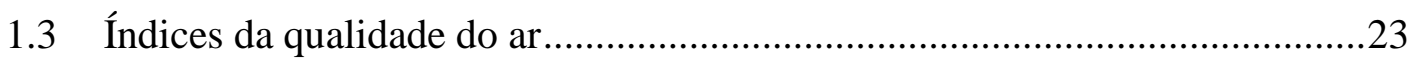

1.4 Vigilância em saúde ambiental relacionada à qualidade do ar ......................28

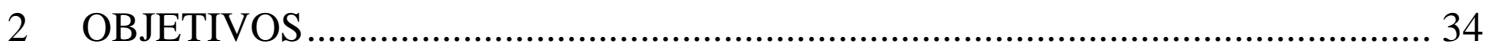

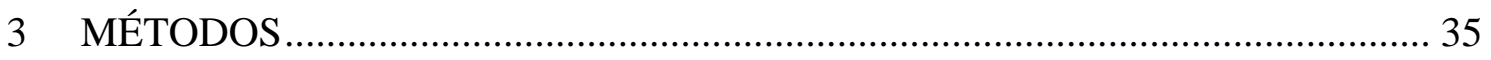

3.1 Metodologia Análise de Riscos - Modelo conceitual....................................35

3.2 ESTUDO 1 - Estudo de Biomonitoramento .................................................36

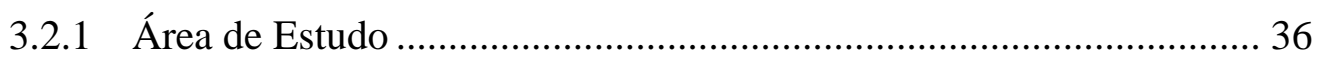

3.2.2 Exposição atmosférica do biomonitor tillandsia usneoides para acessar o material particulado ....................................................... 38

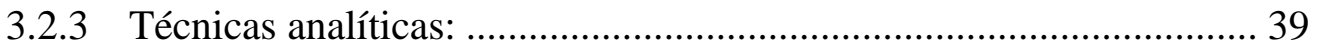

3.3 ESTUDO 2 : Estudo de Caso em evento de massa com abordagem em

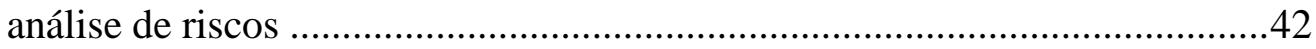

3.3.1 FASE 1 - Identificação do Perigo.................................................. 42

3.3.2 FASE 2 - Estudo de avaliação da exposição à saúde humana .......... 45

3.3.3 FASE 3 - Gerenciamento do Risco ............................................. 49

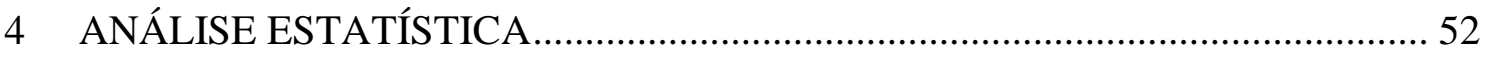

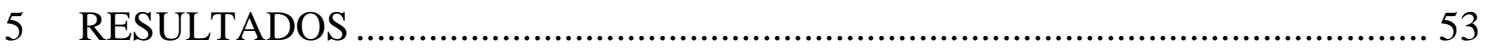

5.1 Quantificação de metais no material particulado por espectrofotometria

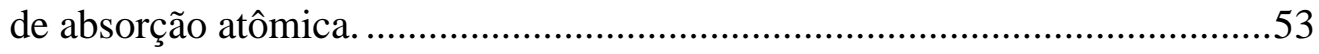

5.2 Análise morfológica e elementar por microscopia eletrônica de varredura .........57

5.3 Espectros de microscopia eletrônica de varredura com microanálise de raios-x (EDS) 
5.4 RESULTADOS ARTIGO 2 - Análise de Risco: Estudo de Caso . .64

5.4.1 Etapa 1 - Identificação do Perigo ……............................................. 64

5.4.2 Etapa 2: Avaliação de exposição à saúde humana ............................. 68

5.4.3 Etapa 3 - Etapa de comunicação de riscos........................................ 68

5.4.4 Resultados em tomada de decisão local .......................................... 69

6 DISCUSSÃO

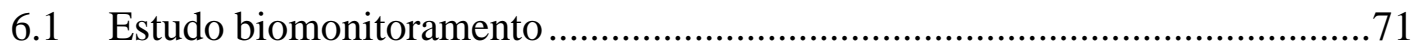

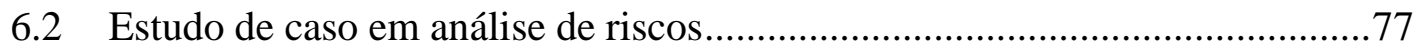

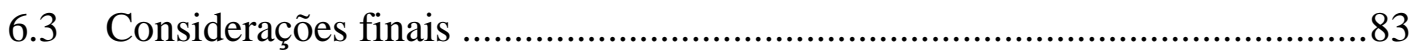

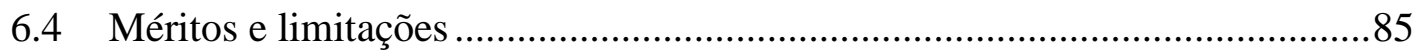

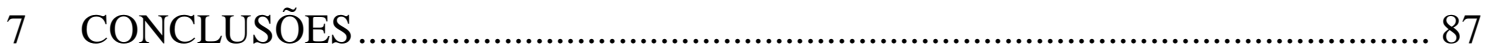

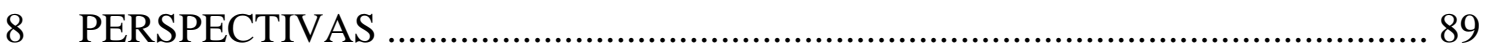

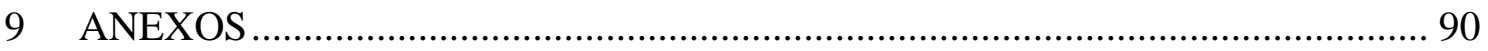

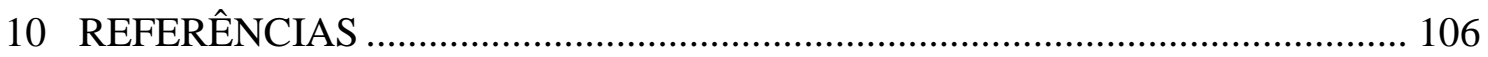




\section{LISTA DE SIGLAS}

EPA

$\mathrm{CDC}$

ATSDR

OMS

MS

SMS

SEMA

INEMA

SMA

IPEN

ProAR

UFRJ

Cetrel

UFBA

CAPES

CAPPesp

CONAMA

FMUSP

USP

AIS

MEV

SUS

VIGIAR

VISAMB

IQA
Environmental Protection Agency

Centers for Disease Control and Prevention

Agency for Toxic Substances and Disease Registry

Organização Mundial de Saúde

Ministério da Saúde

Secretaria Municipal de Saúde

Secretaria de Meio Ambiente da Bahia

Instituto Estadual de Meio Ambiente

Superintendência de Meio Ambiente

Instituto de Pesquisas Energéticas e Nucleares

Programa de Asma e Rinite da Bahia

Universidade Federal do Rio de Janeiro

Central de Tratamento de Efluentes

Universidade Federal da Bahia

Coordenação de Aperfeiçoamento de Pessoal de Nível Superior

Comissão de Ética para Análises dos Projetos de Pesquisa

Conselho Nacional de Meio Ambiente

Faculdade de Medicina da Universidade de São Paulo

Universidade de São Paulo

Avaliação de Impacto à Saúde

Microscopia Eletrônica de Varredura

Sistema Único de Saúde

Vigilância em Saúde Relacionada à Qualidade do Ar

Vigilância em Saúde Ambiental

Índice de Qualidade do Ar 


\section{LISTA DE SÍMBOLOS}

$\begin{array}{ll}\mathrm{NO} & \text { Óxido de Nitrogênio } \\ \mathrm{NO} 2 & \text { Dióxido de Nitrogênio } \\ \mathrm{O} 3 & \text { Ozônio } \\ \mathrm{SO} 2 & \text { Dióxido de Enxofre } \\ \mathrm{CO} & \text { Monóxido de Carbono } \\ \mathrm{MP} 10 & \text { Material Particulado de tamanho aerodinâmico } 10 \text { micrômetros } \\ \mathrm{MP} 2,5 & \text { Material particulado de tamanho aerodinâmico 2,5 micrômetros } \\ \mathrm{mm} & \text { Milímetro } \\ \mathrm{mg} & \text { Miligrama } \\ \mu \mathrm{g} / \mathrm{m}^{3} & \text { Micrograma por metro cúbico } \\ \mu \mathrm{m} & \text { Micrômetro }\end{array}$




\section{LISTA DE FIGURAS}

Figura 1. Representação esquemática comparando o tamanho das particulas ultrafinas, finas, grossas e torácicas, com outras estruturas. Brook R et al. Circulation 2004; 109:2655-2671

Figura 2. Estimativas de risco fornecidas por vários estudos de coorte por incremento de $10 \mu \mathrm{g} / \mathrm{m}^{3}$ em PM2.5 ou PM10

Figura 3. Vias do mecanismo fisiopatológico para doenças cardiovasculares decorrentes da exposição ao material particulado

Figura 4. Mortes atribuíveis aos efeitos da poluição do ar de ambientes internos e externos em 2012, por categoria de doenças (WHO, 2014)

Figura 5. As cinco principais doenças pulmonares e seus condutores ambientais, extraído de Schulger $2014^{(61)}$

Figura 6. Desenho esquemático representando as etapas do processo de análise de riscos, segundo National Research Council, 2009.

Figura 7. Desenho esquemático representando de forma simplificada o processo de análise de riscos

Figura 8. Estudos de avaliação de risco à saúde humana por exposição à substâncias químicas, extraída do módulo 1 IESC/UFRJ, 2013

Figura 9. Visão geral sobre o processo de avaliação de saúde pública, segundo modelo da ATSDR (adaptado) $)^{(13)}$

Figura 10. Apresentação esquemática dos principais passos da avaliação de impacto à saúde (AIS). Adaptação WHO, Air Quality Guidelines, Global Updadte 2005

Figura 11. 1Modelo esquemático sobre a lógica de atuação do VIGIAR

Figura 12. Mapa dos locais de monitoramento na cidade de Salvador, Bahia, Brasil ...38

Figura 13. Fotos das amostras de Tillandsia usneoides expostas nas estações de monitoramento da qualidade do ar e foto com detalhe das cestas com teto de acrílico contendo a planta

Figura 14. Fotos ilustrando os stubs com Tillandsia usneoides preparados para análise em microscopia eletrônica de varredura

Figura 15. Mapa do Circuito de carnaval em Salvador.

Figura 16. Fotos ilustrando a utilização do nefelômetro para medidas de PM 2,5 em cima do trio visualizando ao fundo camarote aberto (foto 1) e sacada (foto 2) com foliões. 
Figura 17. Foto ilustrando demarcação em cartolina aderida ao poste para coleta de poeira acumulada no período de 7 dias, no circuito do carnaval.

Figura 18. Foto de trabalhadores (cordeiros) expostos durante o evento

Figura 19. Foto ilustrando o procedimento de coleta para a citologia

Figura 20. Foto apresentando os métodos: determinação de NO2 pelo método de tubo passivo e medidas de metais no material particulado por Biomonitoramento .....

Figura 21. Foto de Reunião entre os pesquisadores Nelzair Vianna, Dr. Leonardo Andrade e o Secretário de Meio Ambiente da Bahia Dr. Juliano Matos......49

Figura 22. Foto de entrevista concedida à TV na etapa de comunicação do risco

Figura 23. Matéria publicada em site institucional exemplificando a etapa de comunicação de riscos

Figura 24 (A, B, C e D). MEV de Tillandsia usneoides que foram expostas no bairro Campo Grande por 45 dias, mostrando o material particulado adsorvido na superfície da planta

Figura 25 (A, B, C e D). MEV de Tillandsia usneoides que foram expostas no bairro Dique do Tororó por 45 dias, mostrando o material particulado adsorvido na superfície da planta. Fig. 2A: Imagem de baixo aumento mostrando diferentes partículas sobre as escamas. Fig. 2C: Partícula poligonal com partículas menores aderidas

Figura 26 (A, B, C, D, E e F). MEV de Tillandsia usneoides que foram expostas no bairro Pituba por 45 dias no verão, mostrando o material particulado adsorvido na superfície da planta. A: Detalhe de um tricoma.....

Figura 27 (A, B, C e D). MEV de Tillandsia usneoides que foram expostas no bairro Paralela por 45 dias no verão, mostrando o material particulado adsorvido na superfície da planta. A: Imagem pequeno aumento mostrando detalhe de aglomeração em partículas adsorvidas na superfície da planta. B: partícula apresentando superfície plana. C: Imagem apresentando detalhe de partículas menores que $5 \mu \mathrm{m}$

Figura 28 (A, B, C e D). MEV de Tillandsia usneoides que foram expostas no bairro Pirajá por 45 dias no verão, mostrando o material particulado adsorvido na superfície da planta

Figura 29. Espectro de caracterização elementar por microscopia eletrônica de varredura (microanálise de raios-X) da partícula adsorvida na superfície da planta....

Figura 30. Distribuição das partículas por tamanho aerodinâmico retidas pelo biomonitor. 


\section{LISTA DE TABELAS}

Tabela 1. Concentrações de metais encontradas no material particulado em Salvador (BA) referentes amostragem (outono) - Fase 2, expressos em mg/g.

Tabela 2. Concentração de PM2.5 $\left(\mu \mathrm{g} / \mathbf{m}^{3}\right)$ por nefelometria nas áreas controle, trios novos, trios velhos e concentração de trios. Os valores estão expressos em medias e desvio padrão

Tabela 3. Concentração de material particulado total medido pelo método gravimétrico $(\mu \mathrm{g})$.

Tabela 4. Concentrações de material particulado medidos pela nefelometria em áreas de camarotes no circuito do carnaval (Sacadas, Camarotes com ventilação natural, Camarotes climatizados)

Tabela 5. Concentrações de $\mathrm{NO}_{2}$ obtido pelo método de tubo passivo $\left(\mu \mathrm{g} / \mathrm{m}^{3}\right)$ .68

Tabela 6. Lista de matérias publicadas em mídias

Tabela 7. Ciência e Política Pública sobre Qualidade do Ar em Salvador, BA, resultantes da Ação Intersetorial 


\section{RESUMO}

Vianna NA. Poluição do ar em Salvador, BA: Uma abordagem baseada em análise de risco para a tomada de decisão [tese]. São Paulo: Faculdade de Medicina, Universidade de São Paulo; 2014. 117p.

Bases científicas para o entendimento dos efeitos da poluição atmosférica sobre a saúde humana são ainda necessárias em todo o mundo, considerando que os dados locais devem ser utilizados como parâmetro para tomada de decisão e controle da poluição do ar. Países em desenvolvimento carecem de tecnologia para detecção e mensuração dos níveis de poluição do ar, o que dificulta a atualização de legislação sobre padrões da qualidade do ar para o controle das fontes emissoras. Diversas abordagens metodológicas tem sido sugeridas por agências internacionais, no entanto para o contexto local faz-se necessário adaptações que resulte em métodos replicáveis pelas agências brasileiras. No Brasil, o Ministério da Saúde, através da Vigilância em Saúde Ambiental, estimula o desenvolvimento de metodologias que possam viabilizar a implementação do programa de vigilância em saúde relacionada à qualidade do ar. $\mathrm{O}$ objetivo deste estudo foi aplicar a metodologia de análise de riscos para avaliar a qualidade do ar na cidade de Salvador e o impacto sobre a saúde, na perspectiva de implantação de ações da Vigilância em Saúde Ambiental. Este estudo se caracteriza como ciência no contexto da ação. Foram realizados dois estudos para aplicação da metodologia proposta. No primeiro estudo, em fase de identificação do perigo, os poluentes foram caracterizados em termos de sua composição química, utilizando a técnica de biomonitoramento como ferramenta alternativa para acessar as partículas presentes na atmosfera urbana. Para a detecção de metais no material particulado foram utilizadas técnicas analíticas de espectrofotometria de absorção atômica e para a análise morfológica destas partículas foram utilizadas técnicas de microscopia eletrônica de varredura convencional e micro análises de raios-x. A composição química do material particulado foi estudada para entendimento das emissões locais. No segundo estudo, além da identificação do contaminante e caracterização do risco foi também avaliado a exposição à saúde humana. Estratégias de comunicação de riscos foram utilizadas para o envolvimento de partes interessadas. Os resultados de contaminação atmosférica observados nesta tese sugerem que as ferramentas aplicadas no contexto da análise de riscos, em suas diversas etapas, são viáveis, apresentando evidências científicas aos tomadores de decisão, e assim contribuindo com novas tecnologias para o SUS, especialmente na implementação de programa em vigilância da saúde relacionada à qualidade do ar.

Descritores: 1.Poluição do ar 2.Tomada de decisões 3.Qualidade do ar 4.Vigilância em saúde ambiental 5.Análise de risco 6.Monitoramento ambiental 7.Microscopia eletrônica 8.Poluentes do ar 9.Espectrofotometria atômica 10.Saúde ambiental 


\section{SUMMARY}

Vianna NA. Air pollution in Salvador, Bahia: Air pollution in Salvador, Bahia: an approach based on risk analysis for decision making [thesis]. Sao Paulo: "Faculdade de Medicina, Universidade de São Paulo"; 2014. 117p.

Scientific bases for understanding the effects of atmospheric pollution on human health are still necessary in all parts of the world, considering that local data should be used as a parameter for decision-making and the control of air pollution. Developing countries lack the technology to detect and measure levels of air pollution, making it difficult to update legislation on air quality standards for the control of emission sources. Several methodological approaches have been suggested by international agencies, however for the local context it is necessary to make adjustments that will result in replicable methods across Brazilian agencies. In Brazil, the Ministry of Health, through the Environmental Health Surveillance, stimulates the development of methodologies that can facilitate the implementation of a health surveillance program related to air quality. The objective of this study was to apply risk analysis methods to evaluate the air quality of the city of Salvador and its impact on health, from the perspective of the Environmental Health Surveillance's regulatory actions. This study is characterized by science and decision. Two studies were conducted that applied the proposed methods. In the first study, during the hazard identification phase, pollutants were characterized in terms of their chemical composition using a biomonitoring technique as an alternative tool to access the particles present in the urban atmosphere. The analytic techniques of atomic absorption spectrophotometry were used for the detection of metals in the particulate matter, and for the morphologic analysis of these particles, conventional scanning electron microscopy and X-ray microanalysis techniques were used. The chemical composition of the particulate matter was then studied to understand local emissions. In the second study, in addition to contaminant identification and risk characterization, human health exposure was also evaluated. Risk communication strategies were used for the involvement of stakeholders. The observed results of atmospheric contamination in this thesis suggest that the applied tools within the context of risk analysis, in its diverse stages, are viable and present scientific evidence to decision-making, thus contributing new technologies for National Health System, particularly the implementation of a health surveillance program related to air quality.

Descriptors: 1.Air pollution 2.Decision making 3.Air quality 4.Environmental health surveillance 5.Risk analysis 6.Environmental monitoring 7.Electron microscopy 8.Air pollutants 9.Spectrophotometry 10.Environmental Health 


\section{INTRODUÇÃO}

Evidências científicas são necessários para orientar a tomada de decisão relativa aos riscos ambientais em que a população tem sido constantemente exposta, incluindo perspectivas de um adequado gerenciamento das fontes poluidoras ${ }^{(1)}$. Neste contexto, abordagens que possam favorecer o diálogo entre ciência e políticas públicas tem sido estimuladas em todo o mundo ${ }^{(2)}$. Por outro lado, as fronteiras entre os saberes que envolvem o processo de análise do risco ${ }^{(3)}$, em suas distintas etapas, ainda constituem um grande desafio para a ciência ${ }^{(4)}$, sobretudo pela necessidade de articulação entre as partes interessadas no processo decisório, sejam academia, governo, setor privado ou comunidade ${ }^{(5)}$. O diálogo entre estudos epidemiológicos e processos de avaliação de riscos são estimulados para a redução de incertezas na tomada de decisão ${ }^{(6)(7)}$.

Não obstante as limitações e a necessidade de desenvolver métodos mais adequados, estudos de avaliação de impacto na saúde podem ser informativo e eficazes como meio de comunicação com o público em geral, para os tomadores de decisão e outras partes interessadas, para alimentar evidências científicas disponíveis para o processo de formulação de políticas, chamando a atenção para a urgente necessidade de medidas que possam reduzir um importante fator de risco para a saúde de milhões de pessoas em todo o mundo ${ }^{(8)}$. Neste contexto estão inseridos os pilares que sustentaram a motivação e o esforço para a realização desta tese.

Este estudo foi concebido com perspectivas de implementação do Programa de Vigilância em Saúde relacionada à Qualidade do Ar (VIGIAR) da Secretaria Municipal 
de Saúde de Salvador. A articulação intersetorial se constituiu como eixo central, desde as primeiras linhas de concepção do projeto, de acordo com o preconizado pela Instrução Normativa n 1/2005 publicada pelo Ministério da Saúde ${ }^{(9)}$, cujas bases sustentam as diretrizes do Subsistema Nacional de Vigilância em Saúde Ambiental.

Em cada experimento realizado busquei registrar as etapas do processo que pretendeu gerar um modelo de análise de risco no cenário local, desde a identificação do perigo até a tomada de decisão em políticas públicas, visando o gerenciamento da qualidade do ar no contexto local. Assim, todas as etapas do trabalho foram conduzidas e interpretadas sob o enfoque da metodologia proposta ${ }^{(3)}$, sob a perspectiva de desenvolvimento da ciência no contexto da ação.

O modelo teórico conceitual para descrição do processo de análise de risco foi adaptado para a realidade local de acordo com três bases teóricas, considerando aproximar um modelo passível de ser aplicado em regiões economicamente menos favorecidas. Utilizei bases dos modelos conceituais da Organização Mundial de Saúde (OMS) ${ }^{(1)}$, da Agency for Toxic Substances and Disease Registry (ATSDR) ${ }^{(10)}$ e da agencia de proteção ambiental americana - Environmental Protection Agency (EPA) ${ }^{(3)}$.

Considerando a transdisciplinaridade, bem como a diversidade de métodos, técnicas e saberes, sendo elementos necessários para a aplicação da análise de riscos ${ }^{(4)}$, optei por separar os resultados dos estudos realizados, didaticamente identificados em estudo 1 e estudo 2. Em ambos, além dos dados descritivos das análises quantitativas, enfatizo a descrição do processo, no contexto local, onde transcorreram os experimentos.

O primeiro estudo, utilizando o biomonitoramento para a identificação do perigo, constituiu etapa inicial do processo de análise de riscos em Salvador. Até a data de início desta tese não existia rede automática de monitoramento da qualidade do ar na Cidade e portanto, nenhuma série histórica com dados relativos às condições do ar nos locais a 
serem estudados, fato que motivou a utilização de método alternativo para detecção de contaminantes atmosféricos urbanos. Este método tem sido utilizado principalmente em locais que não possuem sistema de monitoramento automatizados para detecção de metais na atmosfera. Esta técnica tem sido também utilizada como forma de se conhecer ou apresentar dados iniciais que indiquem a presença de contaminação por metais na atmosfera, ainda que não substitua a longo prazo, um plano para aquisição de dados por estações de monitoramento, que possuem maior precisão de medição, não só para material particulado, mas para outros poluentes atmosféricos como ozônio, monóxido e dióxido de carbono, dióxido de enxofre, dióxido de nitrogênio, etc. ${ }^{(11)}$. O biomonitoramento por ser contínuo, foi realizado em outras fases ${ }^{(12)}$, mesmo após a instalação da rede automatizada em Salvador. Em anexo se encontra o nosso artigo publicado com foco neste método ${ }^{(11)}$.

O segundo estudo apresentado nesta tese se refere ao experimento (estudo de caso) que utilizou o cenário o carnaval de Salvador como campo de pesquisa. Os experimentos foram realizadas por três anos consecutivos, onde foram exemplificadas as fases de um processo de análise de risco, aplicando métodos e técnicas específicas na coleta e análise de dados. A abordagem metodológica foi essencialmente baseada em análise de riscos para a condução e interpretação dos dados coletados. O processo descrito neste estudo de caso destaca as três principais fases, quais sejam: 1) identificação do perigo; 2) caracterização do risco (avaliação de risco e exposição à saúde humana) e 3) gerenciamento do risco. A comunicação de riscos ${ }^{(13)(14)}$ perpassa por todas as fases durante o período destes experimentos. As evidências científicas foram utilizadas como base científica para implementação de políticas públicas locais e os resultados de impacto social estão descritos em ordem cronológica como anexo desta tese. 


\subsection{Poluição do ar e efeitos sobre a saúde}

A poluição atmosférica é caracterizada pela presença de substâncias indesejáveis no ar em quantidades que podem representar riscos à saúde humana e ao meio ambiente ${ }^{(15)}$. Há uma diversidade de poluentes que são lançados na atmosfera, seja por fontes naturais ou antropogênicas, dentre eles monóxido de carbono, óxidos de nitrogênio, óxidos de enxofre, compostos orgânicos voláteis e material particulado. Diversos estudos tem demonstrado a presença desses poluentes na contaminação atmosférica associando aos efeitos à saúde humana ${ }^{(16)(17)(18)(19)}$. Estudos tem demonstrado que o clima também está associado com o incremento de mortalidade ${ }^{(20)}$.

Alguns destes poluentes são mais consistentemente associados aos efeitos adversos à saúde, a exemplo do material particulado ${ }^{(21)(22)(23)(24)(25)(26)(27)(28-31)(32)(33)(34)(35)}$.

O material particulado consiste numa mistura de componentes químicos orgânicos e inorgânicos, a depender das fontes emissoras presentes no local. É uma mistura de partículas líquidas e sólidas em suspensão no ar. Elas se apresentam em frações grossas, finas e ultrafinas, que variam em tamanho aerodinâmico entre $0,1 \mu \mathrm{m}$ a $10 \mu \mathrm{m}$ conforme demonstrado comparativamente na figura abaixo. Partículas de $10 \mu \mathrm{m}$ são também conhecidas como partículas inaláveis ou fração torácica ${ }^{(36)}$. 

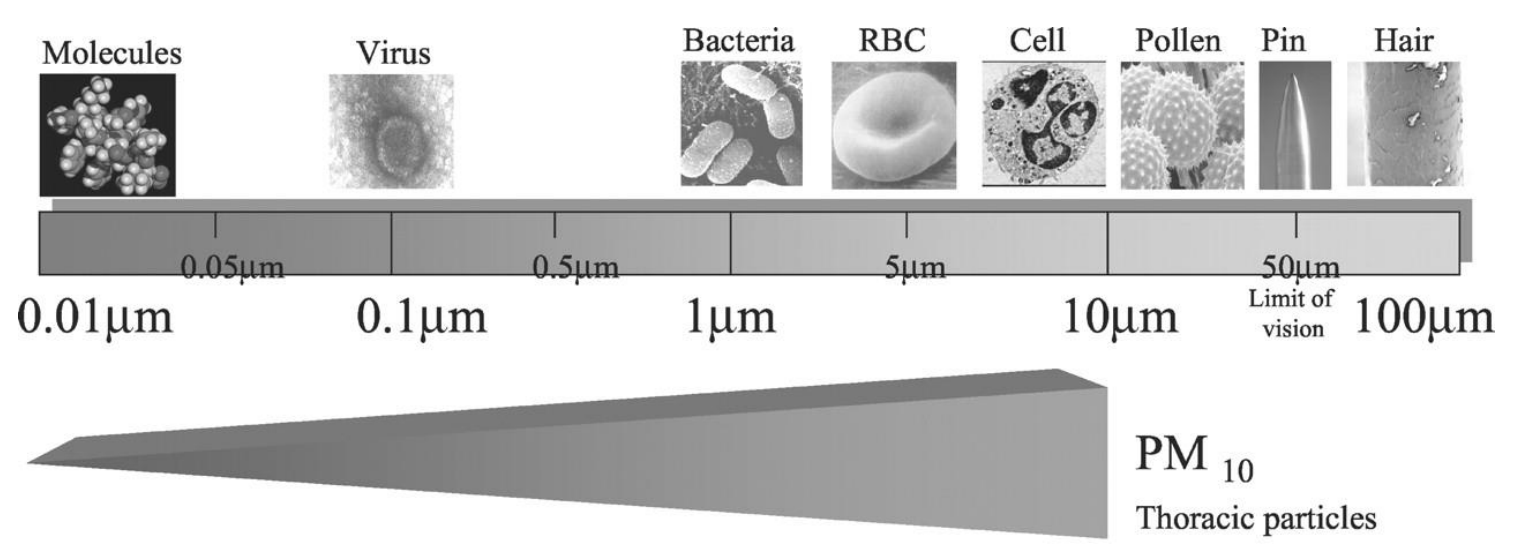

$\mathrm{PM}_{10}$

Thoracic particles

$\mathrm{PM}_{10-2.5}$

Coarse fraction

\section{$\mathrm{PM}_{2.5}$}

Fine particles

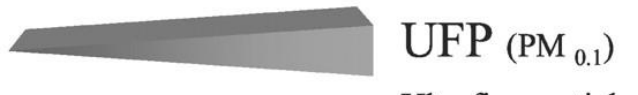

Ultrafine particles

Figura 1. Representação esquemática comparando o tamanho das particulas ultrafinas, finas, grossas e torácicas, com outras estruturas. Brook R et al. Circulation 2004; 109:2655-2671

O material particulado emitido pela combustão do diesel, é considerado o maior contaminante atmosférico em áreas urbanas e o principal responsável pela emissão de partículas finas com tamanho aerodinâmico menor que $2.5 \mu \mathrm{m}$ (PM 2.5). O diesel se comparadas à gasolina, emite um numero 100 vezes maior de partículas considerando o mesmo percurso de viagem ${ }^{(37)}$.

A poluição do ar emitida pelo diesel tem sido associada a doenças agudas e crônicas ${ }^{(38)(39)(40)(41)(42)}$ principalmente à morbidade e mortalidade por doenças respiratórias e cardiovasculares ${ }^{(21)(22) b(25)(35)(43)(44)(45)(46)}$. Mais recentemente tem sido reportado associações com câncer ${ }^{(27)(41)(47)}$. 
Estas partículas podem apresentar uma composição química variada ${ }^{(48)}$ de acordo com as fontes emissoras existentes, influenciando o seu grau de toxicidade, o que pode acarretar os efeitos em maior ou menor grau à saúde.

Alguns autores têm estudado a morfologia das partículas utilizando a microscopia eletrônica de varredura ${ }^{(49)(50)(51)(52)(53)}$. A informação obtida em relação à sua morfologia pode ser importante para a identificação das fontes emissoras, conforme demonstrou Kaegi e colaboradores ${ }^{(54)}$.

Estudos epidemiológicos, clínicos e experimentais têm relacionado efeitos agudos e crônicos de PM 2,5 principalmente com o sistema respiratório e cardiovascular ${ }^{(20)(23)(29)(40)}$. Muitos estudos tem demonstrado a relação entre poluição atmosférica associado a morbidade ${ }^{(28)(42)(55)(56)(57)}$ e mortalidade ${ }^{(16)(25)(34)(44)(58)}$. De acordo com estes autores a exposição prolongada dos seres humanos a partículas em suspensão com diâmetros iguais ou inferiores a 2,5 $\mu \mathrm{m}(\mathrm{PM} 2,5)$ pode iniciar e/ou agravar doenças relacionadas ao trato respiratório tais como asma, bronquite e enfisema pulmonar, e ainda, formar coágulos ou trombos pela obstrução de vasos sanguíneos, acarretar danos irreversíveis ao sistema nervoso central e originar câncer.

Brook e colaboradores ${ }^{(23)}$ reportam um sumário de evidências para os diversos estudos sobre poluição do ar e saúde. O excesso de mortalidade cardiovascular e o aumento das taxas de internação são similarmente associados em exposição aguda. Entretanto há uma significante diferença do risco entre as diferentes regiões geográficas observando o incremento de $10 \mu \mathrm{g} / \mathrm{m}^{3}$ para PM 2,5 e $20 \mu \mathrm{g} / \mathrm{m}^{3}$ para PM 10.

As evidências demonstradas pelos estudos de coorte tem demonstrado um aumento médio de $10 \%$ por todas as causas de mortalidade considerando a elevação de $10 \mu \mathrm{g} / \mathrm{m}^{3}$ para exposição crônica de PM 2,5 ${ }^{(23)}$. O risco de mortalidade para doenças 
cardiovasculares aparece elevado, entretanto com faixa variando de $3 \%$ a $76 \%$. Estudos de série temporal tem demonstrado que o risco para exposição aguda é menor que $30 \%$, conforme apresentado na figura abaixo:

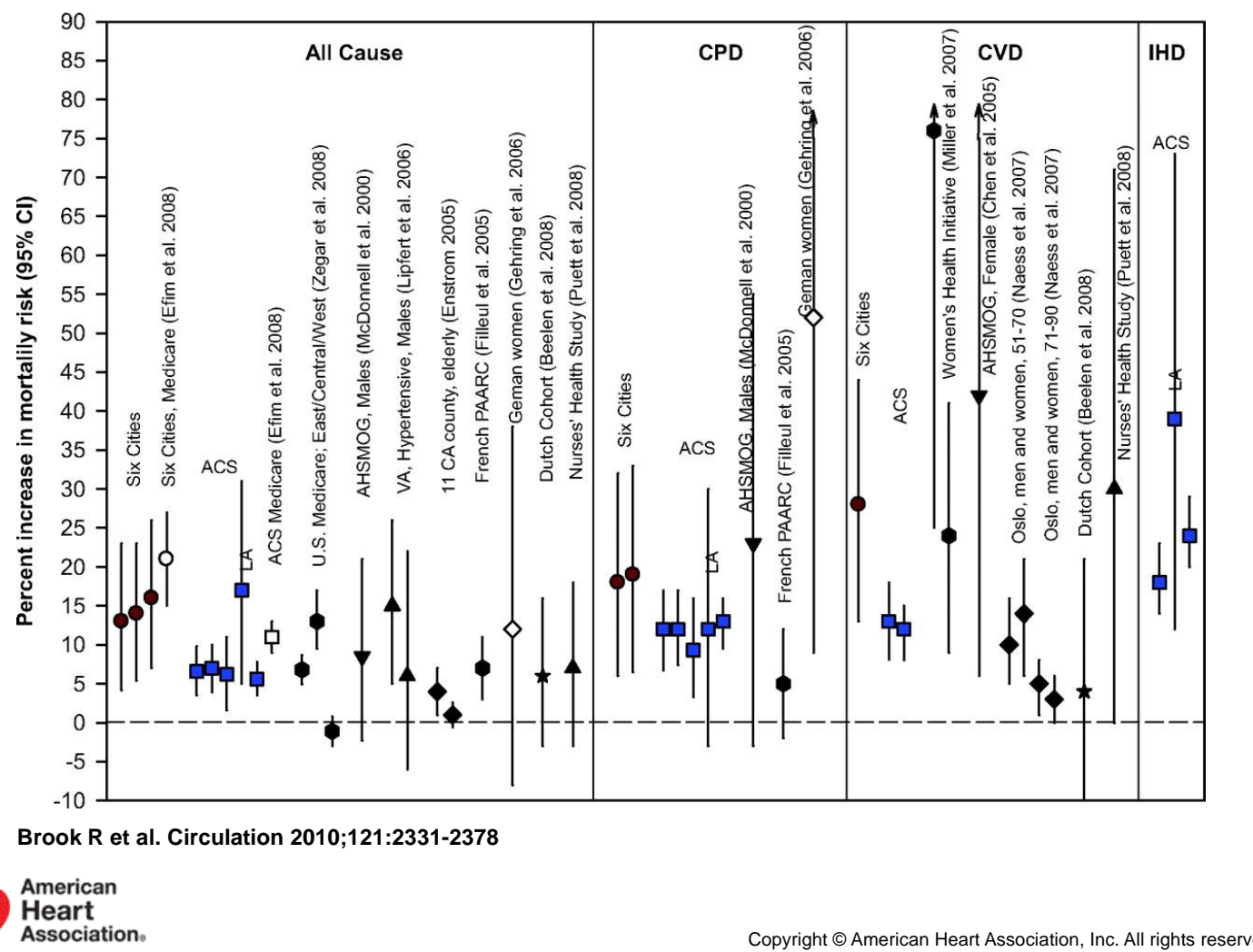

Figura 2. Estimativas de risco fornecidas por vários estudos de coorte por incremento de $10 \mu \mathrm{g} / \mathrm{m}^{3} \mathrm{em}$ PM2.5 ou PM10

Estudo sobre 22 coortes na Europa avaliou a exposição crônica para poluição atmosférica e todas as causas de mortalidade cardiovascular ${ }^{(17)}$. Demonstraram que mais Hazard ratio para a associação entre poluição do ar e diversos efeitos cardiovasculares estão próximos de 1,0, exceto para material particulado e mortalidade para doença cerebrovascular, chegando a 7,0, onde foi sugerida evidencia de associação. 
O mecanismo fisiopatológico da poluição do ar sobre a saúde humana tem sido demonstrada por diversos autores em estudos experimentais e toxicológicos ${ }^{(33)(59)(60)(61)}$, onde um dos principais mecanismos de agressão está relacionado com a via do stress oxidativo sistêmico e as vias de inflamação ${ }^{(23)}$. Além disso duas outras vias são consideradas: Quando o material particulado ou seus constituintes invade a corrente sanguínea, pode provocar efeitos de vasoconstricção, disfunção endotelial, aterosclerose e aumentar a agregação plaquetária; o sistema nervoso autônomo é ativado quando a partícula é inalada, provocando assim um estímulo no sistema adrenérgico, podendo levar a hipertensão e arritmias. A produção de citocinas leva o organismo a um estado pró-inflamatório induzindo a inflamação hepática, alteração no fibrinogênio, aumentando a coagulação do sangue e formação de trombos.

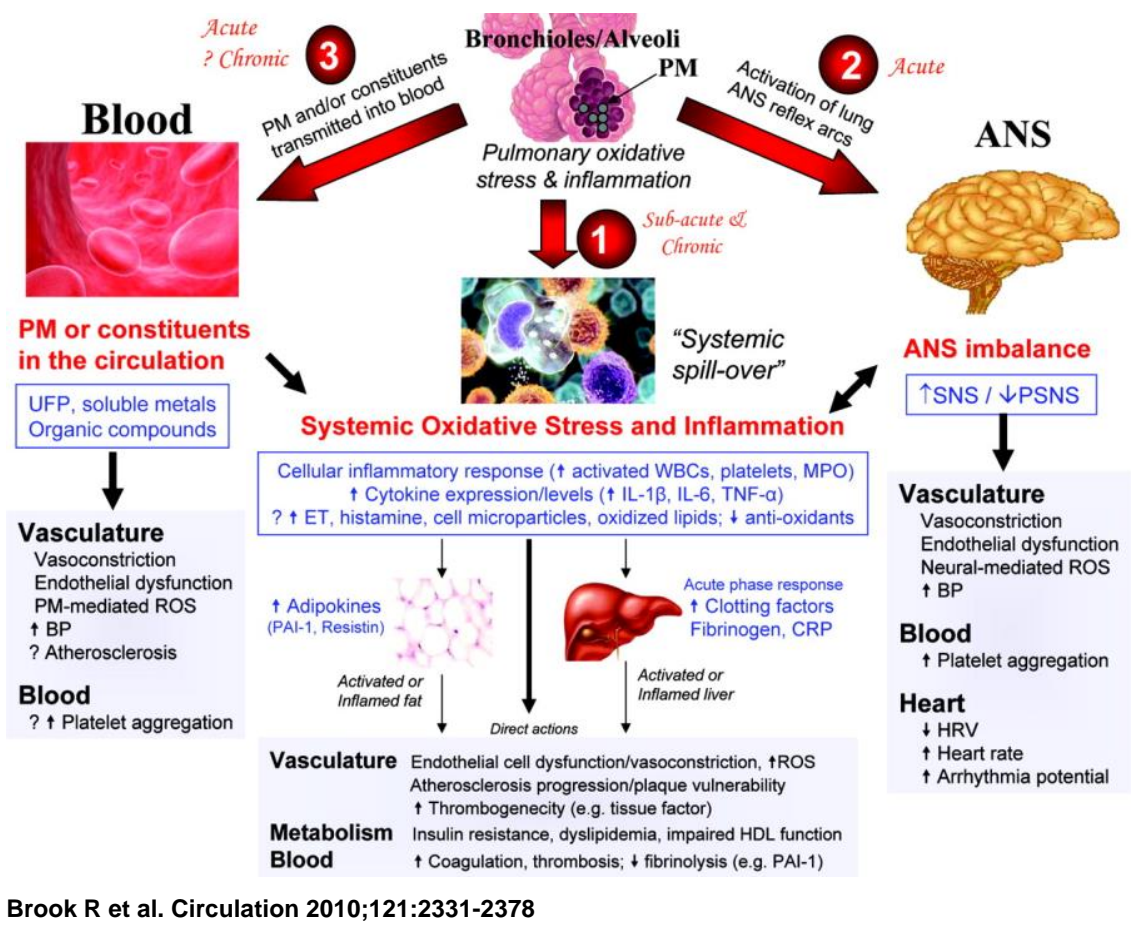

American

Heart

Association

Copyright $\odot$ American Heart Association, Inc. All rights reserved.

Figura 3. Vias do mecanismo fisiopatológico para doenças cardiovasculares decorrentes da exposição ao material particulado 
Os efeitos da poluição atmosférica sobre a superfície ocular tem sido descritos em estudos clínicos e epidemiológicos ${ }^{(62)(63)(64)(65)}$. Estes efeitos estão relacionados com inflamação e irritação da mucosa. Conforme descrito por Novaes e colaboradores, em estudo comparando áreas com diferentes níveis de poluição, existe uma associação entre os níveis de poluição e a hiperplasia de células oculares. Saha e colaboradores avaliaram a exposição de queima de biomassa na Índia ${ }^{(65)}$ e a etiologia da catarata dependente, apontando para um importante problema de saúde ambiental, envolvendo principalmente as mulheres e crianças pobres ${ }^{(65)}$. Torricelli e colaboradores apontam que estudos avaliando os efeitos da poluição sobre a superfície ocular são ainda escassos ${ }^{(63)}$, principalmente a necessidade de estudos que possam relacionar com os efeitos sistêmicos, visto esta ser uma mucosa que pode funcionar como porta de entrada.

De acordo com dados analisados até 2012, a Organização Mundial de Saúde reporta que a poluição do ar, em ambiente externo e interno, é responsável por 7 milhões de mortes em todo o mundo ${ }^{(47)}$. Algumas regiões concentram uma maior carga como as regiões do Pacífico Ocidental e do Sudeste Asiático com 2,8 e 2,3 milhões de mortes, respectivamente. Quase 680.000 mortes ocorrem na África, cerca de 400.000 na região do Mediterrâneo Oriental, na Europa e 287.000 e 131.000 nas Américas. As mortes restantes ocorrem em países de renda alta da Europa (295.000), Américas (96.000), Pacífico Ocidental (68.000) e do Mediterrâneo Oriental (14.000).

Na figura abaixo estão representadas as mortes atribuíveis aos efeitos da poluição do ar de ambientes internos e externos em 2012, por categoria de doenças ${ }^{(47)}$ : 


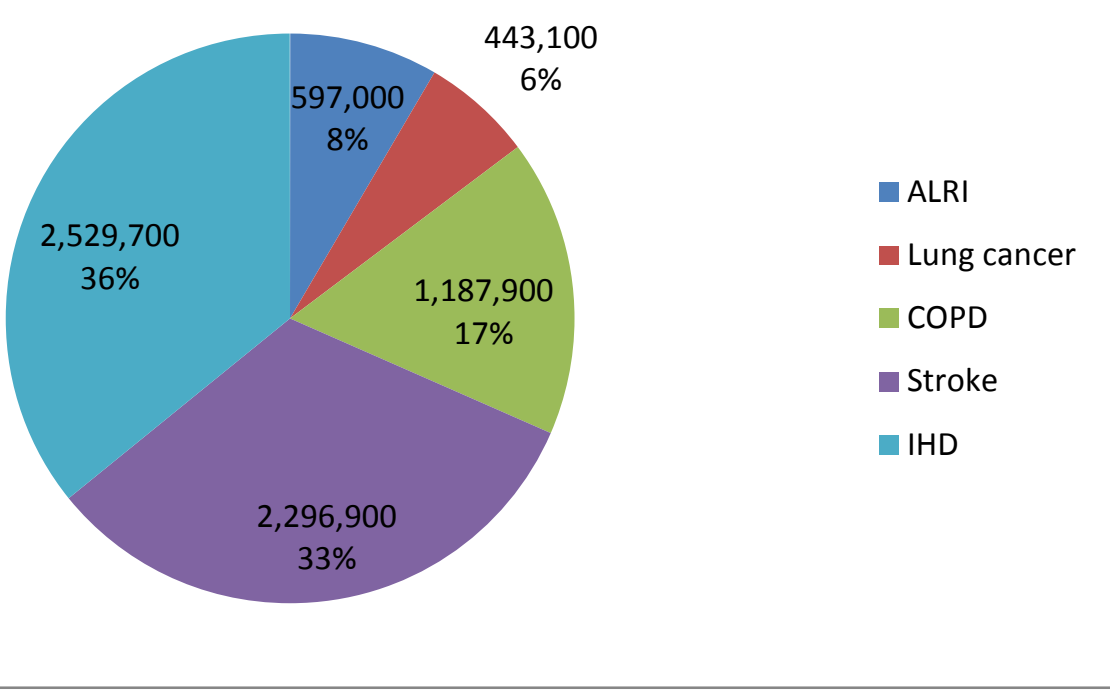

ALRI: doença respiratória aguda baixa; DPOC: doença pulmonar obstrutiva crônica; DCI: doença cardíaca isquêmica.

Figura 4. Mortes atribuíveis aos efeitos da poluição do ar de ambientes internos e externos em 2012, por categoria de doenças (WHO, 2014)

Segundo a Organização Mundial de Saúde (OMS), a epidemia de doenças crônicas está em sua grande parte ligada aos fatores de riscos. Embora muitos dos fatores que predispõem as pessoas a estes agravos sejam preveníveis, políticas públicas e legislação são ainda insuficientes em todo o mundo, principalmente em países subdesenvolvidos e em desenvolvimento. Desta forma, diagnósticos situacionais em diversas localidades são encorajados pela OMS para o planejamento das ações que visam reduzir o impacto dessas doenças no mundo ${ }^{(66)}$.

Schluger e Koppaka ${ }^{(67)}$ abordam que um novo paradigma é necessário para o cuidado em doenças respiratórias, visto que a patogênese das doenças pulmonares tem se apresentado de forma variada, seja câncer, inflamação, infecção ou alterações auto-imunes, onde todas essas patologias são induzidas principalmente por fatores extrínsecos, tais como exposição ambiental, passíveis então de serem modificados. 
O controle da exposição a qualquer um dos fatores de riscos, onde a exposição tem apresentado evidencias forte, moderada ou de exacerbação de sintomas, poderão reduzir de forma significativa essas doenças. O gerenciamento e controle das fontes são de alcance global, com semelhanças em muitas partes do mundo, portanto tem sido estimulados a formação de redes como uma estrutura para pensar essa hierarquia de causas de doença pulmonar, na esperança de que esse quadro possa levar a progressos na redução da carga de morbidade e mortalidade da doença de pulmão em todo o mundo.

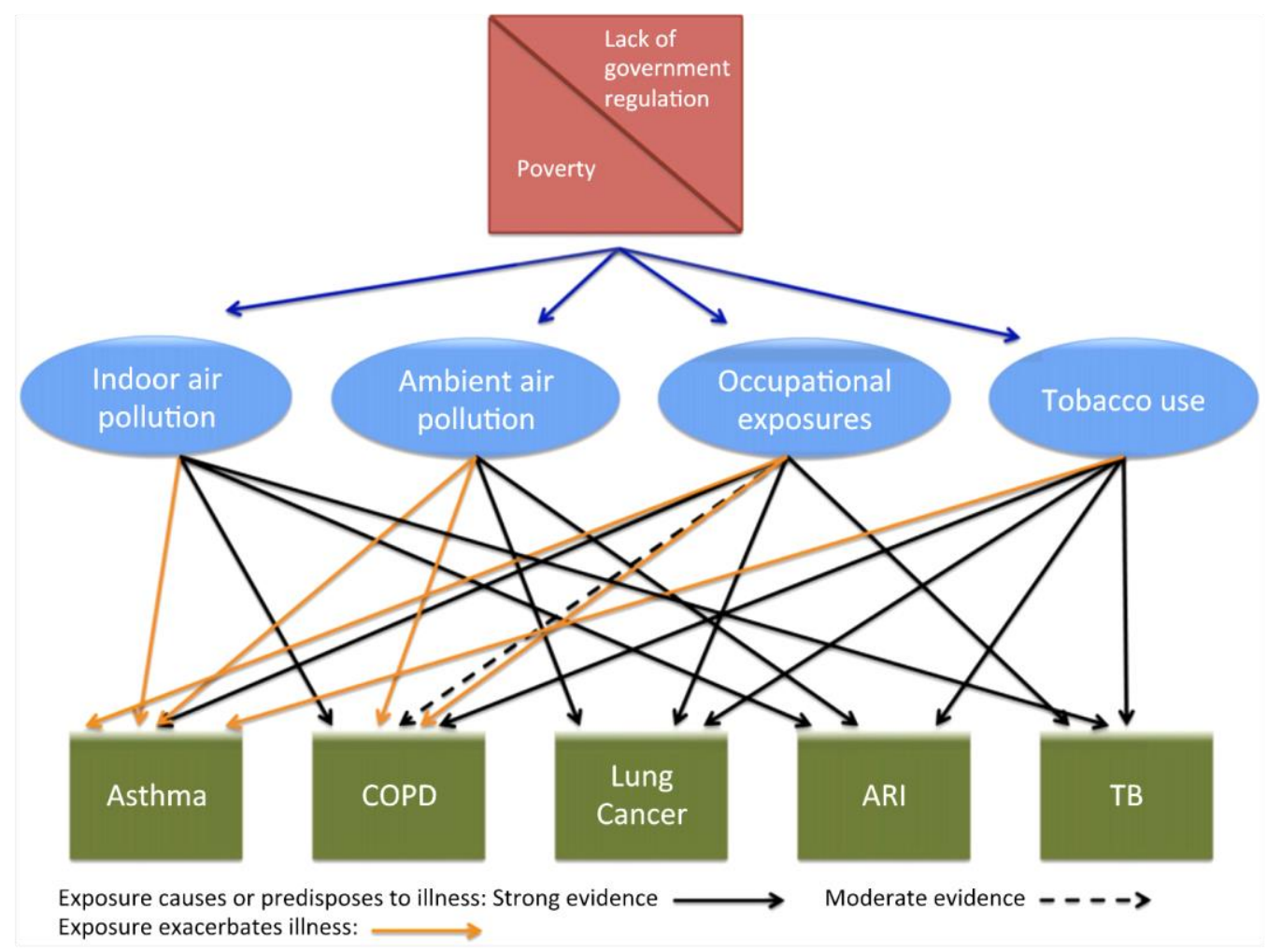

The world's five leading lung diseases and their environmental drivers.

Figura 5. As cinco principais doenças pulmonares e seus condutores ambientais, extraído de Schulger $2014^{(61)}$ 


\subsection{Análise de riscos}

Para efeitos de uniformização e entendimento de conceitos sobre o tema abordado nesta tese, faz-se necessário a definição prévia de alguns termos, de acordo com a Society for Risk Analysis (SRA) ${ }^{(68)}$ :

\section{Perigo - "Hazard"}

Uma condição ou situação física com um potencial para uma consequência indesejada, tais como dano a vida ou ferimento grave.

\section{Avaliação do perigo: "Hazard Assessment"}

Uma análise e avaliação das propriedades químicas, físicas ou biológicas do perigo

\section{Identificação do perigo: "Hazard identification"}

O processo de determinar condições de exposição para um agente poder provocar um aumento na incidência das condições de saúde.

\section{Risco: "Risk"}

O potencial para realização de indesejadas consequências para a vida humana, saúde, propriedade ou para o ambiente. A estimativa de risco é usualmente baseada na probabilidade de ocorrência do evento.

\section{Análise de Risco: "Risk Analysis"}

1. Uma abordagem detalhada incluindo avaliação de risco, caracterização do risco e alternativas de gerenciamento do risco, realizada para entender a natureza das consequências negativas para a vida humana, propriedade ou ambiente. Um processso analítico que fornece informações relacionadas aos eventos indesejáveis. O processo de quantificação das probabilidades e consequências esperadas para identificação de riscos. 


\section{Avaliação de Risco - "Risk assessment"}

O processo de estabelecer informações sobre os níveis aceitáveis de um risco ou nível de riscos para um indivíduo, grupo, sociedade ou ambiente.

\section{Gerenciamento de risco: "Risk management"}

É o processo de ponderação política em consulta com todas as partes interessadas considerando avaliação de riscos e outros fatores. Baseada na avaliação de riscos as decisões são tomadas e as políticas formuladas.

\section{Comunicação de risco: "Risk communication" (69)}

Um processo interativo de troca de informações e opiniões entre indivíduos, grupos e instituições. Isto envolve múltiplas mensagens sobre a existência, natureza forma, severidade ou aceitabilidade dos riscos à saúde.

\section{Avaliação de impacto à saúde ${ }^{(1)}$ : "health impact assessment"}

É o processo que fornece aos tomadores de decisão em políticas públicas informações quantitativa e qualitativa sobre como alguma política, programa ou projeto pode afetar a saúde das pessoas.

\subsubsection{Abordagens em Análise de Riscos e Política Pública}

A tradução do conhecimento científico como evidência para a tomada de decisão tem sido descrita na literatura por diversos autores, utilizando uma multiplicidade de abordagens metodológicas ${ }^{(4)(70)(71)(72)(73)(74),}$ que em alguns casos diferem apenas pelas linguagens específicas a cada área de atuação. Lavis e colaboradores, discutem que os formuladores de políticas e aqueles que os apoiam, muitas vezes se deparam com 
situações nas quais um melhor conhecimento sobre os métodos ajudaria a usar as evidências e lhes permitiria conduzir os trabalhos com maior eficiência ${ }^{(75)}$. Em se tratando especificamente da área de saúde ambiental diversas metodologias tem sido formuladas com o objetivo de abordar a questão do risco ambiental e a tomada de decisão em políticas públicas, o que será apresentado sistematicamente nesta revisão.

A produção social do risco está diretamente ligada à produção social de riquezas ${ }^{(76)}$. Segundo Beck estas "fontes de riqueza estão “contaminadas" por ameaças colaterais (riscos), não sendo isto algo novo, mas que entretanto passou despercebido por muito tempo em meio aos esforços para superar a miséria. $\mathrm{O}$ aspecto social envolvido no processo de gerenciamento dos riscos deve ser considerado, além da visão tecnicista e de gestão pública, visto que o poder de gerenciá-los recai sobre o cidadão que na maioria das vezes assume esse papel sem o real conhecimento do impacto ao qual está submetido. Afirma ainda que todos os perigos (genéticos, químicos, ecológicos, etc.) são produzidos por decisões, indicando um fracasso sobre os sistemas sociais".

João Ubaldo Ribeiro escreve, o que seria a sua última crônica publicada, sobre a forma como a sociedade é imposta a cada dia sobre uma nova regra ${ }^{(77)}$, despertando para a necessidade de um maior envolvimento no processo decisório. Ressalta-se que o diálogo e a comunicação de riscos permeiam o processo educativo, visto que são necessários para a mudança de comportamento ${ }^{(13)}$. Frieden reportou o papel do governo em proteção e segurança à saúde reconhecendo a sua função sobre as leis, mas as ações públicas em grande parte são consideradas como intrusivas. A sociedade aceita muitas medidas de saúde pública que podem ser controversas. Iniciativas de saúde pública deve incluir esforços para promover informação livre e aberta para facilitar a tomada de decisão, protegendo indivíduos e grupos, bem como facilitando a intervenção social ${ }^{(78)}$. 
Segundo Almeida-Filho ${ }^{(79)}$ na atual fase de maturação do campo epidemiológico, uma reavaliação no conceito de risco faz-se necessária.

O conceito de Risco necessita atualizar-se, incorporando a dimensão contingente dos processos de ocorrência de problemas de saúde em populações humanas. O futuro do conceito de risco dependerá da sua capacidade de articular-se aos desenvolvimentos conceituais e metodológicos deste novo campo ideológico, conceitual e metodológico que tem sido denominado de Saúde Coletiva, contribuindo com modelos teóricos e estratégias metodológicas capazes de abordar objetos complexos emergentes. Nesse sentido, propomos incorporar mais uma definição à lista dos conceitos de Risco acima: e) "Risco Contingencial", operador do recém-constituído campo de práticas da Promoção da Saúde.

Adequar as tecnologias para avaliar a exposição, conhecer a relação doseresposta, bem como a habilidade para comunicar o risco aos diferentes atores envolvidos constituem grandes desafios para as metodologias aplicadas em análise de risco ${ }^{(80) .}$ A caracterização da exposição para mistura de multi-poluentes requer um entendimento avançado das fontes de poluição, da transformação química, da interação entre poluentes múltiplos, bem como informação sobre a correlação entre espaço e tempo das suas concentrações individuais. Douglas e colaboradores ${ }^{(80)}$ sugerem que este tipo de abordagem requer um esforço paralelo e colaborativo entre ciência e agências regulatórias, bem como aumentar a base científica em que a exposição a múltiplos poluentes são avaliados simultaneamente, aprimorar ferramentas e técnicas de mensuração e análises de poluentes, análise estatística, epidemiológica e modelagem em avaliação de risco. Limitações em abordagens toxicológicas, epidemiológicas e métodos estatísticos ${ }^{(81)(82)}$ tem sido reportada para o estudo de avaliação de riscos, onde para tanto requer um melhor desenvolvimento de hipótese interdisciplinar, planejamento e execução da pesquisa. 
A seguir relaciono algumas das metodologias, adotadas por agencias nacionais e internacionais, que tem sido amplamente reportadas na literatura para a abordagem do tema em questão.

Uma das metodologias que tem sido utilizada para se estudar o impacto do ambiente sobre a saúde humana é através do processo de análise de riscos, que consiste na busca de todas as informações disponíveis sobre os efeitos tóxicos dos produtos químicos e de uma avaliação para determinar os possíveis riscos associados à exposição ${ }^{(3)}$. Se fundamenta no envolvimento de diversos atores para levantar indicadores em saúde ambiental que possam auxiliar na tomada de decisão em políticas públicas,. Utiliza-se métodos e técnicas diversas que orientam para o gerenciamento do risco. Busca conhecer a exposição em estudos de dose-resposta e sobretudo aprender a comunicar o risco ${ }^{(83)}$, informando e educando a comunidade para promover o auto gerenciamento dos riscos aos quais estão expostos ${ }^{(1,3,13)}$.

De acordo com o National Research Council ${ }^{(3)}$ a abordagem em análise de riscos para um determinado evento de contaminação ambiental deve obedecer às diversas fases, desde a elaboração do problema até a tomada de decisão. Este fluxo naturalmente pode obedecer a dois caminhos. Presume-se uma pergunta inicial: o risco será avaliado por uma ferramenta apropriada que possa fornecer elementos para a tomada de decisão? 1) se sim, inicia-se o planejamento com os setores interessados, passando por diversas fases, (podendo transcorrer em média por dez anos até a tomada de decisão); se não, a tomada de decisão na maioria das vezes, quando ocorre, se baseia nos princípios da precaução ou de prevenção, de acordo com esquema abaixo ${ }^{(3)}$ : 


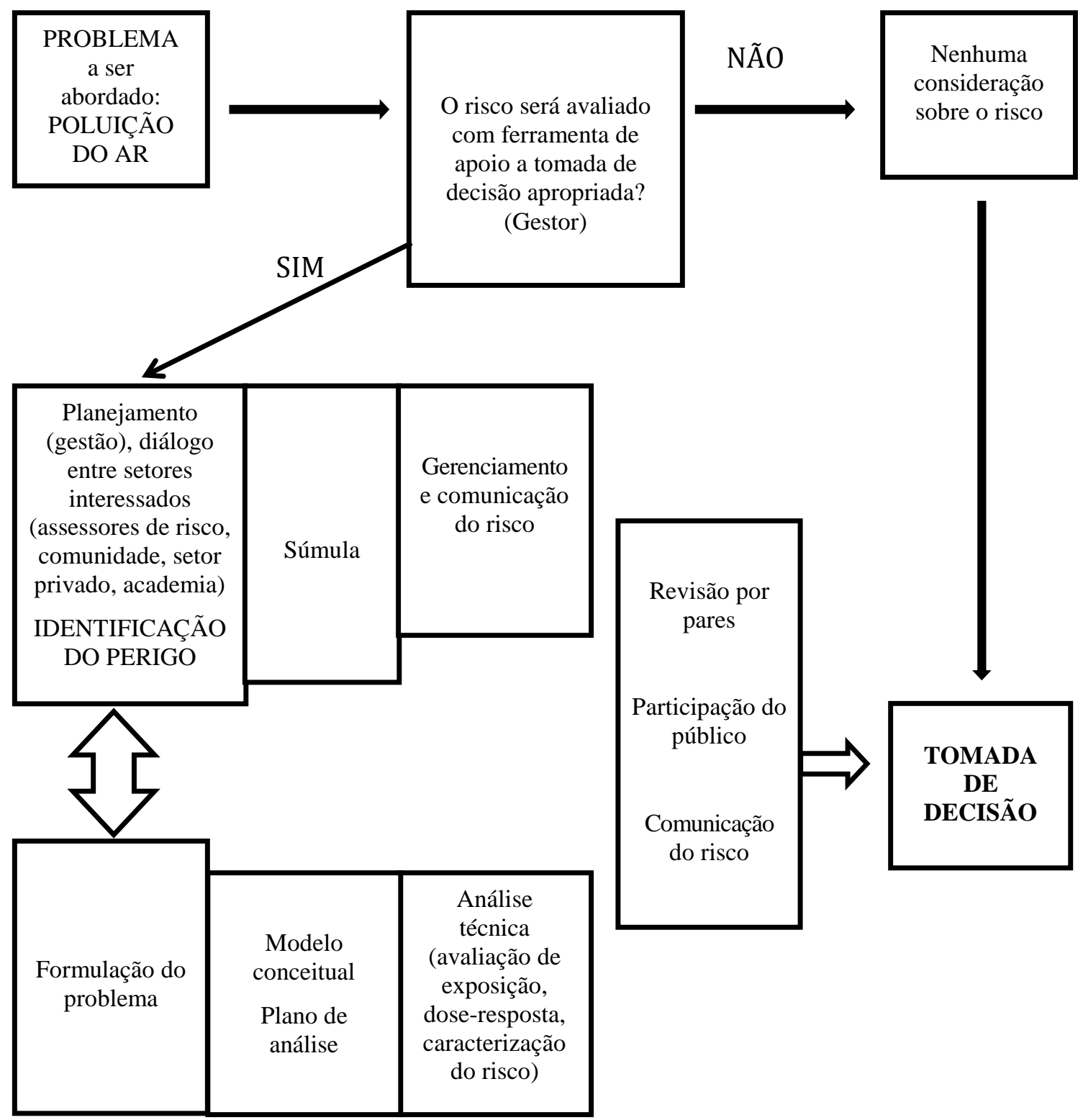

Figura 6. Desenho esquemático representando as etapas do processo de análise de riscos, segundo National Research Council, 2009. 
De forma simplificada, a figura abaixo apresenta esquematicamente as principais etapas do processo de análise de riscos, onde ressalta a avaliação de risco como apenas uma etapa do processo ${ }^{(84)}$.

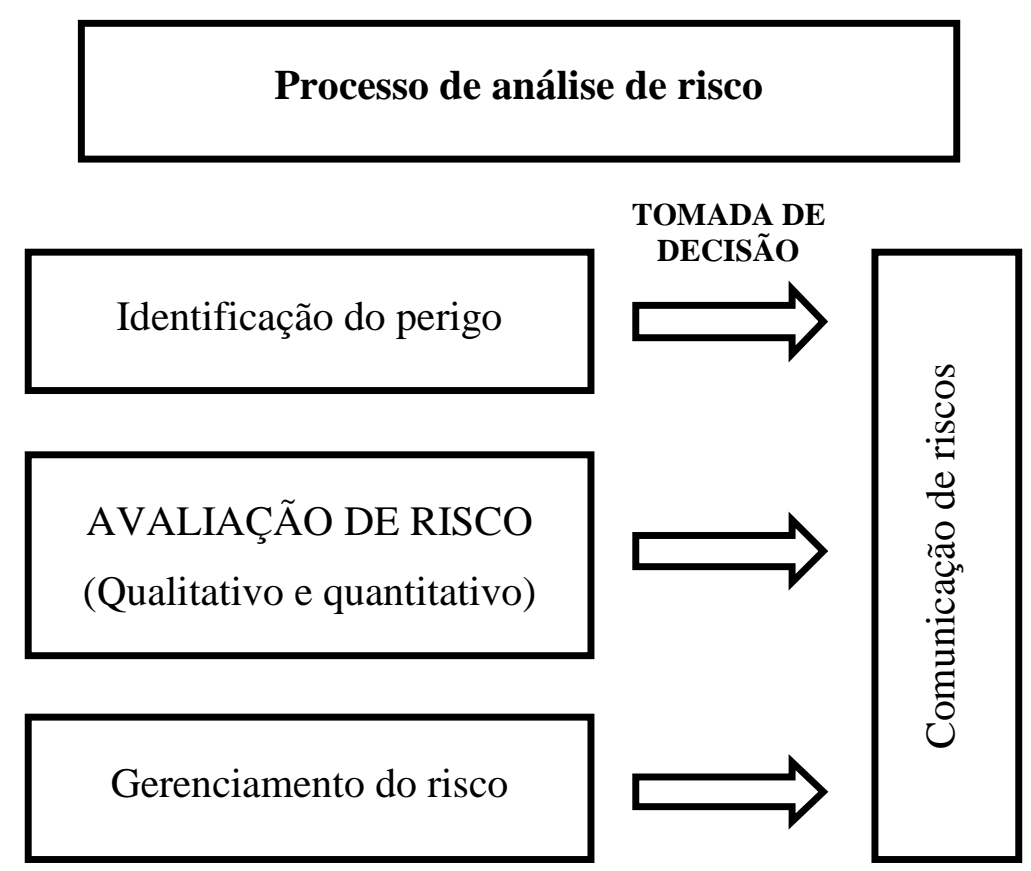

Figura 7. Desenho esquemático representando de forma simplificada o processo de análise de riscos

A metodologia de avaliação de riscos baseada na Agência de Registro de Substâncias Tóxicas e de Doenças dos EUA (Agency for Toxic Substances and Disease Registry -ATSDR), foi adaptada para a realidade brasileira, em estudos sob demanda do Ministério da Saúde, em algumas localidades como Santo Amaro, Duque de Caxias, Paulínia, Mauá, dentre outras ${ }^{(85)}$. Esta abordagem está baseada em: avaliação da informação do local; levantamento das preocupações da comunidade; seleção dos contaminantes de interesse; identificação e avaliação das rotas de exposição; determinação das implicações na saúde; conclusões e recomendações, 
onde fornece subsídios para a identificação de áreas contaminados evidenciando riscos prioritários para orientar políticas públicas no governo brasileiro. Neste tipo de aplicação da Avaliação de Risco à Saúde Humana, o relatório final de avaliação classifica os diversos níveis de perigo à saúde humana e recomenda ações em diversas áreas de governo.

CASOS DE APLICAÇÃO DA METODOLOGIA NO BRASIL

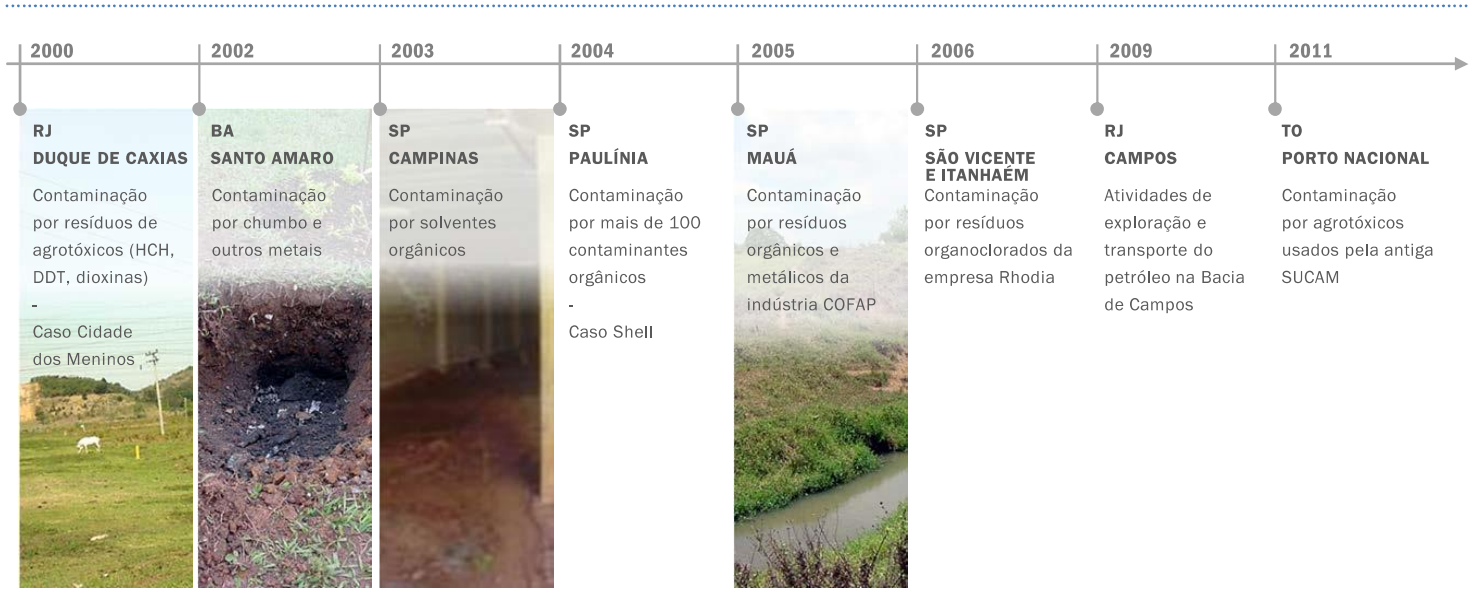

Unidade 1 • Modúlo 1 • Avaliação de Risco à Saúde Humana por Exposiçāo a Sustâncias Químicas

Figura 8. Estudos de avaliação de risco à saúde humana por exposição à substâncias químicas, extraída do módulo 1 IESC/UFRJ, 2013

Nos EUA a partir deste tipo de avaliação, a agência de saúde, ATSDR, procede notificação para a agência de proteção ambiental - a United States Environmental Protection Agency (USEPA), de que existe alguma ameaça para a saúde pública nos locais sob risco, de tal forma que a mesma possa desenvolver alguma intervenção para mitigação ou prevenção da exposição e dos efeitos à saúde humana. A etapa de gerenciamento do risco contemplada no modelo adotado pela U.S.EPA, é crucial para a conclusão do processo de análises de risco. Este modelo desempenha um papel 
fundamental para a prevenção, gestão e mitigação dos riscos principalmente para as autoridades competentes como ferramenta para o apoio à tomada de decisão na escolha de medidas para diminuição do risco, conforme elementos esquematizados abaixo:

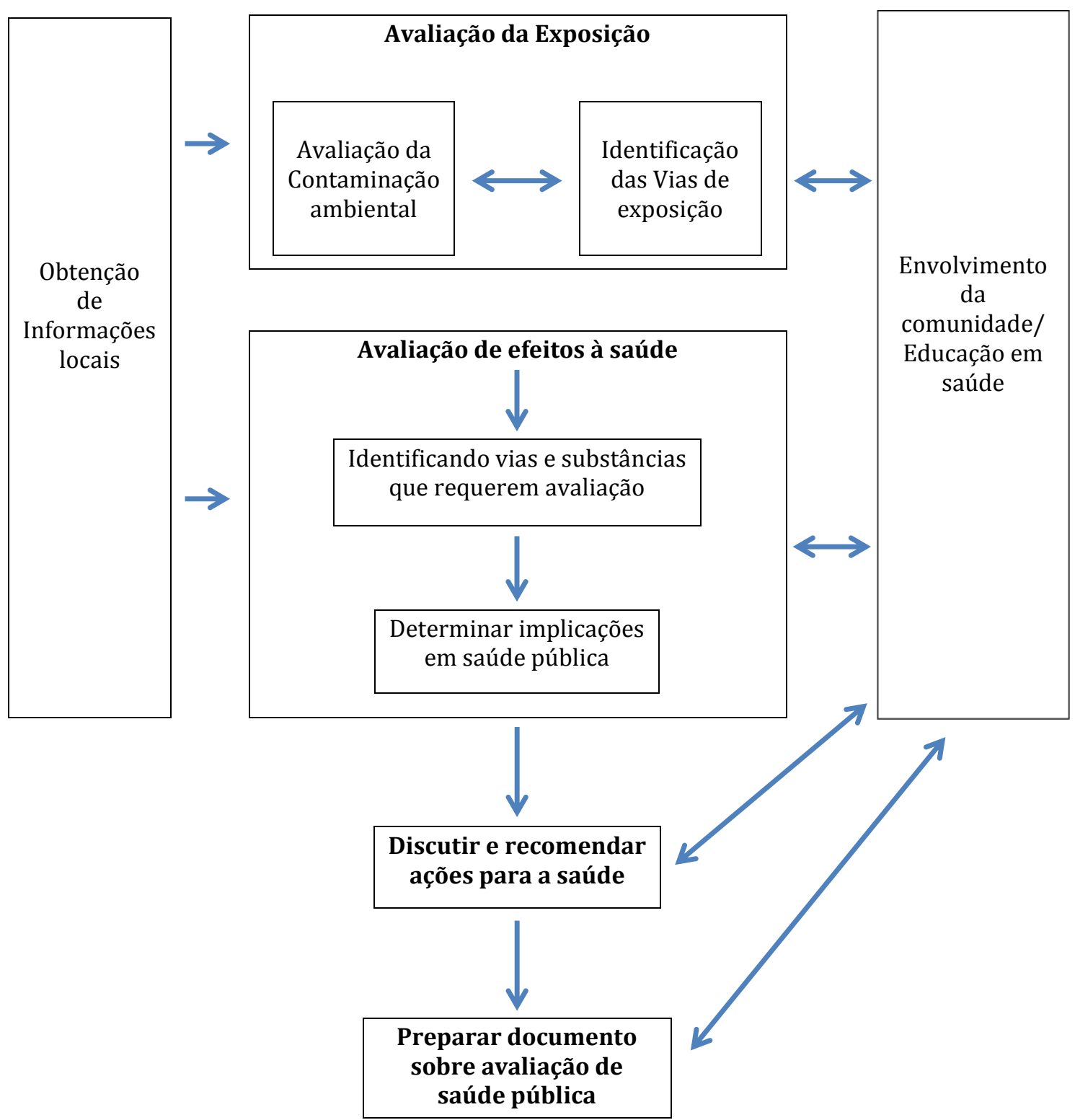

Figura 9. Visão geral sobre o processo de avaliação de saúde pública, segundo modelo da ATSDR (adaptado) $^{(13)}$ 
Basicamente o que difere a metodologia aplicada pela ATSDR é o objetivo da análise desta agencia com foco nas recomendações para a saúde pública, enquanto que a agência ambiental adota metodologias que visam a regulamentação e mitigação dos riscos ${ }^{(10)}$.

Por sua vez o modelo apresentado pela Organização Mundial de Saúde ${ }^{(1)}$ está baseado em avaliação de impacto à saúde (AIS) onde são considerados os seguintes elementos: dados sobre poluição do ar (monitorados ou modelados), risco para a população, estimativa de exposição, função dose-resposta, dados de mortalidade ou morbidade, de acordo com modelo esquemático abaixo:

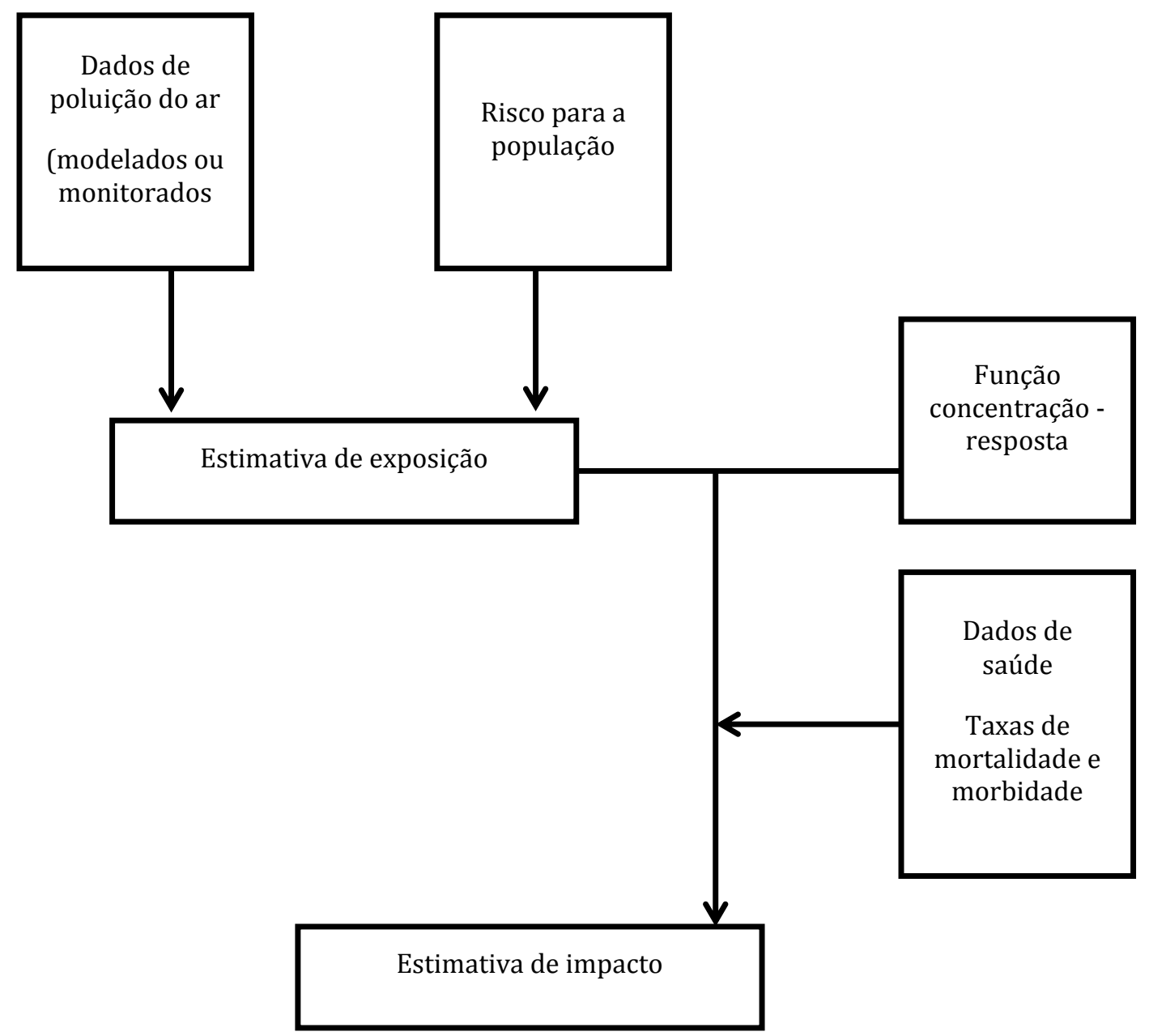

Figura 10. Apresentação esquemática dos principais passos da avaliação de impacto à saúde (AIS). Adaptação WHO, Air Quality Guidelines, Global Updadte 2005 
A comunicação de riscos é um processo interativo de troca de informações entre indivíduos, grupos e instituições ${ }^{(14)}$, perpassa todas as fases do processo e tem sido uma preocupação para as agencias em todo o mundo ${ }^{(83)}$. Chess revela a necessidade de investir mais esforços para responder às solicitações de informações iniciando um diálogo entre os setores ou alertando o público sobre os riscos. Estudos apresentam metodologias para avaliar a percepção, como uma das formar de aproximar o diálogo entre a comunidade e os tomadores de decisão ${ }^{(69)(86)}$. Segundo Moreno e colaboradores conhecer o que a população pensa e sente acerca de um perigo ambiental é fundamental para poder elaborar um plano de comunicação de riscos ${ }^{(14)}$. Ressalta-se ainda que as iniciativas de comunicação devem ser elaboradas de tal maneira que as mensagens alcancem os grupos de forma clara e sucinta, em tempo preciso, com um canal de audiência disponível, seja por mídia, jornais, TV, radio ou boletins ${ }^{(87)}$.

Outras abordagens em estudos específicos incluindo análise de custos também tem sido documentada na literatura. Miraglia e colaboradores tem apresentado ferramentas de análises de custo a partir de estimativa da mortalidade atribuível ${ }^{\left({ }^{8}\right)}$ às concentrações de material particulado e expectativa de vida ${ }^{(89)}$ como uma das metodologias para avaliação de risco.

Cada etapa do processo exige estudos específicos, com metodologias apropriadas nos diversos contextos ${ }^{(90)(91)(80)}$, de modo que possa avaliar sistematicamente os riscos e as vulnerabilidades existentes, bem como identificar prioridades de atuação e definição acerca das medidas de intervenção necessárias. 


\section{3 Índices da qualidade do ar}

Os padrões da qualidade do ar tem sido estabelecidos em todo o mundo de acordo com a legislação de cada localidade. Em países desenvolvidos estes padrões são periodicamente revisados considerando uma adequada margem de segurança para a saúde, a partir de evidências relacionadas a natureza e a severidade do efeito à saúde envolvido, o tamanho da população de risco, bem como o tipo e nível de incertezas ${ }^{(92,93)}$.

No Brasil os padrões vigentes foram regulamentados pelo Ministério do Meio Ambiente e aprovados pela Resolução CONAMA em $1990^{(94)}$, conforme quadro abaixo:

Quadro 1. Padrão nacional da qualidade do ar baseado na resolução CONAMA 03/90

\begin{tabular}{|c|c|c|c|c|}
\hline \multicolumn{5}{|c|}{$\begin{array}{l}\text { Padrões nacionais de qualidade do ar } \\
\text { (Resolução CONAMA n } 03 \text { de } 28 / 06 / 90 \text { ) }\end{array}$} \\
\hline Poluente & $\begin{array}{c}\text { Tempo de } \\
\text { Amostragem }\end{array}$ & $\begin{array}{c}\text { Padrão } \\
\text { Primário } \\
\text { yg/m }{ }^{3}\end{array}$ & $\begin{array}{c}\text { Padráo } \\
\text { Secundário } \\
\text { yg/m } / \mathrm{m}^{3}\end{array}$ & $\begin{array}{l}\text { Método de } \\
\text { Medição }\end{array}$ \\
\hline $\begin{array}{l}\text { particulas totais } \\
\text { em suspensão }\end{array}$ & $\begin{array}{l}24 \text { horas }^{1} \\
\text { MGA }^{2}\end{array}$ & $\begin{array}{c}240 \\
80\end{array}$ & $\begin{array}{c}150 \\
60\end{array}$ & $\begin{array}{l}\text { amostrador de } \\
\text { grandes volumes }\end{array}$ \\
\hline $\begin{array}{l}\text { partículas } \\
\text { inaláveis }\end{array}$ & $\begin{array}{l}24 \text { horas }^{1} \\
\text { MAA }^{3}\end{array}$ & $\begin{array}{c}150 \\
50\end{array}$ & $\begin{array}{c}150 \\
50\end{array}$ & $\begin{array}{c}\text { separação } \\
\text { inercial/filtração }\end{array}$ \\
\hline fumaça & $\begin{array}{l}24 \text { horas }^{1} \\
\text { MAA }^{3}\end{array}$ & $\begin{array}{c}150 \\
60\end{array}$ & $\begin{array}{c}100 \\
40\end{array}$ & refletância \\
\hline $\begin{array}{l}\text { dióxido de } \\
\text { enxofre }\end{array}$ & $\begin{array}{c}24 \text { horas }^{1} \\
\text { MAA }^{3}\end{array}$ & $\begin{array}{c}365 \\
80\end{array}$ & $\begin{array}{c}100 \\
40\end{array}$ & pararosanilina \\
\hline $\begin{array}{l}\text { dióxido de } \\
\text { nitrogênio }\end{array}$ & $\begin{array}{l}1 \text { hora }^{1} \\
\text { MAA }^{3}\end{array}$ & $\begin{array}{l}320 \\
100\end{array}$ & $\begin{array}{l}190 \\
100\end{array}$ & quimiluminescência \\
\hline $\begin{array}{l}\text { monóxido de } \\
\text { carbono }\end{array}$ & $\begin{array}{l}1 \text { hora }^{1} \\
8 \text { horas }^{1}\end{array}$ & $\begin{array}{l}40.000 \\
35 \mathrm{ppm} \\
10.000 \\
9 \mathrm{ppm}\end{array}$ & $\begin{array}{c}40.000 \\
35 \mathrm{ppm} \\
10.000 \\
9 \mathrm{ppm}\end{array}$ & $\begin{array}{l}\text { infravermelho } \\
\text { não dispersivo }\end{array}$ \\
\hline ozônio & 1 hora $^{1}$ & 160 & 160 & quimiluminescência \\
\hline
\end{tabular}


Apenas o Estado de São Paulo revisou os padrões vigentes, apresentando novas metas para adequação dos padrões locais através de Decreto Estadual no ano de $2013{ }^{\left({ }^{(9)} \text {, }\right.}$ processo iniciado em 2008 baseado em diretrizes da Organização Mundial de Saúde. Este decreto estabelece metas intermediárias e metas finais a partir de ações gradativas, conforme quadro abaixo:

Quadro 2. Padrões da Qualidade do ar do Estado de São Paulo, estabelecidos pelo Decreto Estadual $59113 / 2013$

Padrões Estaduais de Qualidade do Ar (Decreto Estadual no 59113 de 23/04/2013)

\begin{tabular}{|c|c|c|c|c|c|}
\hline Poluente & $\begin{array}{c}\text { Tempo de } \\
\text { Amostragem }\end{array}$ & $\begin{array}{c}\mathrm{MI1} \\
\left(\mu \mathrm{g} / \mathrm{m}^{3}\right)\end{array}$ & $\begin{array}{c}M I 2 \\
\left(\mu g / m^{3}\right)\end{array}$ & $\begin{array}{c}\mathrm{MI3} \\
\left(\mu \mathrm{g} / \mathrm{m}^{3}\right)\end{array}$ & $\begin{array}{c}\text { PF } \\
\left(\mu g / m^{3}\right)\end{array}$ \\
\hline $\begin{array}{c}\text { partículas } \\
\text { inaláveis }\left(\mathrm{MP}_{10}\right)\end{array}$ & $\begin{array}{l}24 \text { horas } \\
\text { MAA }^{1}\end{array}$ & $\begin{array}{c}120 \\
40\end{array}$ & $\begin{array}{c}100 \\
35\end{array}$ & $\begin{array}{l}75 \\
30\end{array}$ & $\begin{array}{l}50 \\
20\end{array}$ \\
\hline $\begin{array}{l}\text { partículas inaláveis } \\
\text { finas }\left(\mathrm{MP}_{2,5}\right)\end{array}$ & $\begin{array}{l}24 \text { horas } \\
\text { MAA }^{1}\end{array}$ & $\begin{array}{l}60 \\
20\end{array}$ & $\begin{array}{l}50 \\
17\end{array}$ & $\begin{array}{l}37 \\
15\end{array}$ & $\begin{array}{l}25 \\
10\end{array}$ \\
\hline $\begin{array}{l}\text { dióxido de enxofre } \\
\qquad\left(\mathrm{SO}_{2}\right)\end{array}$ & $\begin{array}{l}24 \text { horas } \\
\text { MAA }^{1}\end{array}$ & $\begin{array}{l}60 \\
40\end{array}$ & $\begin{array}{l}40 \\
30\end{array}$ & $\begin{array}{l}30 \\
20\end{array}$ & $\begin{array}{c}20 \\
-\end{array}$ \\
\hline $\begin{array}{l}\text { dióxido de nitrogênio } \\
\qquad\left(\mathrm{NO}_{2}\right)\end{array}$ & $\begin{array}{l}1 \text { hora } \\
\text { MAA }^{1}\end{array}$ & $\begin{array}{c}260 \\
60\end{array}$ & $\begin{array}{c}240 \\
50\end{array}$ & $\begin{array}{c}220 \\
45\end{array}$ & $\begin{array}{c}200 \\
40\end{array}$ \\
\hline Ozônio $\left(\mathrm{O}_{3}\right)$ & 8 horas & 140 & 130 & 120 & 100 \\
\hline $\begin{array}{l}\text { monóxido de carbono } \\
\text { (CO) }\end{array}$ & 8 horas & - & - & - & 9 ppm \\
\hline fumaça* (FMC) & $\begin{array}{l}24 \text { horas } \\
\text { MAA }^{1}\end{array}$ & $\begin{array}{c}120 \\
40\end{array}$ & $\begin{array}{c}100 \\
35\end{array}$ & $\begin{array}{l}75 \\
30\end{array}$ & $\begin{array}{l}50 \\
20\end{array}$ \\
\hline $\begin{array}{c}\text { partículas totais } \\
\text { em suspensão* (PTS) }\end{array}$ & $\begin{array}{l}24 \text { horas } \\
\mathrm{MGA}^{2}\end{array}$ & $\begin{array}{l}- \\
-\end{array}$ & $\begin{array}{l}- \\
-\end{array}$ & $\begin{array}{l}- \\
-\end{array}$ & $\begin{array}{c}240 \\
80\end{array}$ \\
\hline Chumbo** $(\mathrm{Pb})$ & $M A^{1}$ & - & - & - & 0,5 \\
\hline
\end{tabular}

Fonte: CETESB, disponível em www.cetesb.sp.gov.br 
O índice de qualidade do ar é uma ferramenta matemática desenvolvida para simplificar o processo de divulgação da qualidade do ar no que tange aos efeitos sobre à saúde humana e facilitar o entendimento e interpretação da comunidade em geral. Esse índice é utilizado desde $1981^{(96)}$. Os índices são interpretados de acordo com os padrões estabelecidos por lei e divulgado a partir do nível de poluente mais elevado monitorado pela rede da qualidade do ar, conforme quadro abaixo:

Quadro 3. Índice da Qualidade do Ar (IQA) estabelecidos pela Resolução CONAMA 03/90

\begin{tabular}{|c|c|c|c|c|c|c|c|c|}
\hline \multicolumn{9}{|c|}{ ÍNDICE DA QUALIDADE DO AR (IQAr) } \\
\hline Qualidade & Índice & $\begin{array}{c}\text { Níveis de } \\
\text { Cautela } \\
\text { sobre a Saúde }\end{array}$ & $\begin{array}{c}\underset{\left(\mu \mathrm{g} / \mathbf{m}^{3}\right)}{\text { PTS }} \\
\text { (1) }\end{array}$ & $\begin{array}{c}\text { PI10 } \\
\left(\mu \mathrm{g} / \mathrm{m}^{3}\right)\end{array}$ & $\begin{array}{c}\mathrm{S02} \\
\left(\mu \mathrm{g} / \mathbf{m}^{3}\right)\end{array}$ & $\begin{array}{c}\mathrm{NO2} \\
\left(\mu \mathrm{g} / \mathbf{m}^{3}\right)\end{array}$ & $\begin{array}{c}\mathrm{CO} \\
(\mathbf{p p m})\end{array}$ & $\begin{array}{c}\mathbf{O 3} \\
\left(\mu \mathrm{g} / \mathrm{m}^{3}\right)\end{array}$ \\
\hline O Boa & $0-50$ & Seguro à Saúde & $0-80$ & $0-50$ & $0-80$ & $0-100$ & $0-4,5$ & $0-80$ \\
\hline (5) Regular & $51-100$ & Tolerável & $81-240$ & $51-150$ & $81-365$ & $101-320$ & $4,6-9,0$ & $81-160$ \\
\hline O Inadequada & 101-199 & $\begin{array}{c}\text { Insalubre para } \\
\text { Grupos } \\
\text { Sensíveis }\end{array}$ & $241-374$ & $151-249$ & $366-799$ & $321-1129$ & $9,1-14,9$ & 161-399 \\
\hline G Má & 200-299 & $\begin{array}{c}\text { Muito } \\
\text { Insalubre } \\
\text { (Nível de } \\
\text { Atenção) }\end{array}$ & $375-624$ & $250-419$ & $800-1599$ & $1130-2259$ & $15,0-29,9$ & $400-799$ \\
\hline O Péssima & 300-399 & $\begin{array}{l}\text { Perigoso } \\
\text { (Nível de } \\
\text { Alerta) }\end{array}$ & $625-874$ & $420-499$ & $1600-2099$ & 2260-2999 & $30,0-39,9$ & 800-999 \\
\hline O Crítica & $\begin{array}{l}400 \mathrm{ou} \\
\text { maior }\end{array}$ & $\begin{array}{c}\text { Muito Perigoso } \\
\text { (Nível de } \\
\text { Emergência) }\end{array}$ & $\geq 875$ & $\geq 500$ & $\geq 2100$ & $\geq 3000$ & $\geq 40$ & $\geq 1000$ \\
\hline $\begin{array}{l}\text { Os índices, até a } \\
\text { CONAMA } 03 \mathrm{de}\end{array}$ & ficação & EGULAR, aten & aos $\mathrm{Pa}$ & es de $Q$ & idade do $A$ & r estabele & os pela $\mathrm{F}$ & olução \\
\hline
\end{tabular}

Fonte: http://www.fepam.rs.gov.br/qualidade/iqar.asp 
Quadro 4. Efeitos na saúde de acordo com o IQA

\begin{tabular}{|c|c|c|}
\hline Qualidade & Índice & Significado \\
\hline Boa & $0-50$ & Praticamente não há riscos à saúde. \\
\hline Regular & $51-100$ & $\begin{array}{c}\text { Pessoas de grupos sensíveis (crianças, idosos e pessoas com } \\
\text { doenças respiratórias e cardíacas), podem apresentar sinto- } \\
\text { mas como tosse seca e cansaço. A população, em geral, não } \\
\text { é afetada. }\end{array}$ \\
\hline Inadequada & $101-199$ & $\begin{array}{c}\text { Toda a população pode apresentar sintomas como tosse seca, } \\
\text { cansaço, ardor nos olhos, nariz e garganta. Pessoas de gru- } \\
\text { pos sensíveis (crianças, idosos e pessoas com doenças respi- } \\
\text { ratórias e cardíacas), podem apresentar efeitos mais sérios } \\
\text { na saúde. }\end{array}$ \\
\hline Má & $200-299$ & $\begin{array}{l}\text { Toda a população pode apresentar agravamento dos sintomas } \\
\text { como tosse seca, cansaço, ardor nos olhos, nariz e garganta } \\
\text { e ainda apresentar falta de ar e respiração ofegante. Efeitos } \\
\text { ainda mais graves à saúde de grupos sensíveis (crianças, } \\
\text { idosos e pessoas com doenças respiratórias e cardíacas). }\end{array}$ \\
\hline Péssima & $>299$ & $\begin{array}{l}\text { Toda a população pode apresentar sérios riscos de manifes- } \\
\text { tações de doenças respiratórias e cardiovasculares. Aumento } \\
\text { de mortes prematuras em pessoas de grupos sensíveis }\end{array}$ \\
\hline
\end{tabular}

Fonte: http://www.fepam.rs.gov.br/qualidade/iqar.asp

A partir desses diversos índices, canais podem ser disponibilizados para informação, permitindo ao indivíduo planejar as suas atividades diárias, tais como: atividades físicas ao ar livre onde a qualidade do ar seja mais saudável, evitando horários de picos de poluição; ou monitorar exposição de indivíduos susceptíveis a doenças respiratórias e cardiovasculares, se necessário utilização de máscaras. Espaços de divulgação científica tem disponibilizado orientações sobre a necessidade de acesso por meio de mensagens em sites oficiais ou dirigidas a grupos específicos que apresentam vulnerabilidade na exposição ${ }^{(97)}$.

A geração de dados locais em todo o Brasil são cruciais para fornecer informações que suportem a tomada de decisão em políticas públicas, bem como a revisão para implementação em regulamentações locais.

Pope faz uma análise sobre a evolução dos estudos em poluição do ar e saúde nos Estados Unidos sob a perspectiva da tradução de pesquisa e ações em políticas públicas ${ }^{(2)}$. 
Este autor apresenta um paralelo entre a pesquisa e as ações políticas até os dias atuais naquele país, reforçando a importância de se estabelecer uma agenda entre estes dois campos. Apresenta os fatos históricos que demarcaram os primeiros episódios entre as décadas de 30-50, que em sequencia originaram os primeiros estudos sobre efeitos da poluição do ar sobre a saúde humana, o que culminou no surgimento da primeira legislação para o controle da poluição do ar, em 1955, e outros eventos conforme quadro abaixo:

Quadro 1. Pesquisa e Política Pública sobre poluição por material particulado (adapatado Pope, NEJM 351;11. Sep 9, 2004) ${ }^{(2)}$

\begin{tabular}{|c|c|}
\hline Pesquisa & Política Pública nos EUA \\
\hline \multicolumn{2}{|l|}{$\begin{array}{l}\text { 1930-1950 - Estudos dos primeiros episódios } \\
\text { de poluição. }\end{array}$} \\
\hline & $\begin{array}{l}\text { 1955, } 1963 \text { - Primeira legislação nacional } \\
\text { 1967,1970,1971Clean Air Act, National } \\
\text { Ambient Air Quality Standars (NAAQS) }\end{array}$ \\
\hline $\begin{array}{l}\text { 1960-1980 } \\
\text { Estudos ecológicos e outros; Estudos } \\
\text { toxicológicos. }\end{array}$ & $\begin{array}{l}\text { Estabelecido padrão para PM10, substituindo } \\
\text { padrões prévios para material particulado total. }\end{array}$ \\
\hline \multicolumn{2}{|l|}{$\begin{array}{l}\text { 1989-1995 } \\
\text { Reports, esforços de pesquisas vagamente } \\
\text { conectados. }\end{array}$} \\
\hline & 1997 Promulgação dos padrões para PM 2,5 \\
\hline \multirow{2}{*}{\multicolumn{2}{|c|}{$\begin{array}{l}\text { 1995- presente } \\
\text { Controvérsias a respeito dos efeitos à saúde de } \\
\text { baixos níveis de poluição do ar; reanálises de } \\
\text { estudos chaves; rápido crescimento em estudos } \\
\text { epidemiológicos, toxicológicos e outros. }\end{array}$}} \\
\hline & \\
\hline & $\begin{array}{l}\text { 1998-2001 Padrões para PM } 2,5 \text { desafiados, } \\
\text { bloqueadas no tribunal federal de apelações, mas } \\
\text { finalmente confirmada pelo Supremo Tribunal. }\end{array}$ \\
\hline \multirow{2}{*}{\multicolumn{2}{|c|}{$\begin{array}{l}\text { 2000-presente } \\
\text { Aumento do foco sobre o papel da poluição do } \\
\text { ar em doenças cardiovasculares, os efeitos a } \\
\text { longo prazo e efeitos fisiopatológicos. }\end{array}$}} \\
\hline & \\
\hline & $\begin{array}{l}\text { 2002-presente Revisão adicional para padrões } \\
\text { de PM 2,5; debate sobre custo-benefício. }\end{array}$ \\
\hline
\end{tabular}


Olmo e colaboradores ${ }^{(98)}$, em revisão sistemática sobre estudos que relacionam os efeitos da poluição sobre a saúde humana, avaliou quais destes estudos mencionaram assuntos em políticas públicas e demonstraram a necessidade de incorporar evidencias epidemiológicas que possam dar suporte à legislação brasileira e sobretudo discutir implicações de politicas públicas em estudos epidemiológicos.

Brilhante e colaboradores ${ }^{(99)}$ abordam a necessidade de estratégias baseadas na intersetorialidade para o enfrentamento de problemas no campo da saúde e ambiente. Em Salvador a abordagem intersetorial foi proposta por Vianna e colaboradores ${ }^{(100)}$, visando a aproximação entre a pesquisa e o poder público. A articulação entre os setores envolvidos, tais como, pesquisa, governo, comunidade e setor privado, tem sido estimulado em nível local para a formação de rede que possa gerar evidencias para a tomada de decisão.

\subsection{Vigilância em saúde ambiental relacionada à qualidade do ar}

A vigilância em saúde ambiental é definida pelo SUS como "um conjunto de ações que proporcionam o conhecimento e a detecção de qualquer mudança nos fatores determinantes e condicionantes do meio ambiente que interferem na saúde humana, com a finalidade de recomendar e adotar as medidas de prevenção e controle dos fatores de riscos e das doenças ou agravos relacionados à variável ambiental".

O Programa VIGIAR (Vigilância em Saúde Relacionada à Qualidade do Ar) está instituído no âmbito do Ministério da Saúde brasileiro (MS) por meio da Secretaria de Vigilância em Saúde / Departamento de Vigilância em Saúde Ambiental e Saúde do Trabalhador / Coordenação Geral de Vigilância em Saúde Ambiental (SVS/DSAST/CGVAM). 
Está inserido no contexto da vigilância em saúde de populações expostas a poluentes atmosféricos e vem sendo estruturada desde 2001. O objetivo deste programa é desenvolver ações visando recomendar e instituir medidas de promoção da saúde, de prevenção dos fatores de risco relacionados à exposição aos poluentes atmosféricos, em atenção integral, conforme pressupostos do Sistema Único de Saúde.

Barcellos e colaboradores apontam para a necessidade de articulação interinstitucional para minimizar as lacunas entre as sobreposições de atribuições entre os setores de saúde e ambiente ${ }^{(101)}$, tendo como pressupostos a intersetorialidade e interdisciplinaridade. Considera ainda como limitante a capacidade do quadro técnico em analisar informações sobre saúde e ambiente.

A construção de indicadores em saúde ambiental tem como referência o modelo de organização e análise de indicadores baseado em FPSEEA: Força Motriz, Pressões, Situação Ambiental, Exposição Ambiental, Efeitos, Ações, que têm sido empregados pela Organização Mundial da Saúde ${ }^{(102)}$.

Villardi e colaboradores ${ }^{(103)}$ abordam o histórico e modelo de atuação que tem sido proposto ao Programa Vigiar, desde o início da sua implantação em 2001. As primeiras ações ocorreram a partir de 2004, em áreas piloto, com características urbanas e industriais. Em 2009 passou a compor o VIGIPEQ (Programa de Vigilância a Populações Expostas a contaminantes Químicos) no âmbito da Coordenação Geral de Vigilância em Saúde Ambiental (VIGIAR/VIGIPEQ/CGVAM/DSAST/SVS). A atuação do VIGIAR vem seguindo o modelo proposto, ainda em construção, em lógica que pode seguir dois sentidos: Proativa (Prevenção, Recuperação e Promoção) e Reativa (Demanda ou Denúncia). A lógica proativa inicia com a identificação e priorização de áreas contaminadas através da aplicação do IIMR, um Instrumento de 
Identificação de Municípios de Risco, implementado em nível local pelas secretarias municipais de saúde. Seguida pela etapa de diagnóstico/avaliação/análise para estabelecimento de protocolos e rotina de vigilância e atenção à saúde. Por outro lado a lógica reativa parte de eventos de denúncia ou demanda. Abaixo, representação esquemática do modelo:

\section{Lógica de Atuação}

Proativa: Prevenção, Recuperação e Promoção

Educação/Comunicação de Risco em Saúde

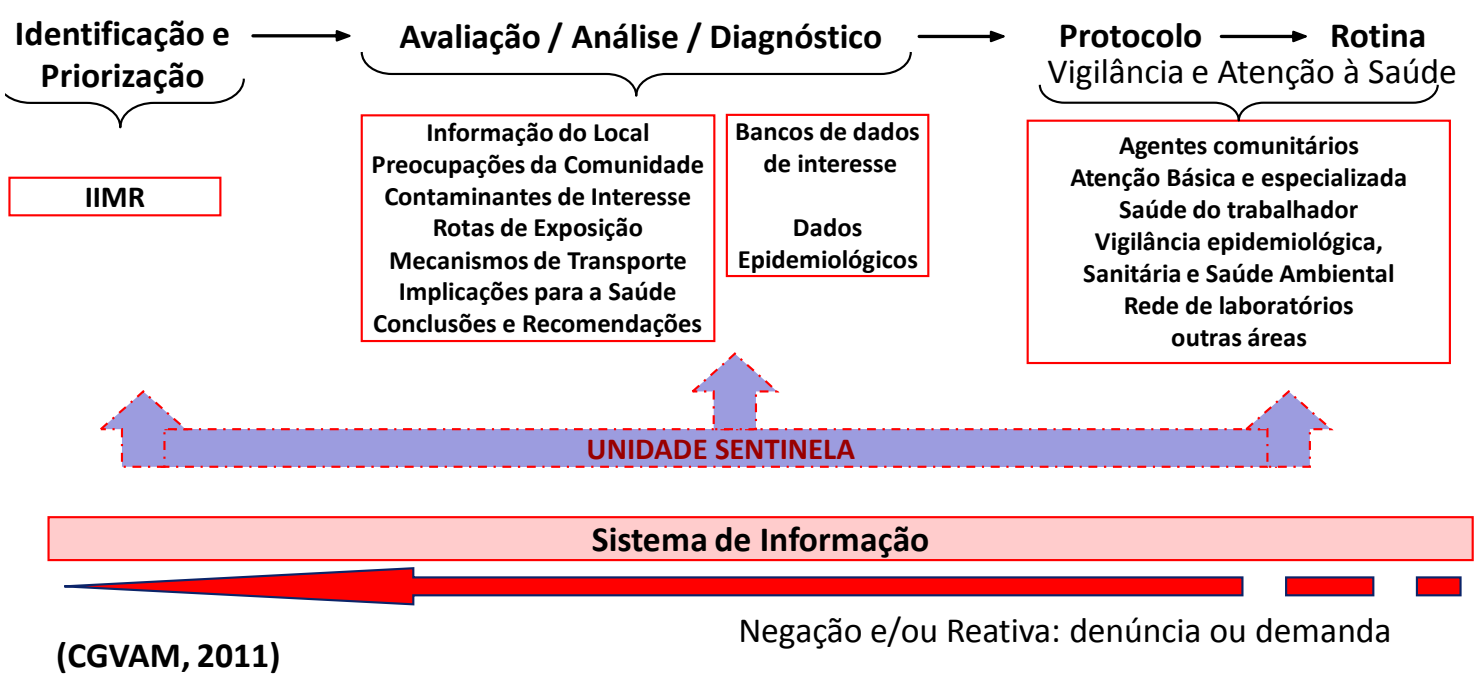

Fonte: CGVAM, 2011, Ministério da Saúde

Figura 11. 1Modelo esquemático sobre a lógica de atuação do VIGIAR

As unidades sentinelas são centros que deverão ser implementados pelas secretarias municipais visando realizar a vigilância epidemiológica para doenças respiratórias em grupos susceptíveis (crianças e idosos), gerando um sistema de informação para análise do programa VIGIAR ${ }^{(104)}$. 
Um dos grandes desafios para o setor público, no tocante ao gerenciamento de risco e a implementação dos programas de vigilância preconizados pelo Ministério da Saúde no Brasil, é a elaboração de métodos capazes de reproduzir realidades que possam ser transponíveis a todo território, visto que tecnologias de monitoramento de poluentes atmosféricos não são acessíveis para todas as comunidades ${ }^{(102)}$.

Compete aos municípios a responsabilidade pela promoção, coordenação e execução de estudos e pesquisas aplicadas na área de vigilância em saúde ambiental conforme instrução normativa $\mathrm{n}^{\circ} 1$ de 2005 , publicada pela Secretaria de Vigilância em Saúde (SVS) ${ }^{(9)}$, contudo os órgãos ambientais de muitos Estados e Municípios não possuem infra estrutura e quadro de pessoal adequados para desenvolver ações específicas frente a situações de contaminação, dada a escassez de recursos ou capacidade técnica para a análise ${ }^{(101)}$.

Uma das questões que se coloca é qual a participação relativa das fontes móveis na geração do aerossol urbano em diferentes cidades de nosso País. Em São Paulo, esta questão já é conhecida, entretanto não seria possível extrapolar os dados de uma região para outra, visto que possuem características climáticas, situação geográfica e perfis de trânsito bastante distintos. Políticas públicas locais devem contemplar a mitigação de riscos aos quais estão expostos a sua população. Para tanto, a tomada de decisão deve ser sustentada por dados e indicadores locais que possam diminuir as incertezas acerca dos potenciais riscos. A caracterização do poluente, a exposição à saúde humana e a comunicação de riscos são etapas cruciais para o desenvolvimento desses indicadores, visto que as condições ambientais, climáticas, sociais e econômicas podem diferir de uma localidade para outra.

Ainda são escassos estudos locais em países em desenvolvimento que relacionem a poluição atmosférica com as emissões veiculares ${ }^{(105)}$. Países em desenvolvimento, 
como o Brasil, podem acumular diferentes tipos de riscos, desde aqueles inerentes à evolução tecnológica e industrial dos grandes centros, como também aqueles associados às condições básicas de vulnerabilidade social, cultural e ambiental.

Lyra ${ }^{(106)}$ realizou um estudo, utilizando um modelo matemático, onde foram inventariados e projetadas as emissões fixas e móveis na região metropolitana de Salvador, demonstrando que as fontes veiculares contribuem para a poluição atmosférica urbana. A influencia de outras fontes pode ocorrer pela proximidade da cidade com o maior polo petroquímico da América Latina, com um parque industrial em franca expansão, composto de três grandes núcleos industriais que juntos contemplam mais de 40 empresas. Este cenário ainda carece de dados concretos relacionados aos índices de poluição atmosférica e qualidade do ar que tenham utilizado modelos receptores para material particulado em suspensão, metais pesados e gases tóxicos, seja de origens veiculares ou industriais.

Em Salvador até o ano de 2010 não havia rede de estações automáticas para o monitoramento da qualidade do ar. Vianna e colaboradores ${ }^{(11)}$, realizaram um estudo pioneiro utilizando biomonitoramento para caracterizar o nível de metais presentes no material particulado da atmosfera urbana, evidenciando níveis de contaminação por elementos traços para poluição veicular. Este estudo deu início às ações de intersetorialdade na perspectiva de formação de rede para implementação do Programa VIGIAR da Secretaria Municipal de Saúde.

A validação de técnicas consideradas mais rudimentares para detecção de poluentes são recomendadas pela Organização Mundial de Saúde, pela relevância no levantamento de indicadores em saúde ambiental, especialmente pela possibilidade de alcance territorial, dos custos envolvidos e do desenvolvimento de tecnologias viáveis para o Sistema Único de Saúde (SUS). 
Neste contexto, a realização de um estudo local em Salvador propondo a abordagem em análise de risco, foi concebido de modo a poder contribuir para avaliar estas questões, buscando avançar em evidencias científicas para a tomada de decisão em políticas relacionadas à vigilância em saúde e qualidade do ar. 


\section{OBJETIVOS}

\section{$\underline{\text { Objetivo Geral }}$}

Avaliar a poluição atmosférica em Salvador baseado em princípios da abordagem análise de riscos

\section{Objetivos específicos}

1. Estudar a morfologia e composição elementar das partículas através de microscopia eletrônica de varredura convencional e analítica com micro-análise de raios-X.

2. Determinar as concentrações de metais no material particulado em suspensão em locais da cidade de Salvador.

3. Determinar as concentrações ambientais de PM 2,5 em evento de massa na cidade de Salvador.

4. Avaliar exposição da poluição atmosférica à saúde ocular.

5. Propor indicadores para orientar as ações de vigilância em saúde ambiental e tomada de decisão em políticas públicas. 


\section{MÉTODOS}

O projeto de doutorado foi aprovado pela Comissão de Ética para Análise de Projetos de Pesquisa (CAPPesq), da Faculdade de Medicina da Universidade de São Paulo, conforme protocolo n 0165/09 (Anexo 1)

\subsection{Metodologia Análise de Riscos - Modelo conceitual}

Este estudo foi realizado em etapas estruturadas utilizando a abordagem em análise de riscos, obedecendo critérios conceituais específicos à cada etapa, os quais conduziram às diferentes fases da sua execução, desenvolvido conforme esquema abaixo:

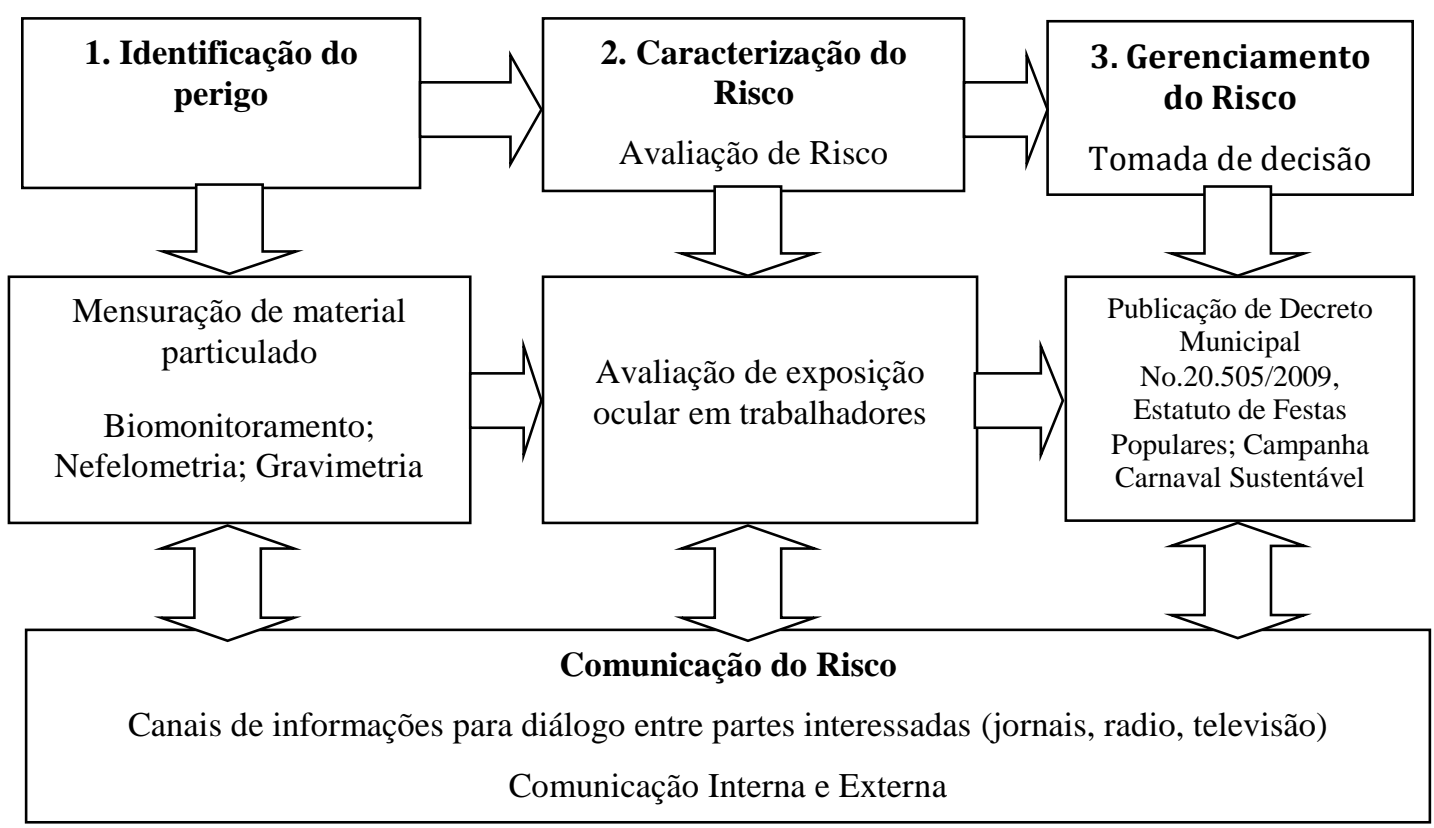


A abordagem em análise de riscos foi aplicada inicialmente testando ferramentas passíveis de serem utilizadas no contexto local para levantar indicadores em saúde ambiental que pudessem subsidiar decisões locais no tocante à regulamentação local e controle das emissões atmosféricas.

$\mathrm{Na}$ formulação do problema a ser estudado foram realizados encontros para diálogo entre gestores, assessores de risco, comunidade científica e comunidade e geral.

Para as fases de mensuração de poluentes atmosféricos foram aplicadas técnicas experimentais de abordagem quantitativa.

A seguir apresento separadamente a metodologia aplicada em cada estudo:

- Estudo 1: Biomonitoramento

- Estudo 2: Estudo de caso em evento de massa

\subsection{ESTUDO 1 - Estudo de Biomonitoramento}

\subsection{1 Área de Estudo}

Salvador é uma cidade litorânea, localizada a $12^{\circ} 58^{\prime} 15^{\prime \prime} \mathrm{S}$ e $38^{\circ} 30^{\prime} 39^{\prime \prime} \mathrm{O}$, Estado da Bahia, Mesorregião Metropolitana de Salvador, Microrregião Salvador, seus municípios limítrofes são Lauro de Freitas, Simões Filho e Candeias. Possui área total de $693.276 \mathrm{Km}^{2}$, população 2.902 .927 habitantes ${ }^{(107)}$, densidade demográfica 3.859,44 hab/ $\mathrm{Km}^{2}$, altitude 8 metros, clima Tropical Atlântico, fuso horário UTC-3. Os indicadores são: IDH 0,805 ${ }^{(108)}$ PIB R $\$ 14.218 .146$ mil; PIB per capta $\mathrm{R} \$ 14.411,73$. 
A frota veicular em Salvador é de 887.831 veículos, correspondendo a $25,1 \%$ da frota baiana, ${ }^{(109)}$, distribuídos em auto (610.050-68,71\%), camioneta (92.294 - 10,84\%), caminhão (22.646 - 2,55\%), ônibus $(10.090-1.13 \%)$, microônibus (4.336-0,48\%), moto (115.832-13,047\%), outros $(28.583-3,21 \%)$ e representa a maior frota de veículos de todo o Norte-Nordeste.

Na região metropolitana está localizado o maior Polo Petroquímico da América Latina, o que pode representar uma significativa fonte de poluição atmosférica para a cidade e o entorno.

Para o estudo com biomonitoramento foram escolhidos cinco pontos representativos na cidade de Salvador para o transplante das amostras. Os critérios utilizados para a escolha dos locais a serem monitorados foram baseados em localização das estações automáticas de monitoramento da qualidade do ar, administrada por parceria público-privada.

Os biomonitores utilizados para o transplante foram retirados de áreas consideradas controle (Piatã, BA, Chapada Diamantina) por não existir fontes de emissão de poluentes próximas a estes locais.

De acordo com método aplicado por Vianna e colaboradores ${ }^{(11)}$ as amostras foram transplantadas para cinco bairros em Salvador: Paralela, Rio Vermelho, Dique do Tororó, Pirajá e Pituba, em locais onde estão situadas as estações automáticas de monitoramento da qualidade do ar em Salvador (exceto Pituba), ficando expostas por um período de 45 dias. 


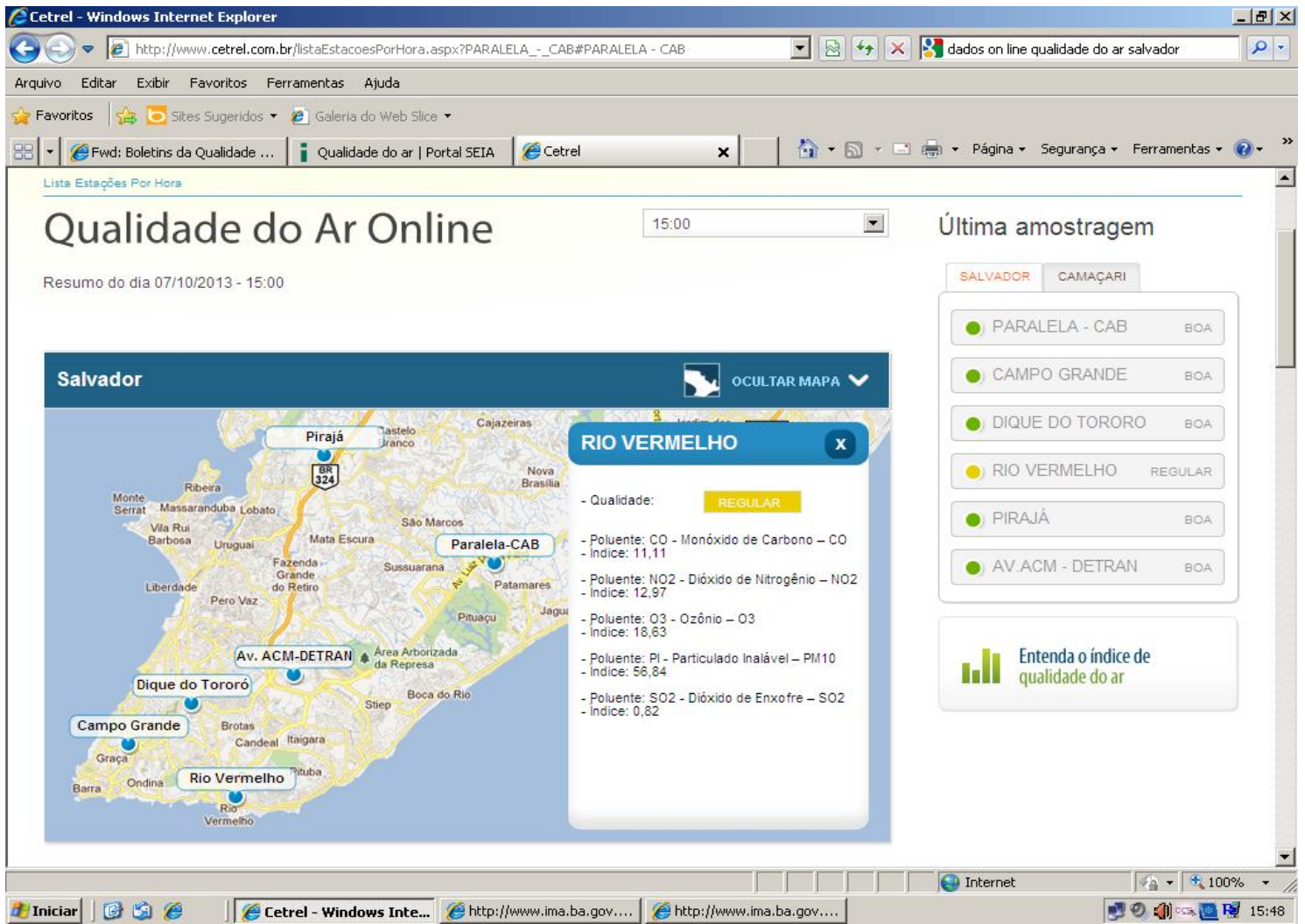

Figura 12. Mapa dos locais de monitoramento na cidade de Salvador, Bahia, Brasil

\subsubsection{Exposição atmosférica do biomonitor tillandsia usneoides para acessar o material particulado}

As plantas utilizadas para monitoramento das concentrações de metais pesados na atmosfera em diferentes locais foram coletadas em Piatã, BA, região da Chapada Diamantina, local considerado controle sem influencia de tráfego.

Aproximadamente 7 quilos da planta viva foram coletados e transportadas para Salvador. Inicialmente foi feita uma triagem para remoção de outros organismos, de modo a selecionar apenas a espécie em questão. Aproximadamente 25 gramas da planta viva foram separadas e lavadas previamente com água destilada. Foram então introduzidas em 
cestas plásticas de polietileno com cobertura de acrílico limpas (Figura 13) e distribuídas pelos pontos estudados.
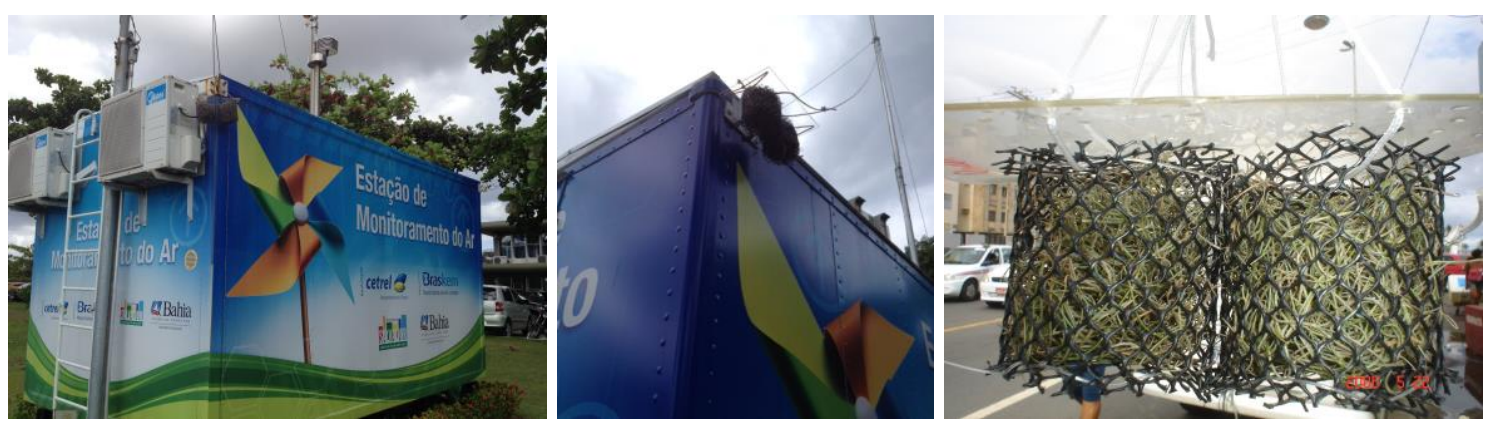

Figura 13. Fotos das amostras de Tillandsia usneoides expostas nas estações de monitoramento da qualidade do ar e foto com detalhe das cestas com teto de acrílico contendo a planta

Após o período de exposição, as cestas foram retiradas dos locais e as plantas preparadas para quantificação de metais por espectrofotometria de absorção atômica e para estudo das partículas por microscopia eletrônica convencional e analítica.

\subsubsection{Técnicas analíticas:}

\section{Quantificação de metais pesados por espectrofotometria de absorção atômica}

De acordo com a metodologia aplicada por Vianna e colaboradores ${ }^{(11)}$, após o período do transplante, as plantas foram transferidas para sacos plásticos tipo "Zip" e levadas para o Laboratório de Radioisótopos Eduardo Penna Franca, do Instituto de Biofísica Carlos Chagas Filho da Universidade Federal do Rio de Janeiro, para preparação e quantificação das concentrações de metais. As amostras de cada local foram fragmentadas com auxílio de tesouras limpas até ficarem com dimensões 
homogêneas. Frações de $0,5 \mathrm{~g}$ de massa seca para cada réplica (triplicata) foram transferidas para beckers Pirex de $50 \mathrm{~mL}$, que foram introduzidos em forno-mufla a $400^{\circ} \mathrm{C}$ para calcinação por 4 dias. Em seguida foram transferidas para placas aquecedoras mantidas a $70^{\circ} \mathrm{C}$, onde a matéria orgânica restante foi digerida por soluções de ácidos concentrados (ácido nítrico P.A. $65 \%$ e ácido clorídrico P.A. $37 \%$ ) por 05 dias. Finalmente a solução ácida foi evaporada em solução de ácido clorídrico $0,1 \mathrm{~N}$ em volume final de $10 \mathrm{~mL}$ para leitura em aparelho especial. As concentrações de metais pesados foram quantificadas por espectrofotometria de absorção atômica de chama, em aparelho Varian 1479. Os metais escolhidos para análise foram: Cromo, Cobre, Ferro, Manganês e Zinco, por serem metais traçadores de poluição urbana encontrados no material particulado e que poderão estar relacionados com mecanismos de alteração do metabolismo celular culminando em eventos adversos à saúde humana. Os resultados foram expressos em $\mu \mathrm{g} / \mathrm{g}$ de massa seca.

\section{Microscopia Eletrônica de Varredura Convencional e Analítica}

Fragmentos de aproximadamente $4 \mathrm{~mm}$ de Tillandsia usneoides expostas aos poluentes atmosféricos e do local controle foram obtidos e depositados diretamente sobre fita dupla-face de carbono sobre suporte de alumínio específico para microscopia eletrônica de varredura (MEV). As amostras receberam uma cobertura de carbono para torná-las mais condutoras de calor que é gerado em função do bombardeamento do feixe de elétrons do MEV. As amostras foram analisadas sem nenhuma fixação química de forma que as partículas de poeira são mantidas sobre a superfície da planta da mesma forma que estavam no campo. A morfologia de cada partícula foi analisada individualmente através da captura de sinal de elétrons secundários e também retro-espalhados, sendo 
que estes últimos, indicam a composição de elementos de grande número atômico. A composição elementar fina das partículas é determinada através da técnica analítica de microanálise de raios-X, energia dispersiva. $\mathrm{O}$ detector de raios-X está acoplado a um programa de computador que aloca os picos de raios-X em função de sua energia específica identificando cada átomo separadamente na forma de um espectro. O MEV utilizado foi o JEOL JSM 6390 LV localizado no Laboratório de Microscopia de Fundação Oswaldo Cruz, Bahia.

As imagens de MEV contendo as partículas adsorvidas a superfície da planta foram utilizadas para medições das dimensões das mesmas, utilizando o software Image J (NIH). As imagens de MEV possuem escala micrométrica que foi utilizada para calibração do programa. Pelo menos 200 partículas foram medidas de cada localidade e os resultados distribuídos nas seguintes dimensões: 0 - 2,5; 2,5 -10; 10 -50; 50 -100 $\mu \mathrm{m}$.

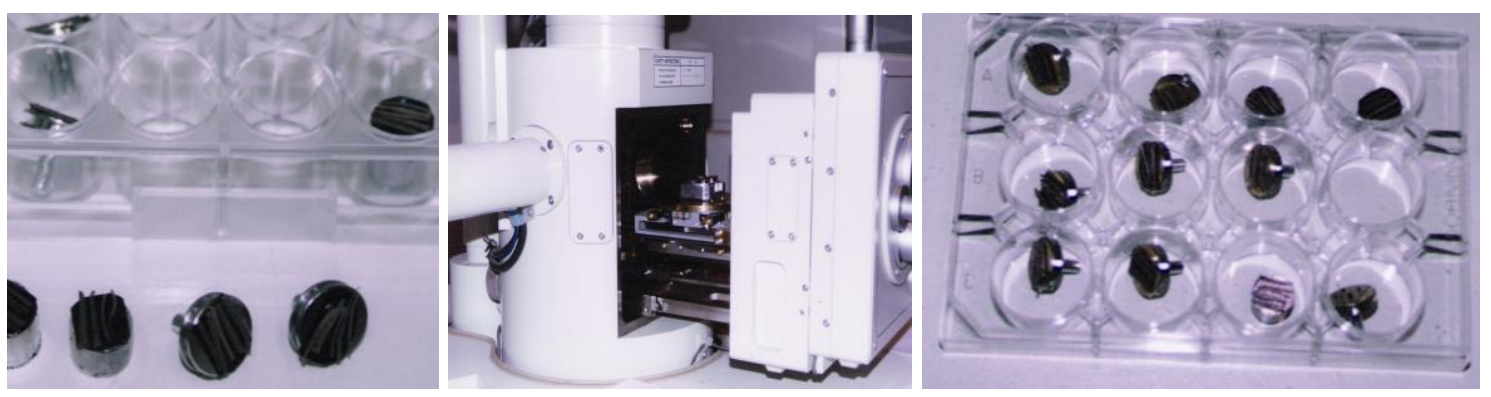

Figura 14. Fotos ilustrando os stubs com Tillandsia usneoides preparados para análise em microscopia eletrônica de varredura 


\subsection{ESTUDO 2 : Estudo de Caso em evento de massa com abordagem em análise de riscos}

\section{Local do estudo: Carnaval de Salvador}

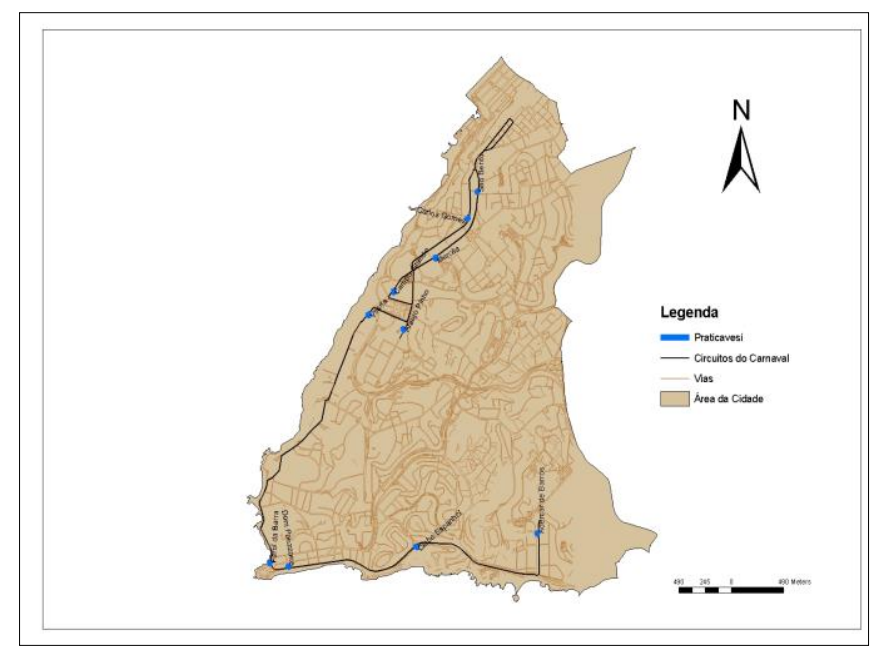

Figura 15. Mapa do Circuito de carnaval em Salvador

\section{Período de Estudo}

Este estudo foi realizado em três fases por um período de 3 anos.

\subsubsection{FASE 1 - Identificação do Perigo}

Foi realizado uma abordagem experimental por 3 anos consecutivos, incluindo as etapas de identificação do perigo, caracterização do risco (estudo de exposição à saúde) e gerenciamento do risco. O cenário do carnaval de Salvador foi o evento de massa utilizado para avaliar a exposição a poluentes atmosféricos. 
Na primeira etapa, identificação do perigo, foram feitas medidas de poluentes atmosféricos por meio de três técnicas: nefelometria, gravimetria e biomonitoramento.

O método de biomonitoramento usando a bromélia Tillandsia usneoides como biomonitor atmosférico, foi utilizada buscando levantar indicadores de metais presentes no material particulado. Técnicas de Espetrofotometria de Absorção Atômica e Microscopia Eletrônica de Varredura foram utilizadas para quantificação de metais e análise morfológica, respectivamente.

As medidas foram feitas nos três circuitos do carnaval (Pelourinho, Campo Grande e Barra-Ondina), baseado nos seguintes critérios: locais sem trio (controle), trios velhos (>10 anos fabricação), trios novos (<10 anos) e concentração de trios (antes de entrar na Avenida). Os locais eram fixos buscando contemplar os diversos tipos de motores distribuídos no percurso, bem como em locais da festa onde não havia presença dos trios elétricos, para controle do estudo. Foram feitas também medidas em camarotes ao longo do circuito, distribuídos da seguinte forma: Ambientes fechados (climatizados), Ambientes abertos (ventilação natural) e Sacadas (área mais próxima aos trios).
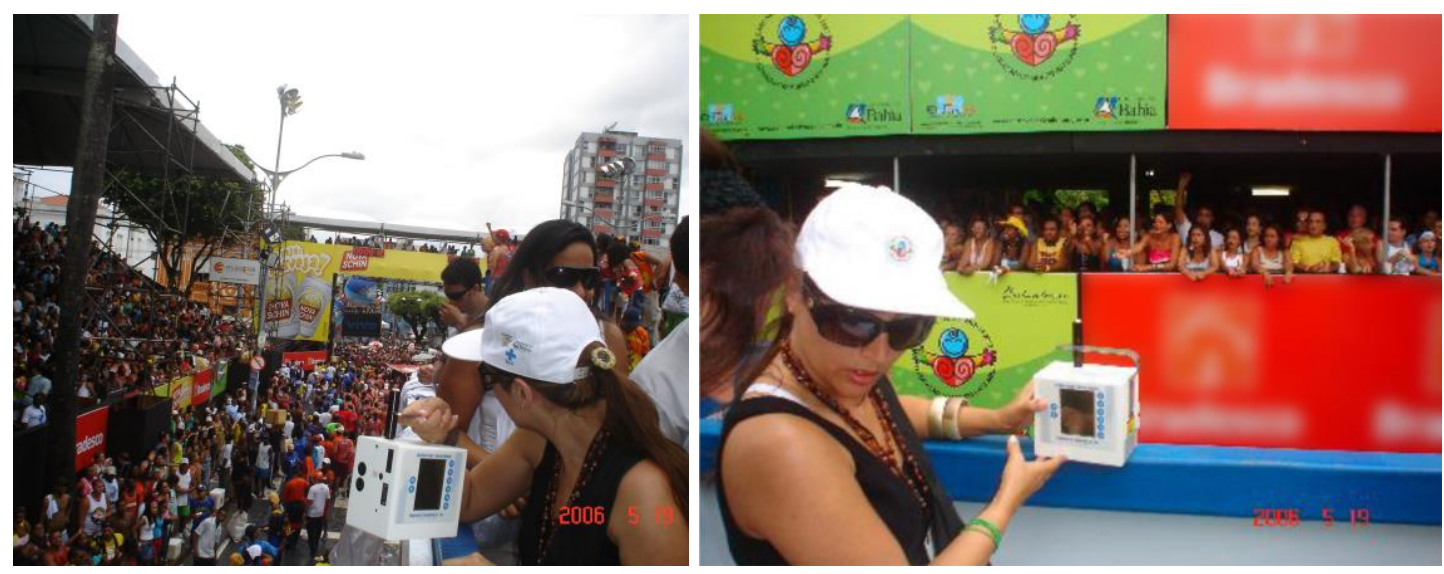

Figura 16. Fotos ilustrando a utilização do nefelômetro para medidas de PM 2,5 em cima do trio visualizando ao fundo camarote aberto (foto 1) e sacada (foto 2) com foliões 
Os níveis de poluição por material particulado com tamanho aerodinâmico de 2,5 $\mu \mathrm{m}$, foram mensurados utilizando nefelômetro portátil TSI modelo 8520 DUSTTRAK. Técnicas gravimétricas e nefelométricas foram utilizadas para determinação de massa do material particulado, emitida por motores a diesel.

As medidas de concentração da poeira grossa foram realizadas utilizando técnicas gravimétricas. Este modelo foi aplicado da seguinte forma: um dia antes do início do carnaval, 10 postes foram demarcados no circuito da festa com o auxílio de uma cartolina contendo um retângulo vazado em altura aproximada de 3 metros. Estes locais foram previamente lavados com água destilada e escovas com cerdas rígidas. Após sete dias retirou-se a poeira acumulada nas áreas demarcadas com o auxílio de gazes umedecidas que tinham sido previamente preparadas em laboratório, secas em estufas, pesadas e embaladas em sacos plásticos. Após o procedimento de retirada da poeira acumulada, este material foi levado ao laboratório LPAE para realizar procedimentos de secagem e pesagem.

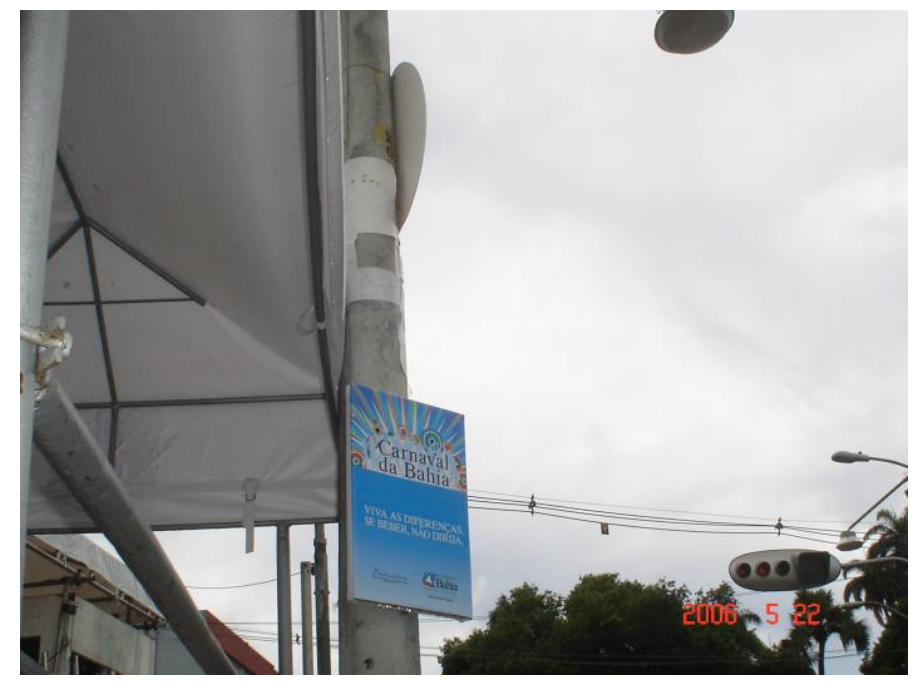

Figura 17. Foto ilustrando demarcação em cartolina aderida ao poste para coleta de poeira acumulada no período de 7 dias, no circuito do carnaval 


\subsubsection{FASE 2 - Estudo de avaliação da exposição à saúde humana}

A segunda etapa consistiu no estudo de avaliação de exposição da poluição atmosférica à saúde humana. O objetivo deste estudo foi investigar se existem sintomas de desconforto ocular e alterações da superfície ocular causadas pela exposição aguda à poluição gerada por diferentes níveis de emissões veiculares gerados pelos trios elétricos no carnaval de Salvador, em trabalhadores envolvidos nas diferentes atividades.

Foram coletados dados clínicos, citológicos e ambientais para estudar o impacto concentrações de poluentes atmosféricos sobre a superfície ocular.

\section{Determinação da amostra}

Foram selecionados 28 voluntários entre os trabalhadores diretamente relacionados com as atividades dos blocos carnavalescos em 3 diferentes funções: cordeiros, motoristas e ambulantes. Foram coletadas amostras, em dois momentos do estudo: 1 dia antes e 1 dia após o período carnavalesco.

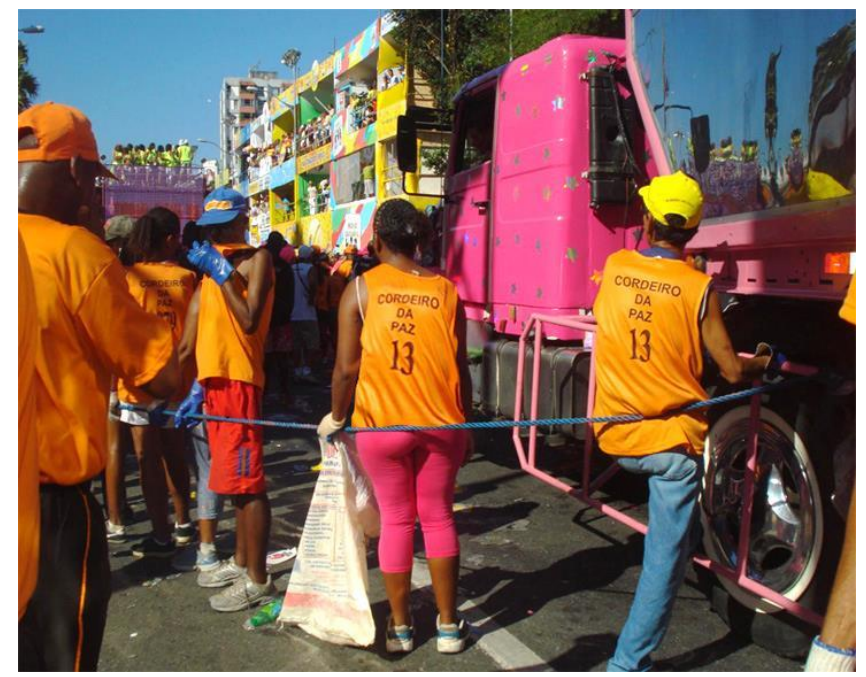

Figura 18. Foto de trabalhadores (cordeiros) expostos durante o evento 
Os indivíduos selecionados foram avaliados por meio de questionário específico, de testes clínicos (Schirmer, BUT e coloração com Rosa Bengala) e de citologia de impressão (conjuntiva tarsal inferior e bulbar inferior).

Para avaliar sinais e sintomas foi utilizado um inventário de sintomas e uma versão em português do OSDI* (Ocular Surface Disease Index) ${ }^{(110)}$, que avalia a frequência de alguns sintomas de olho seco (nos últimos sete dias) e o seu impacto em algumas atividades de vida diária. Também foi realizada a avaliação subjetiva por meio de um inventário dos sintomas mais frequentemente relacionados ao desconforto ocular, abrangendo a intensidade, frequência e tempo de aparecimento dos mesmos, além do impacto destes na produtividade dos indivíduos pesquisados.

Foram realizados:

\section{Entrevista:}

\section{1. questionário OSDI}

1.2. inventário de sintomas mais frequentes (intensidade/ frequência/ tempo)

\section{Exame Oftalmológico:}

Biomicroscopia (avaliação glândulas de meibomius, córnea, conjuntiva e filme lacrimal)

Tempo de ruptura do Filme Lacrimal

Coloração com Fluoresceína

Coloração com Verde de Lissamina

Teste de Schirmer

Citologia de impressão - avaliação das células superficiais (caliciformes e epiteliais) 


\subsubsection{Amostras de conjuntiva bulbar inferior}

\section{Amostras de conjuntiva tarsal inferior}

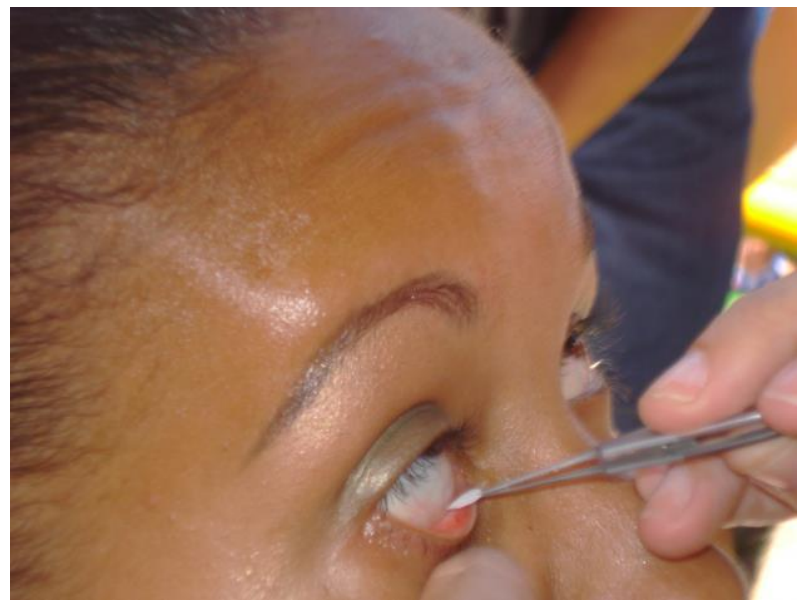

Figura 19. Foto ilustrando o procedimento de coleta para a citologia

\section{Monitoramento da exposição através da utilização de tubos passivos para medidas de NO2}

Para determinar as quantidades de dióxido de nitrogênio (NO2) foi aplicado o método passivo de acordo com Novaes e colaboradores ${ }^{(62)}$. Nós selecionamos nove locais ao longo do circuito de carnaval (Casa de Italia, Vitória, Canela, Piedade, Praça Municipal, Farol da Barra, Castro Alves, Ondina Espanhol, Ondina Apart) onde foram instalados os dispositivos de amostragem passiva durante os 7 dias. $\mathrm{O}$ amostrador continha um filtro de celulose estéril embebido com $2 \%$ de trietanolamina, $0,05 \%$ o-methoxyphenol e metabissulfito de sódio a $0,025 \%$. O nitrito produzidos durante a amostragem foi determinado colorimetricamente. 


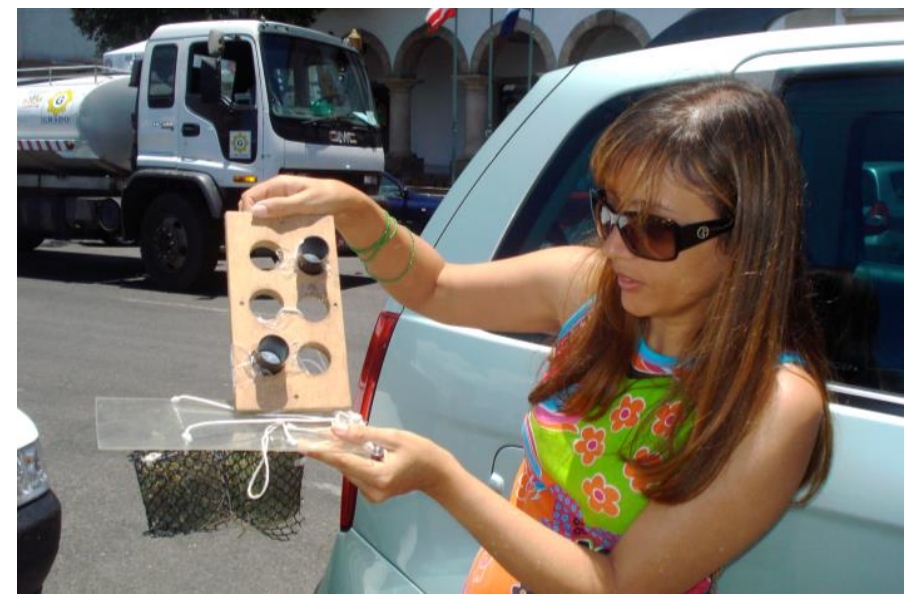

Figura 20. Foto apresentando os métodos: determinação de $\mathrm{NO}_{2}$ pelo método de tubo passivo e medidas de metais no material particulado por Biomonitoramento

\section{População de Estudo}

Foram incluídos no estudo 28 trabalhadores do carnaval de Salvador que desenvolviam atividades durante os sete dias do evento. Durante o evento prévio de capacitação, que ocorre uma semana antes por todos os setores envolvidos no evento, foi apresentado e projeto onde os colaboradores foram convidados a participar. Neste momento assinaram os termos de consentimento e foi marcada a consulta oftalmológica em clínica da rede, para exames e coleta de dados.

\section{Critérios de Inclusão e Exclusão}

Critérios de Inclusão: Foram incluídas pessoas que aceitarem participar do estudo após leitura do termo de consentimento livre e esclarecido, que tenham idade entre 20 e 65 anos, e que trabalhavam nas diferentes funções selecionadas durante o período de Carnaval.

Critérios de Exclusão: Foram excluídos fumantes, usuários de lentes de contato, pessoas com doenças oculares associadas, pessoas que viajem para outra cidade no período do estudo (7 dias) e aquelas que não aceitaram participar após leitura do termo de consentimento livre e esclarecido. 


\subsubsection{FASE 3 - Gerenciamento do Risco}

A terceira etapa consistiu em aplicação de ferramentas de gerenciamento do risco, incluindo a comunicação de riscos. Para fins didáticos enumeramos esta etapa como terceira fase, entretanto ela ocorre em todas as fases do estudo, onde foram executadas ações de articulação e envolvimento entre as partes interessadas. Desde a primeira fase o cronograma de execução do projeto foi apresentado à comunidade em reunião com os setores interessados e divulgado amplamente pela mídia local.

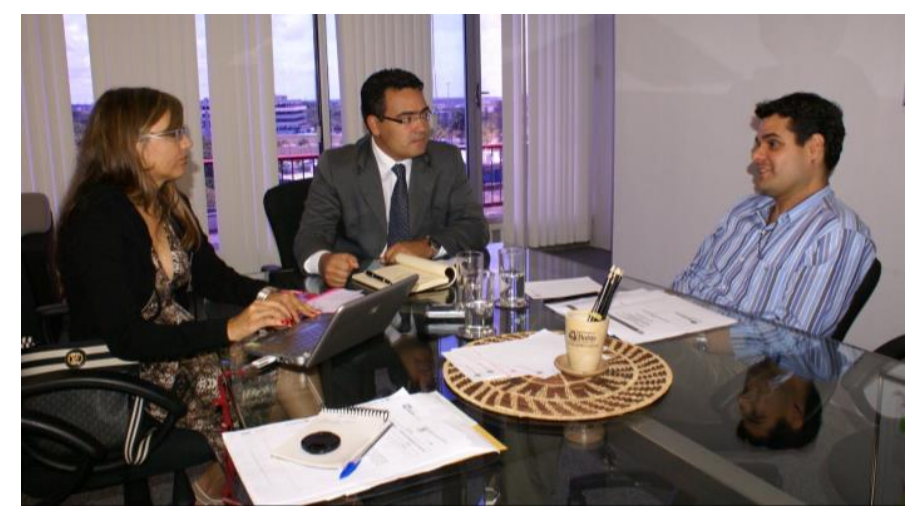

Figura 21. Foto de Reunião entre os pesquisadores Nelzair Vianna, Dr. Leonardo Andrade e o Secretário de Meio Ambiente da Bahia Dr. Juliano Matos

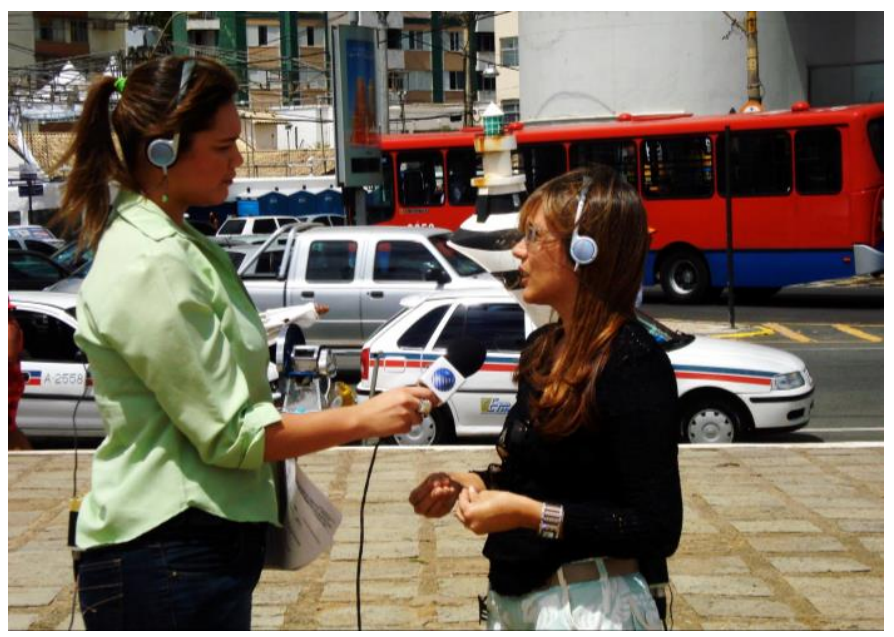

Figura 22. Foto de entrevista concedida à TV na etapa de comunicação do risco 
A ampla divulgação sobre os métodos a serem adotados para medir a poluição foram realizados por meio de mídia e canais de comunicação (jornais, sites institucionais, diário oficial e TV), conforme matéria abaixo extraída do site da Secretaria de Meio Ambiente da Bahia:

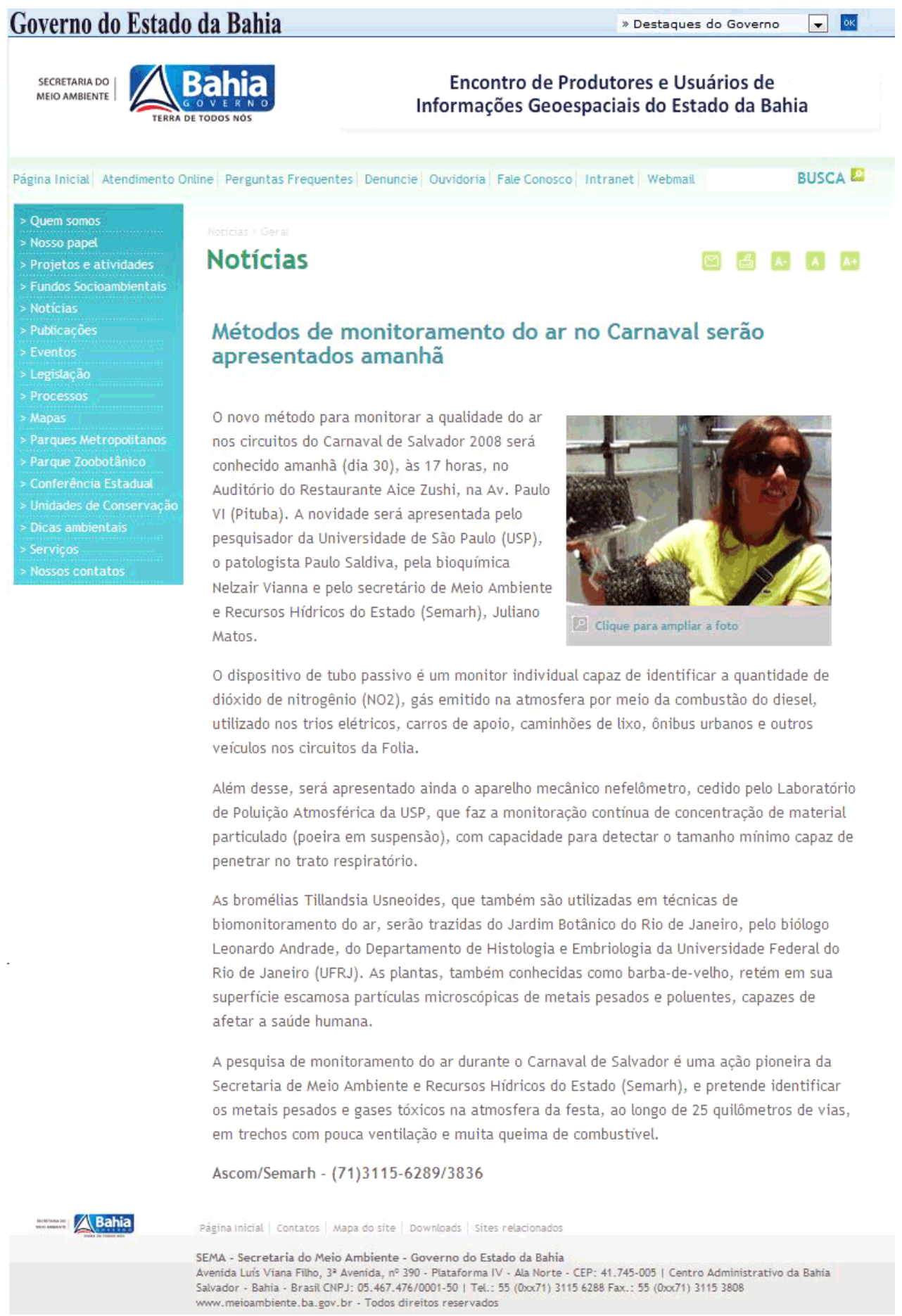

Figura 23. Matéria publicada em site institucional exemplificando a etapa de comunicação de riscos 
Da mesma forma os resultados preliminares de cada fase foram apresentados sob a forma de relatórios, coletivas de imprensa promovidas pelo governo do Estado, bem como palestras em setores da comunidade e órgãos representativos. Assim foi contemplada a divulgação interna e externa, utilizando bases para um plano de comunicação de riscos, segundo Moreno e colaboradores ${ }^{(14)}$.

Relatórios finais foram apresentados à comunidade através de ação articulada entre os setores de saúde, meio ambiente, instituições de pesquisa, comunidade e meios de comunicação. 


\section{ANÁLISE ESTATÍSTICA}

No estudo 1 a análise estatística foi feito através de análise descritiva dos resultados.

Para o estudo 2 foi utilizado também um modelo de regressão linear múltipla onde a variável dependente foi a citologia tarsal e como variáveis explicativas as concentrações médias de NO2, os dias de exposição ao poluente, número de horas trabalhadas por dia e sintoma de olhos secos.

As análises foram realizadas utilizando o programa R versão 2.3.1 and SPSS versão 15 (SPSS Inc., Chicago, IL, USA). 


\section{RESULTADOS}

\subsection{Quantificação de metais no material particulado por espectrofotometria de absorção atômica.}

As concentrações dos metais presentes no material particulado sofreram variações por bairro, apresentando índices mais elevados quando comparadas com os locais controles em áreas não urbanizadas.

A Tabela 1 apresenta os resultados da fase 2 de biomonitoramento. Nesta amostragem, o bairro de Pirajá apresentou as concentrações médias mais elevadas de Zinco (Zn), Ferro (Fe), Manganês (Mn), Cromo (Cr) e Níquel (Ni). O bairro da Pituba apresentou valores mais elevados para $\mathrm{Cr}$, comparando com os outros bairros analisados. No Rio Vermelho o nível de cobre foi o que se apresentou mais elevado, chegando a 6 vezes maior que a média do mesmo metal para as plantas de área controle.

Os metais avaliados se apresentaram em concentrações médias de acordo com a seguinte ordem: $\mathrm{Fe}>\mathrm{Mn}>\mathrm{Zn}>\mathrm{Cu}>\mathrm{Ni}$. 
Tabela 1. Concentrações de metais encontradas no material particulado em Salvador (BA) referentes amostragem (outono) - Fase 2, expressos em $\mathrm{mg} / \mathrm{g}$.

\begin{tabular}{|c|c|c|c|c|c|c|}
\hline Locais & Zn (mg/kg) & $\mathrm{Fe}(\%)$ & Mn (mg/kg) & $\mathrm{Cr}$ (mg/kg) & Ni (mg/kg) & $\mathrm{Cu}(\mathrm{mg} / \mathrm{kg})$ \\
\hline Controle & $\begin{array}{c}5.3 \\
(4.1-8.9)\end{array}$ & $\begin{array}{c}1.6 \\
(1.4-1.7)\end{array}$ & $\begin{array}{c}28.9 \\
(27.4-30.8)\end{array}$ & $\begin{array}{c}2.8 \\
(2.6-3)\end{array}$ & $\begin{array}{c}0.7 \\
(0.6-0.8)\end{array}$ & $\begin{array}{c}1.7 \\
(1.5-1.9)\end{array}$ \\
\hline Pirajá & $\begin{array}{c}20 \\
(18.2-21.7)\end{array}$ & $\begin{array}{c}3.1 \\
(3-3.3)\end{array}$ & $\begin{array}{c}90.9 \\
(87.2-97)\end{array}$ & $\begin{array}{c}4 \\
(3.9-4.2)\end{array}$ & $\begin{array}{c}1.1 \\
(0.9-1.3)\end{array}$ & $\begin{array}{c}8.4 \\
(7.7-9)\end{array}$ \\
\hline Paralela I & $\begin{array}{c}16.7 \\
(14.7-17.5)\end{array}$ & $\begin{array}{c}2.1 \\
(1.9-2.3)\end{array}$ & $\begin{array}{c}50.7 \\
(42.4-54.7)\end{array}$ & $\begin{array}{c}2.6 \\
(2.4-2.8)\end{array}$ & $\begin{array}{c}0.8 \\
(0.7-0.9)\end{array}$ & $\begin{array}{c}10.4 \\
(7.9-13.1)\end{array}$ \\
\hline Rio Vermelho & $\begin{array}{c}14.3 \\
(13.3-15.4)\end{array}$ & $\begin{array}{c}2.4 \\
(2.1-2.7)\end{array}$ & $\begin{array}{c}62.5 \\
(55.1-67.4)\end{array}$ & $\begin{array}{c}3 \\
(2.7-3.3)\end{array}$ & $\begin{array}{c}0.8 \\
(0.6-1)\end{array}$ & $\begin{array}{c}12.6 \\
(11.8-13.7)\end{array}$ \\
\hline C. Grande & $\begin{array}{c}21.2 \\
(18.2-22.6)\end{array}$ & $\begin{array}{c}2.5 \\
(2.1-2.9)\end{array}$ & $\begin{array}{c}62.9 \\
(53.6-70.3)\end{array}$ & $\begin{array}{c}2.9 \\
(2.4-3.3)\end{array}$ & $\begin{array}{c}0.7 \\
(0.5-0.9)\end{array}$ & $\begin{array}{c}5.8 \\
(5.3-6.5)\end{array}$ \\
\hline Dique & $\begin{array}{c}16.8 \\
(15.9-18.1)\end{array}$ & $\begin{array}{c}1.7 \\
(1.6-1.9)\end{array}$ & $\begin{array}{c}39.4 \\
(33.1-45.7)\end{array}$ & $\begin{array}{c}2.2 \\
(2-2.4)\end{array}$ & $\begin{array}{c}0.5 \\
(0.5-0.6)\end{array}$ & $\begin{array}{c}4 \\
(3.7-4.4)\end{array}$ \\
\hline Paralela II & $\begin{array}{c}12.3 \\
(11.9-12.7)\end{array}$ & $\begin{array}{c}1.9 \\
(1.8-2)\end{array}$ & $\begin{array}{c}34.5 \\
(31.9-37.1)\end{array}$ & $\begin{array}{c}2.2 \\
(2.1-2.3)\end{array}$ & $\begin{array}{c}0.6 \\
(0.5-0.7)\end{array}$ & $\begin{array}{c}4.3 \\
(4.2-4.4)\end{array}$ \\
\hline Pituba & $\begin{array}{c}16.9 \\
(11.8-21.3)\end{array}$ & $\begin{array}{c}1.8 \\
(1.7-1.9)\end{array}$ & $\begin{array}{c}28.9 \\
(27.6-29.6)\end{array}$ & $\begin{array}{c}3.8 \\
(3.1-5.3)\end{array}$ & $\begin{array}{c}0.8 \\
(0.5-1.2)\end{array}$ & $\begin{array}{c}9.9 \\
(8-12.9)\end{array}$ \\
\hline
\end{tabular}

O Gráfico 1 mostra os resultados da campanha realizada durante o carnaval e também da região controle (neste caso Pituba, bairro localizado fora do circuito).

Nesta amostragem, os metais analisados foram Cadmio (Cd), Cobre $(\mathrm{Cu})$, Manganês (Mn), Zinco (Zn), Ferro (Fe), Cromo (Cr), Cumbo (Pb) e Níquel (Ni) e demonstraram variabilidade da distribuição no material particulado dos diversos locais estudados.

Os metais avaliados se apresentaram em concentrações médias de acordo com a seguinte ordem $\mathrm{Fe}>\mathrm{Mn}>\mathrm{Zn}>\mathrm{Ni}>\mathrm{Pb}>\mathrm{Cr}>\mathrm{Cu}>\mathrm{Cd}$. $\mathrm{O} \quad \mathrm{Cd}$ se manteve elevado nesta estação no bairro da Barra. 
Gráfico 1. Concentrações de metais no material particulado adsorvidos na Tillandsia usneoides no período de 7 dias, no circuito do carnaval de Salvador

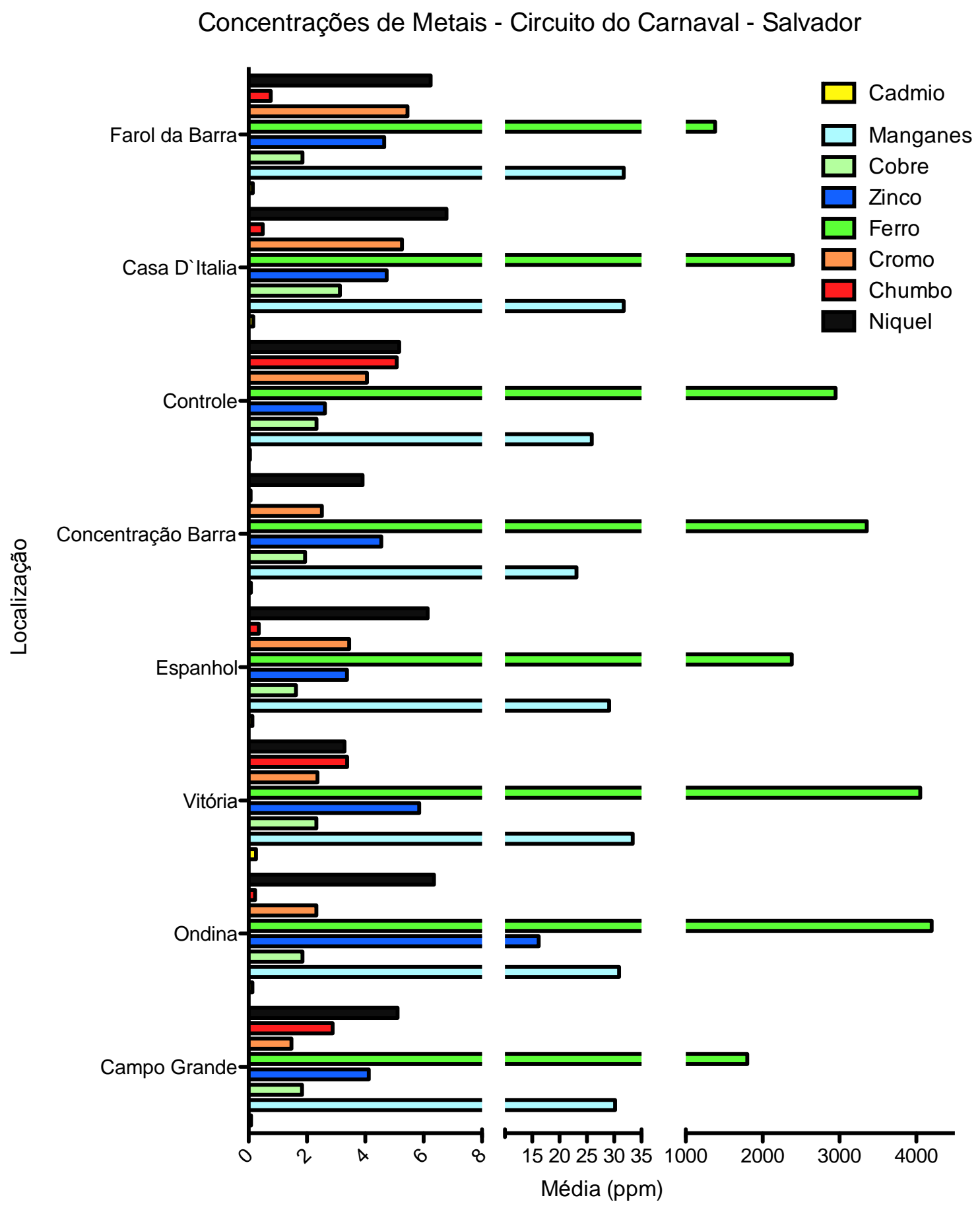


Os pontos Vitória e Ondina I e Ondina II apresentaram os níveis mais elevados de Fe. O Zn se apresentou mais elevado em Ondina e Vitória. O Mn se apresentou mais elevado na Vitória, Carlos Gomes e Farol da Barra. O Cu se apresentou mais elevado na Carlos Gomes e Vitória.

Gráfico 2. Concentrações dos metais $\mathrm{Zn}, \mathrm{Mn}, \mathrm{Fe}$ e $\mathrm{Cu}$ no material particulado adsorvidos pela Tillandsia usneoides no circuito do Carnaval de Salvador

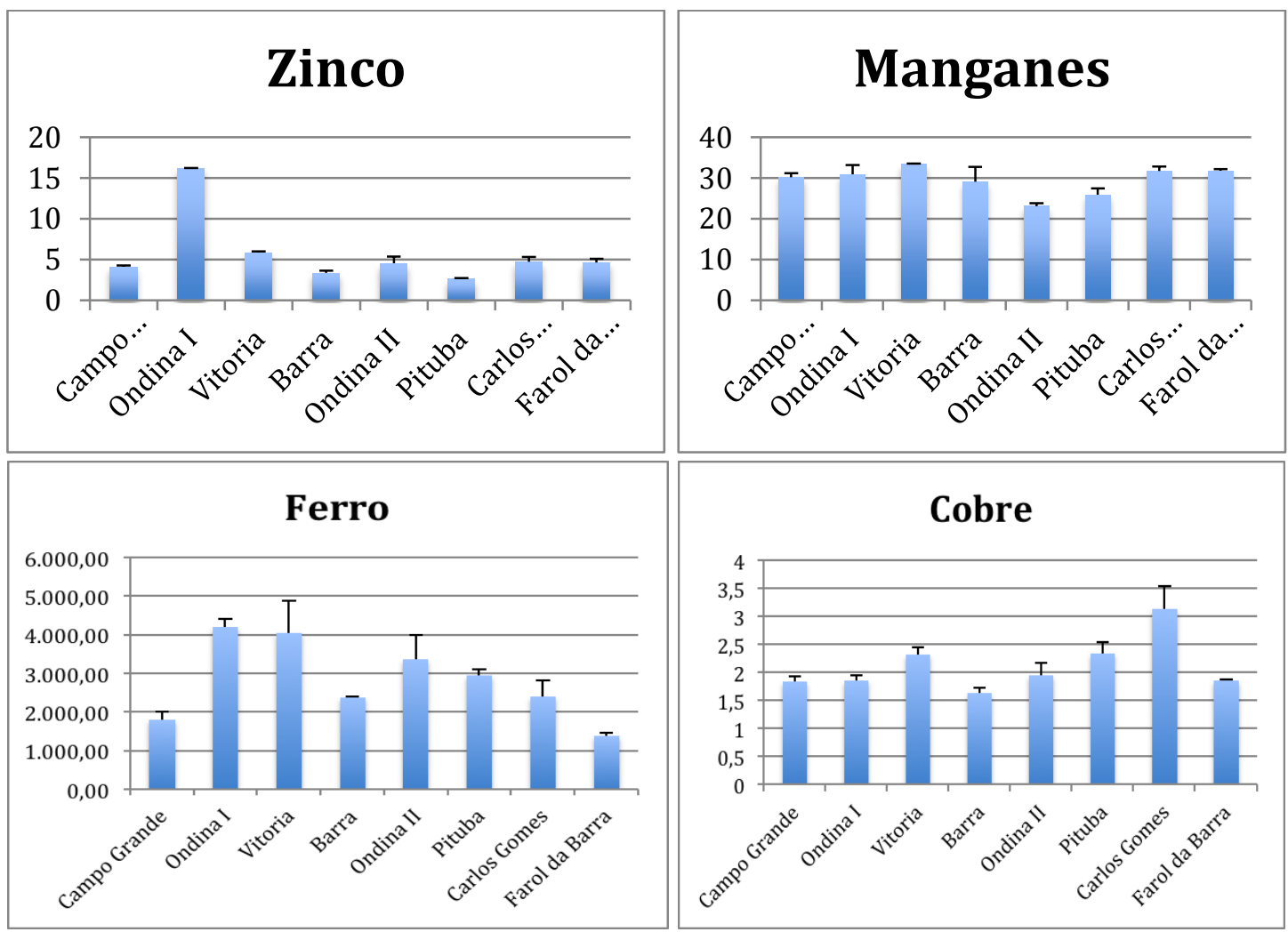

O Cr e Ni se apresentaram mais elevados no Farol da Barra e Carlos Gomes. O Cd se apresentou mais elevado na Vitória, Carlos Gomes e farol da Barra. $\mathrm{O} \mathrm{Pb}$ apresentou o nível mais elevado na Pituba, conforme resultados apresentados no Grafico 3. 
Gráfico 3. Concentrações dos metais $\mathrm{Cr}, \mathrm{Pb}, \mathrm{Ni}$ e $\mathrm{Cd}$ no material particulado adsorvido pela Tillandsia usneoides no circuito do carnaval de Salvador

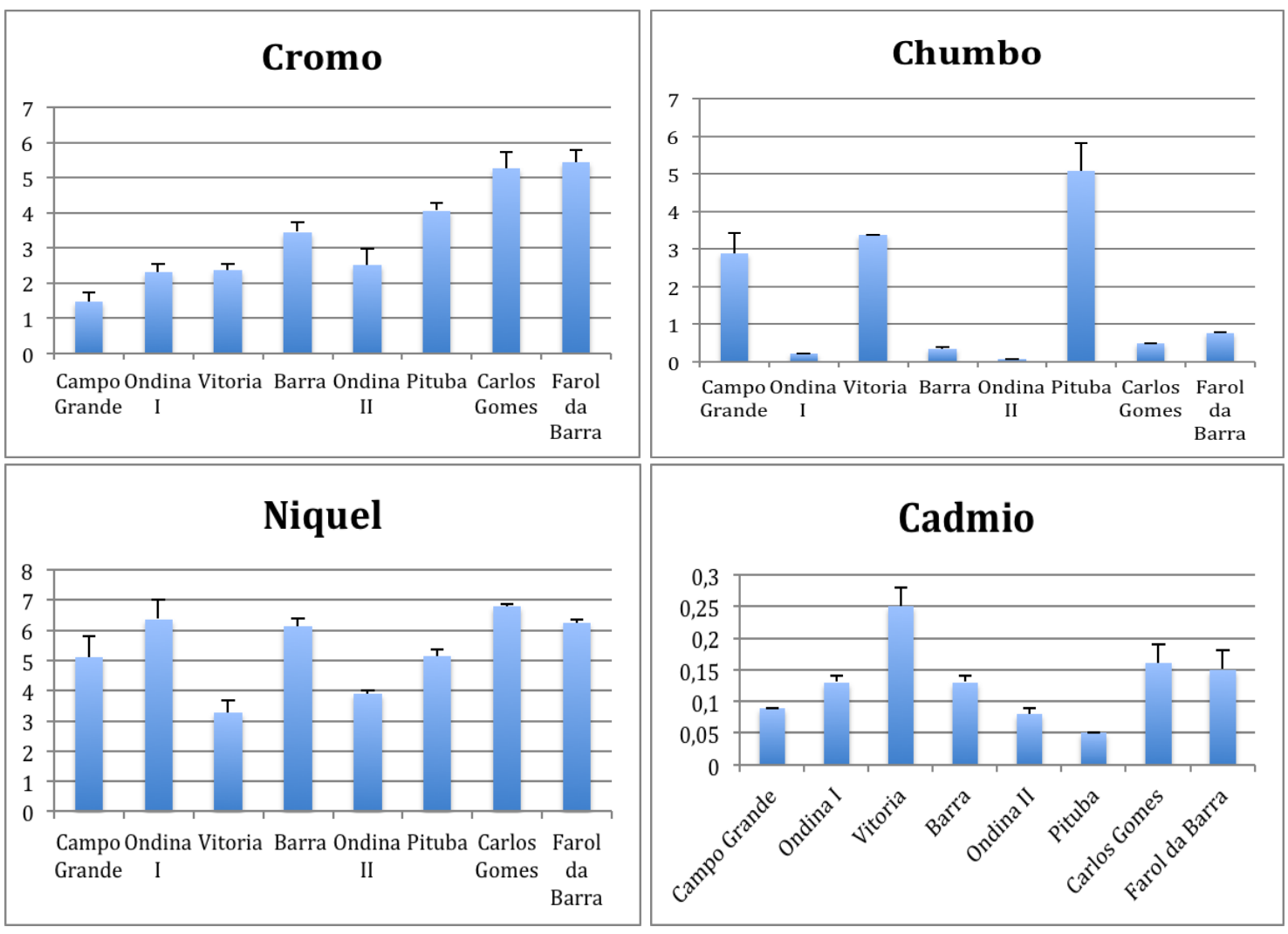

\subsection{Análise morfológica e elementar por microscopia eletrônica de varredura}

Através da microscopia eletrônica de varredura convencional foi possível observar as características morfológicas das partículas adsorvidas no biomonitor, conforme demonstrados nas Figuras 24 a 28 . Visto que o material analisado foi proveniente da atmosfera urbana, originadas de fontes emissoras diversificada, as partículas apresentaram variabilidade nas dimensões e na forma. Observou-se que as partículas variaram na sua forma e tamanho, de partículas esféricas a cubos cristalinos. Algumas são totalmente planas e em camadas, globulares e outras são fibrosas provenientes de poeira urbana. Apresentaram-se isoladas ou agregadas formando 
aglomerados, e em alguns casos aparentando partícula única. A superfície das partículas também apresentou diferentes texturas, algumas são lisas enquanto outras são muito irregulares e porosas.

As figuras mostram imagem com diferentes tipos de aumento mostrando características morfológicas das partículas sobre as escamas. Detalhe de algumas partículas com diferentes formatos, retangulares, arredondadas, cilíndricas e outras amorfas.

Detalhes morfológicos estão representados nas figuras abaixo:
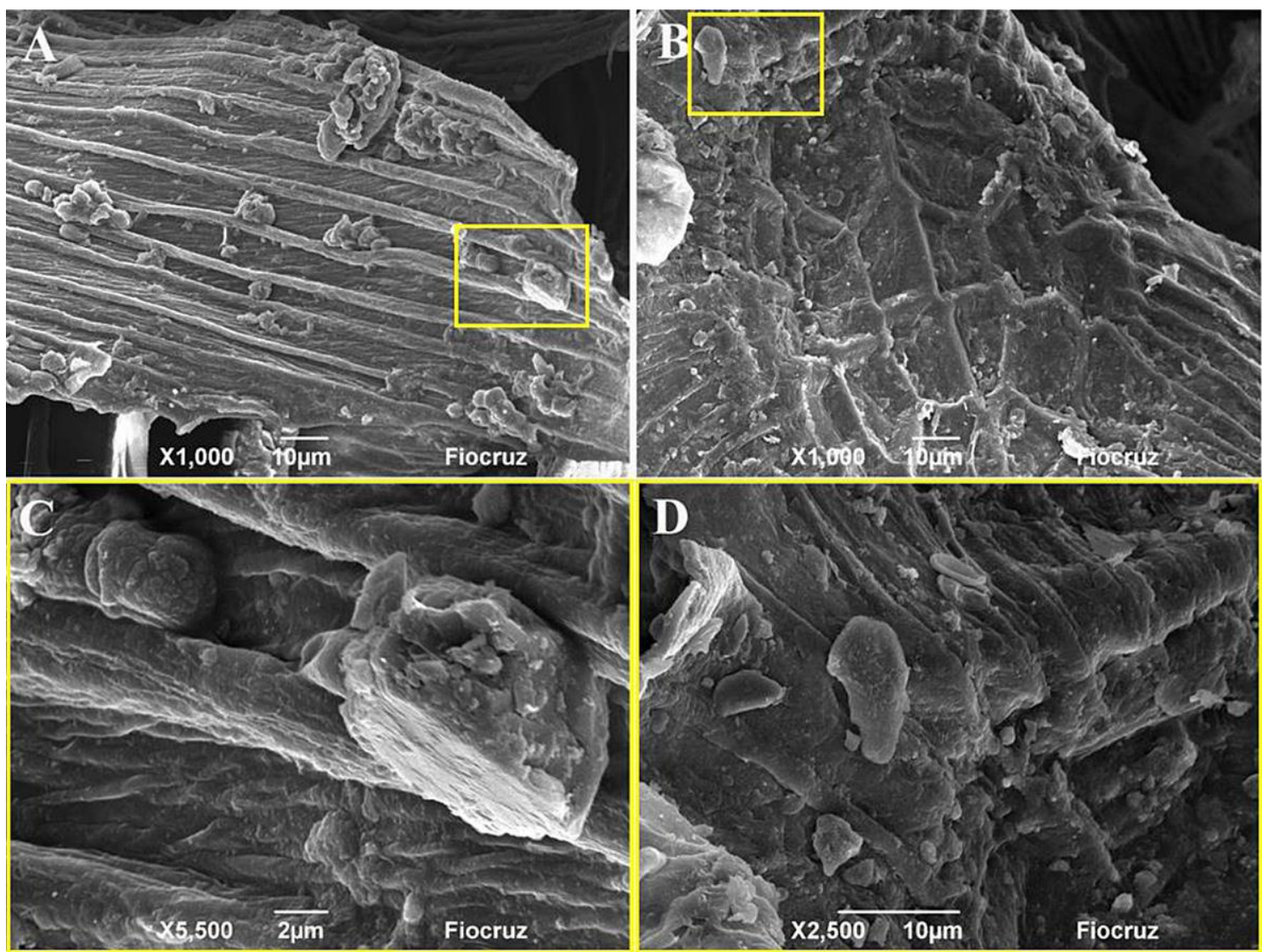

Figura 24 (A, B, C e D). MEV de Tillandsia usneoides que foram expostas no bairro Campo Grande por 45 dias, mostrando o material particulado adsorvido na superfície da planta 

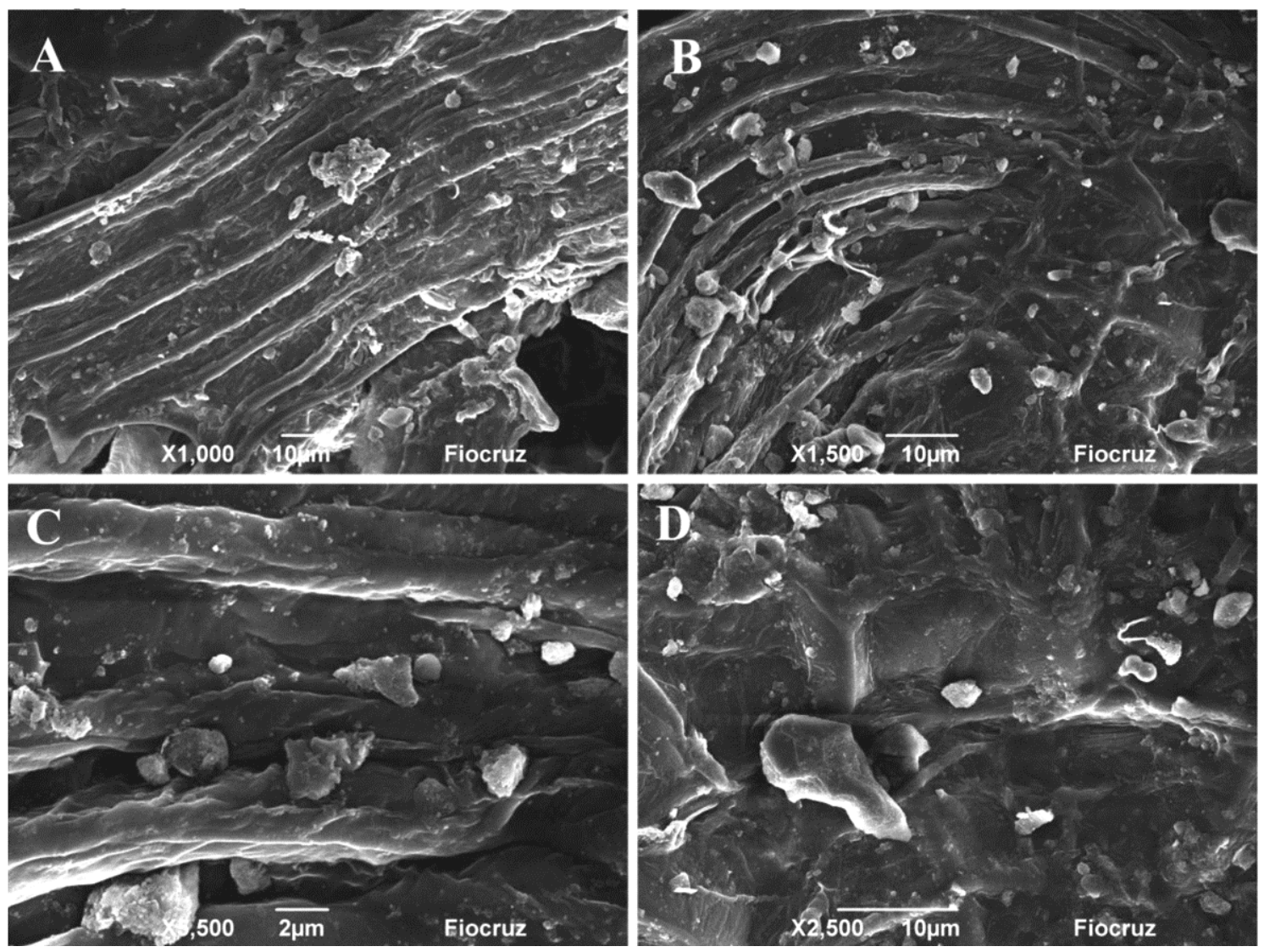

Figura 25 (A, B, C e D). MEV de Tillandsia usneoides que foram expostas no bairro Dique do Tororó por 45 dias, mostrando o material particulado adsorvido na superfície da planta. Fig. 2A: Imagem de baixo aumento mostrando diferentes partículas sobre as escamas. Fig. 2C: Partícula poligonal com partículas menores aderidas 

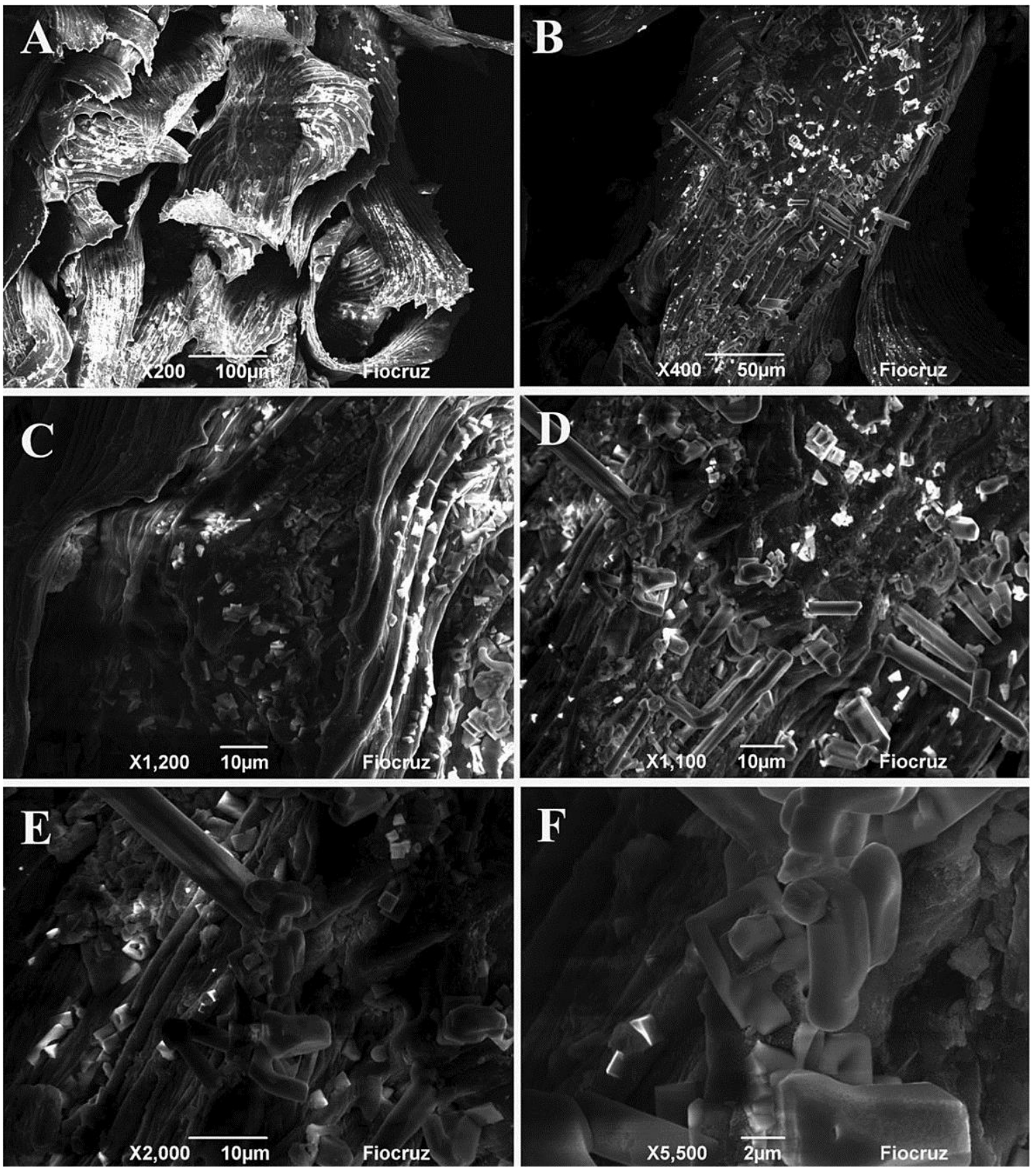

Figura 26 (A, B, C, D, E e F). MEV de Tillandsia usneoides que foram expostas no bairro Pituba por 45 dias no verão, mostrando o material particulado adsorvido na superfície da planta. A: Detalhe de um tricoma 

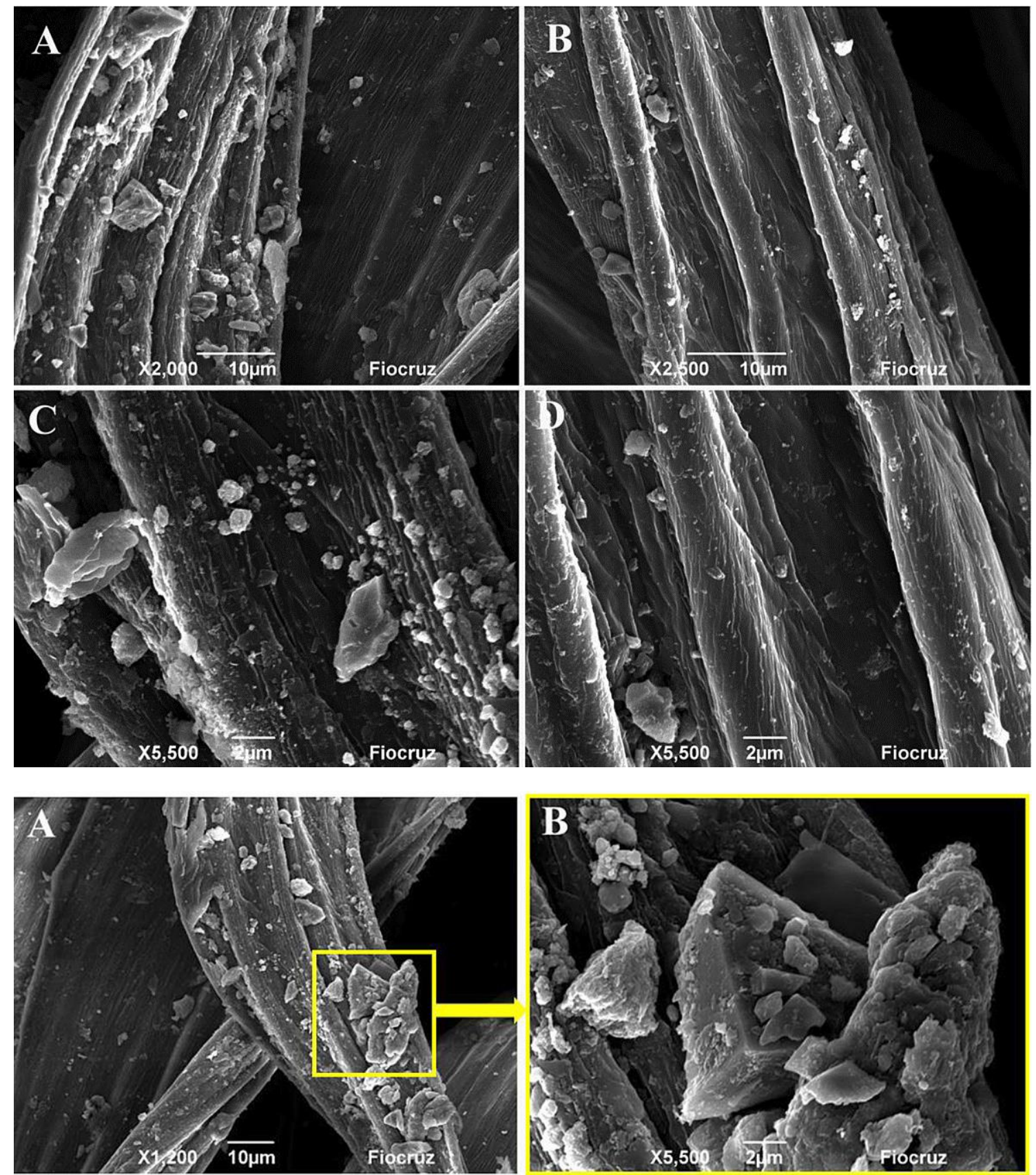

Figura 27 (A, B, C e D). MEV de Tillandsia usneoides que foram expostas no bairro Paralela por 45 dias no verão, mostrando o material particulado adsorvido na superfície da planta. A: Imagem pequeno aumento mostrando detalhe de aglomeração em partículas adsorvidas na superfície da planta. B: partícula apresentando superfície plana. C: Imagem apresentando detalhe de partículas menores que $5 \mu \mathrm{m}$ 

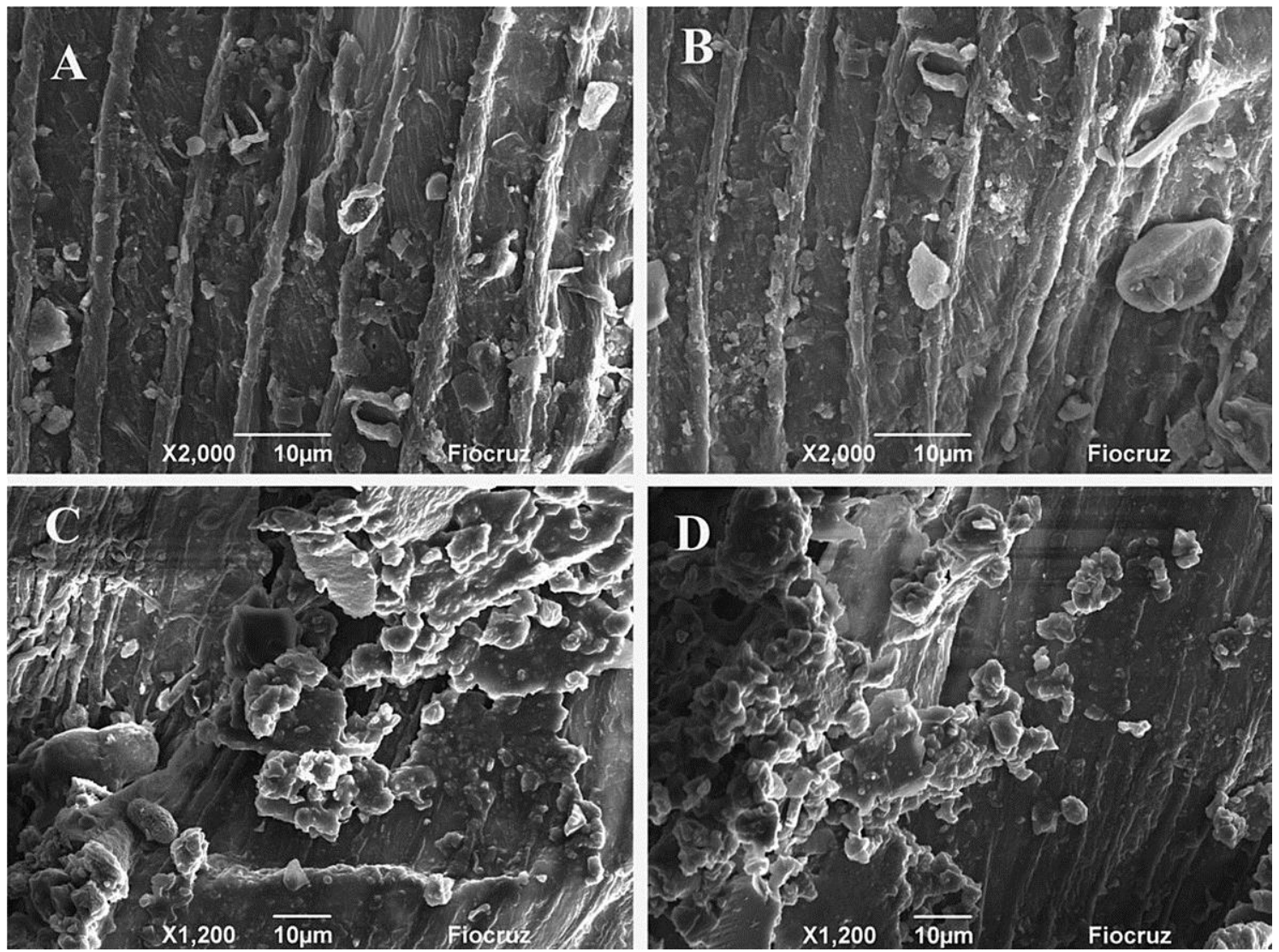

Figura 28 (A, B, C e D). MEV de Tillandsia usneoides que foram expostas no bairro Pirajá por 45 dias no verão, mostrando o material particulado adsorvido na superfície da planta

\subsection{Espectros de microscopia eletrônica de varredura com microanálise}

\section{de raios-x (EDS)}

Através da microscopia eletrônica de varredura com microanálise de raios-X foi realizada a análise elementar das partículas adsorvidas na superfície da planta. As partículas analisadas apresentaram na sua composição átomos de $\mathrm{C}, \mathrm{O}, \mathrm{Na}, \mathrm{Al}, \mathrm{Si}, \mathrm{Cl}, \mathrm{K}, \mathrm{Ca}$.

A Figura 29 representa um espectro de uma partícula destacando a presença de alguns dos metais estudados, tais como $\mathrm{Cu}, \mathrm{Cr}$ e $\mathrm{Mn}$. 


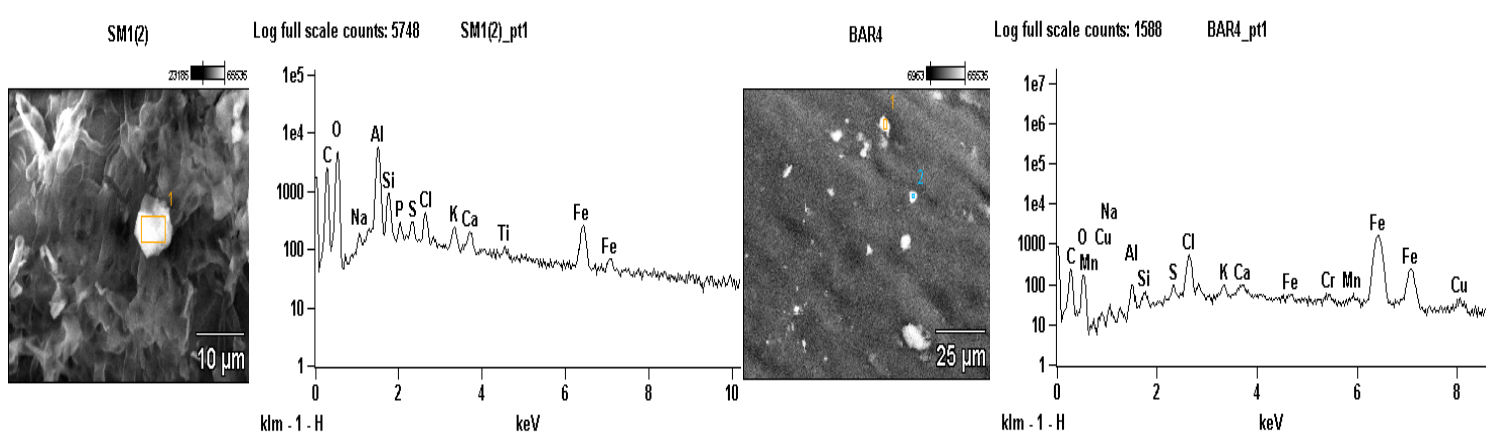

Figura 29. Espectro de caracterização elementar por microscopia eletrônica de varredura (microanálise de raios-X) da partícula adsorvida na superfície da planta

A distribuição das dimensões das partículas adsorvidas à superfície da planta foram distribuídas nas faixas de $0-2,5 ; 2,5-10 ; 10-50 ; 50-100 \mu$ m e está representada na Figura 30. Partículas na faixa de $2,5 \mu \mathrm{m}$ apresentaram percentuais acima de $60 \%$ no Campo Grande, Dique, Paralela e Pirajá. Todos os bairros apresentaram percentuais acima de $70 \%$ de partículas até $10 \mu \mathrm{m}$. Estes resultados demonstraram que o material particulado analisado da atmosfera urbana de Salvador, se encontrou predominantemente na faixa de partículas inaláveis.

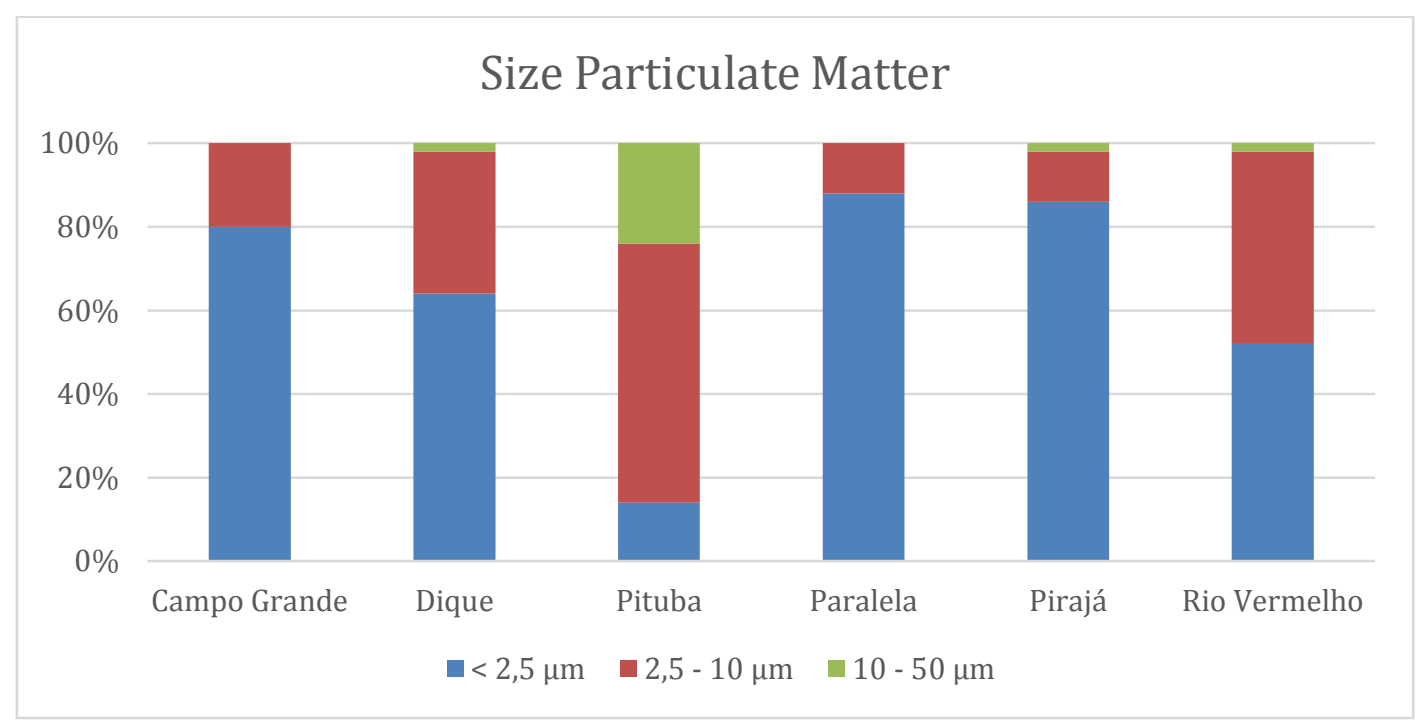

Figura 30. Distribuição das partículas por tamanho aerodinâmico retidas pelo biomonitor 


\subsection{RESULTADOS ARTIGO 2 - Análise de Risco: Estudo de Caso}

\subsubsection{Etapa 1 - Identificação do Perigo}

\section{Determinação de PM 2,5}

O Gráfico 4 apresenta resultados das mensurações realizadas pela técnica nefelométrica utilizando o equipamento portátil com leitura a laser nos locais do circuito carnavalesco: sem trio, trios novos, trios velhos(trajeto) e concentração de trios. Os locais analisados apresentaram diferentes concentrações de material particulado. Foram detectados níveis elevados de partículas com média de $600 \mu \mathrm{g} / \mathrm{m}^{3}$ na área de concentração dos trios, em ordem decrescente para o trajeto com médias de $200 \mu \mathrm{g} / \mathrm{m}^{3} \mathrm{e}$ $75 \mu \mathrm{g} / \mathrm{m}^{3}$ para trios novos e velhos respectivamente. Nos locais sem trio detectamos média de $30 \mu \mathrm{g} / \mathrm{m}^{3}$. Observamos que os trios velhos apresentaram níveis mais elevados de emissão de partículas quando comparados aos trios novos. Nos locais onde a circulação do ar estava comprometida, os picos de material particulado apresentaram níveis mais elevados $\left(750 \mu \mathrm{g} / \mathrm{m}^{3}\right)$. 
Tabela 2. Concentração de PM2.5 $\left(\mu \mathrm{g} / \mathbf{m}^{3}\right)$ por nefelometria nas áreas controle, trios novos, trios velhos e concentração de trios. Os valores estão expressos em medias e desvio padrão

\section{Área controle Trios Novos Trios velhos Concentração (sem trios) \\ de trio}

\begin{tabular}{lcccc}
\hline Média $\left(\mu \mathrm{g} / \mathrm{m}^{3}\right)$ & 19.1 & 52.4 & 210 & 580 \\
Desvio padrão & 2.5 & 9.4 & 69.1 & 134 \\
\hline
\end{tabular}

Gráfico 4. Concentração de material particulado (PM2,5) medidos pela nefelometria $\left(\mu \mathrm{g} / \mathrm{m}^{3}\right)$

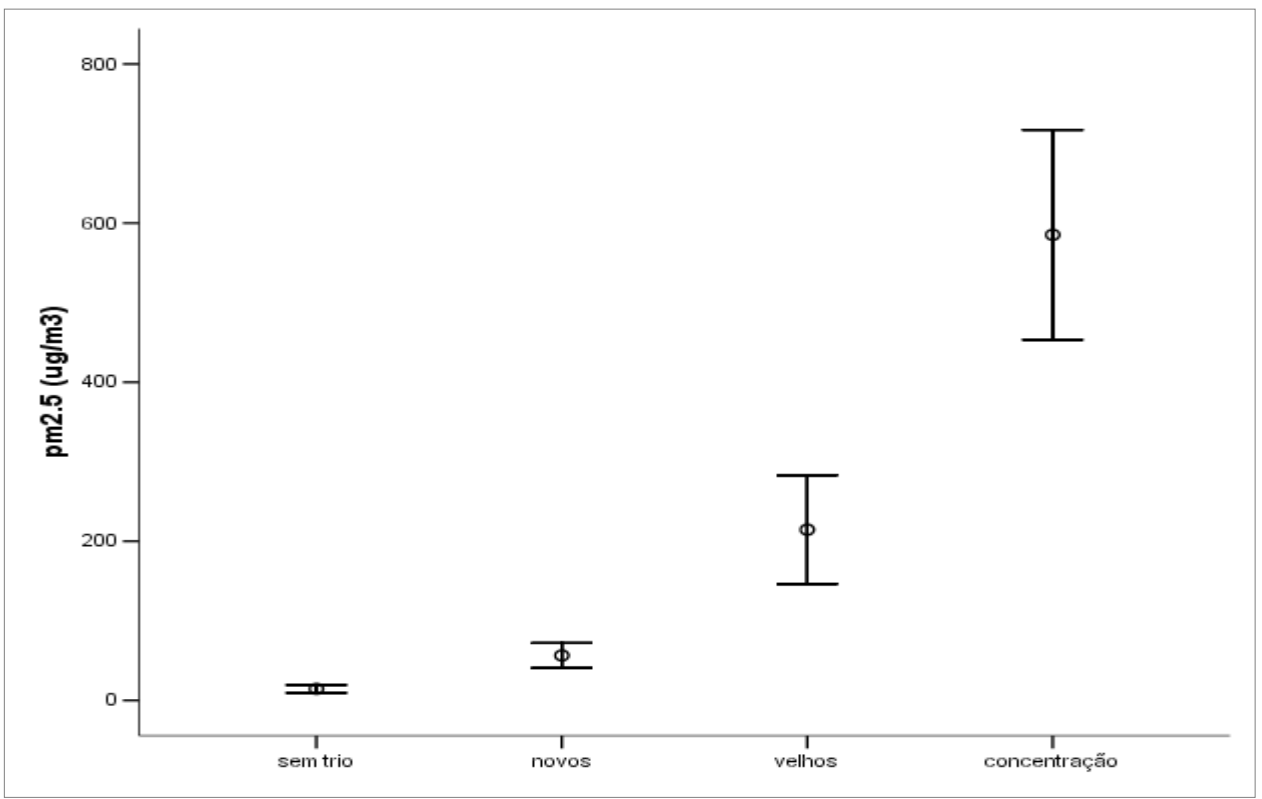


Tabela 3. Concentração de material particulado total medido pelo método gravimétrico $(\mu \mathrm{g})$

\begin{tabular}{lccc}
\hline & $\begin{array}{c}\text { Área controle } \\
\text { (sem trios) }\end{array}$ & Ruas do circuito & $\begin{array}{c}\text { Área de } \\
\text { concentração }\end{array}$ \\
\hline Média $(\mu \mathrm{g})$ & 15.5 & 20.9 & 35.6 \\
Desvio padrão & 2.3 & 4.6 & 6.7 \\
\hline
\end{tabular}

Gráfico 5. Concentração de poeira medida pelo método gravimétrico $(\mu \mathrm{g})$

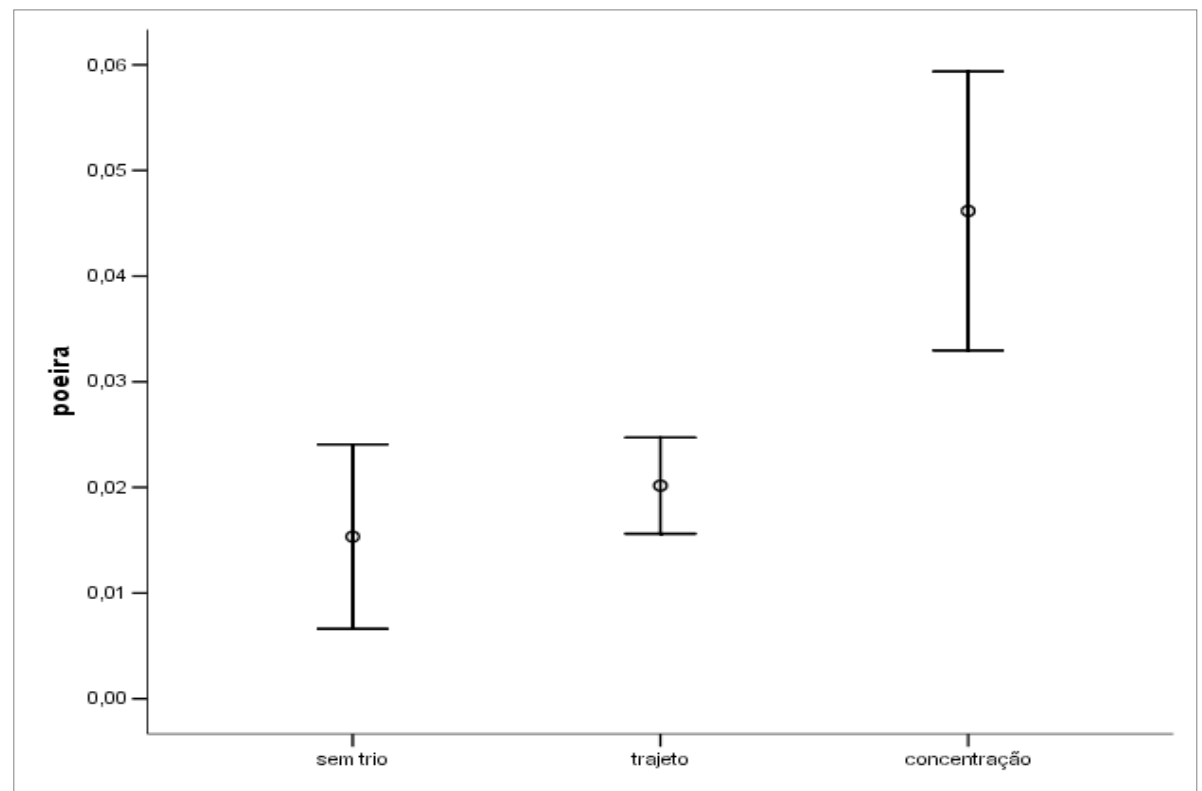

Os resultados utilizando técnicas gravimétricas e nefelométricas apresentaram resultados equivalentes de acúmulo de poeira detectáveis (Gráficos 4 e 5).

O Gráfico 6 apresenta resultados das mensurações realizadas em ambiente interno (camarotes) no circuito do carnaval. As concentrações de PM2.5 dentro dos camarotes foram registradas pelo nefelômetro, apresentando medias de 400,28 $\mu \mathrm{g} / \mathrm{m}^{3}$ durante a passagem do trio em ambiente aberto, $1265 \mu \mathrm{g} / \mathrm{m}^{3}$ em ambientes fechados e 
$53.03 \mu \mathrm{g} / \mathrm{m} 3$ nas varandas dos camarotes. Picos de até $1600 \mu \mathrm{g} / \mathrm{m}^{3}$ foram detectados em ambiente fechado e climatizado.

Tabela 4. Concentrações de material particulado medidos pela nefelometria em áreas de camarotes no circuito do carnaval (Sacadas, Camarotes com ventilação natural, Camarotes climatizados)

\begin{tabular}{lccc}
\hline & $\begin{array}{c}\text { Sacada próximas a } \\
\text { passage dos trios }\end{array}$ & $\begin{array}{c}\text { Áreas abertas } \\
\text { (ventilação natural) }\end{array}$ & $\begin{array}{c}\text { Áreas fechados } \\
\text { (climatizados) }\end{array}$ \\
\hline Médias $\left(\mu \mathrm{g} / \mathrm{m}^{3}\right)$ & 53.7 & 390 & 1,265 \\
Desvio padrão & 15.4 & 180 & 650 \\
\hline
\end{tabular}

Gráfico 6. Concentração de material particulado (PM2.5) medido pela nefelometria em camarotes (sacadas, ambientes climatizados e ambientes com ventilação natural) no circuito do carnaval

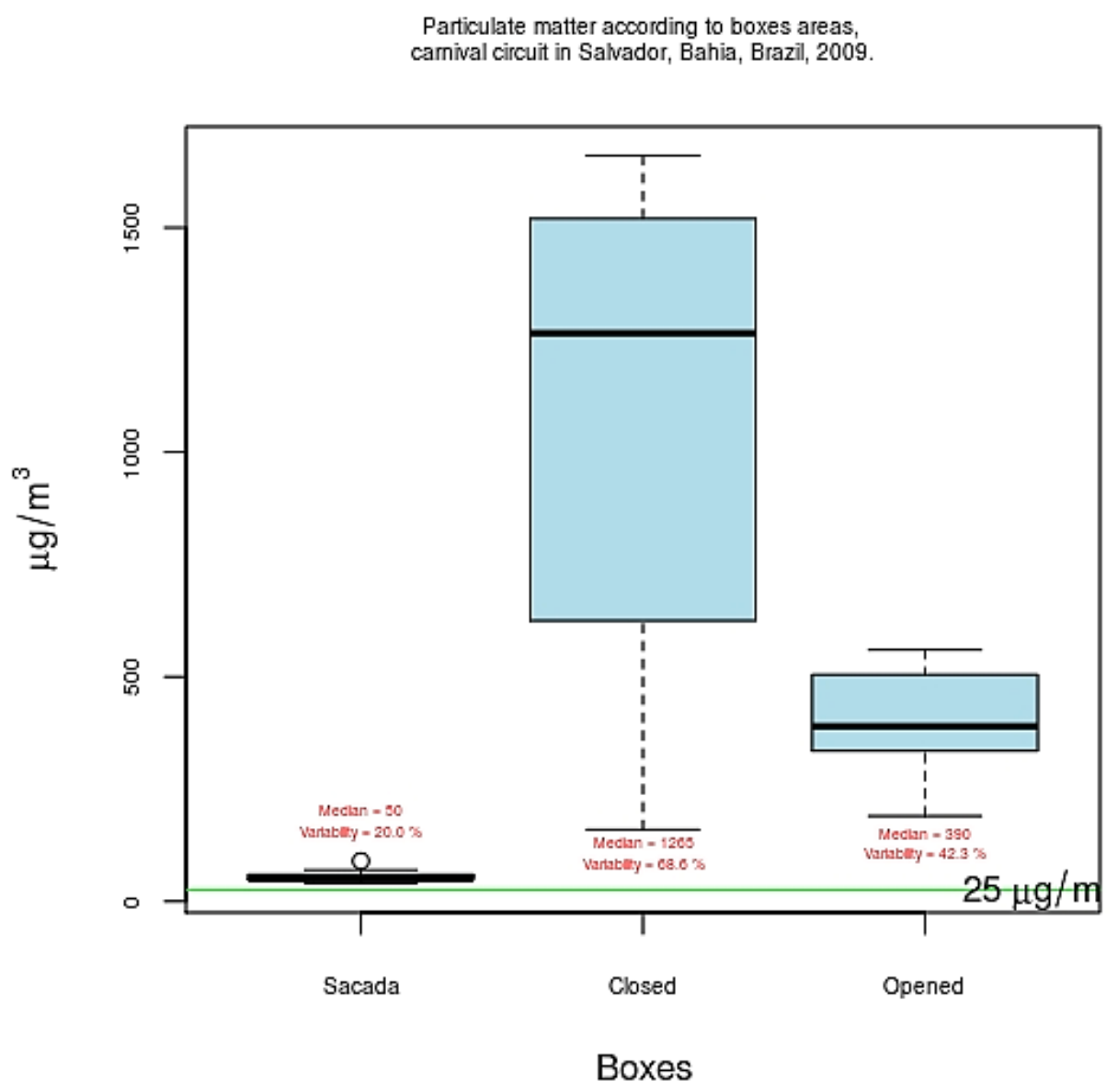




\subsubsection{Etapa 2: Avaliação de exposição à saúde humana}

As concentrações de $\mathrm{NO}_{2}$ variaram de $30,5 \mu \mathrm{g} / \mathrm{m}^{3}$ a $79,7 \mu \mathrm{g} / \mathrm{m}^{3}$. O tempo de exposição avaliado variou entre 3 e 6 dias, e o número de horas trabalhadas por dia variou de 5 a $24 \mathrm{~h}$. Os sintomas mais frequentes de desconforto ocular foram ardor (64\%), irritação (54\%) e olhos vermelhos (46\%). Obtiveram-se resultados significativos associando o número de pontos PAS positivos (muco) na citologia tarsal com as concentrações médias de $\mathrm{NO}_{2}\left(\mathrm{p}<0,05, \mathrm{R}^{2}=0,33\right)$.

Tabela 5. Concentrações de $\mathrm{NO}_{2}$ obtido pelo método de tubo passivo $\left(\mu \mathrm{g} / \mathrm{m}^{3}\right)$

\begin{tabular}{lccccccccc}
\hline Locais & $\begin{array}{c}\text { Casa } \\
\text { Itália }\end{array}$ & Vitória & Canela & Piedade & $\begin{array}{c}\text { Praça } \\
\text { Municipal }\end{array}$ & $\begin{array}{c}\text { Farol da } \\
\text { Barra }\end{array}$ & $\begin{array}{c}\text { Castro } \\
\text { Alves }\end{array}$ & $\begin{array}{c}\text { Ondina } \\
\text { Espanhol }\end{array}$ & $\begin{array}{c}\text { Ondina } \\
\text { Apart }\end{array}$ \\
\hline Mean NO & 70.94 & $74.83^{* *}$ & 65.86 & 47.60 & $34.63^{*}$ & 43.04 & 40.66 & 57.24 & 36.26 \\
\hline & & & & & & & & & \\
Range & $76,87-$ & $69.92-$ & $60.45-$ & $47.25-$ & $30.45-$ & $40.5-$ & $39.14-$ & $53.01-$ & $33.72-$ \\
& 79.72 & 71.26 & 47.94 & 38.79 & 45.71 & 42.18 & 61.47 & 38.79 \\
\hline
\end{tabular}

* Controle (ruas sem trios). **Area de concentração de trios

\subsubsection{Etapa 3 - Etapa de comunicação de riscos}

A tabela 6 apresenta a divulgação em mídia onde o tema foi apresentado à comunidade através de matérias veiculadas em imprensa escrita, bem como publicações institucionais. Este indicador representa a fluidez da informação científica sendo apresentada à comunidade e setores interessados na abordagem de análise de riscos. 
Tabela 6. Lista de matérias publicadas em mídias

\begin{tabular}{l|l}
\hline Título & Tipo de mídia \\
\hline Monitoramento do Ar no Carnaval & Bahia Viva, Salvador, p. 22 - 23, 05 abr. 2008. \\
\hline $\begin{array}{l}\text { Poluição do ar excede limites no carnaval. } \\
\text { Pesquisa monitora poluição do ar }\end{array}$ & A Tarde, Salvador, 15 fev. 2008. \\
\hline $\begin{array}{l}\text { Salvador é uma das campeãs em doenças respiratórias. } \\
\text { Ar fica mais poluído no carnaval }\end{array}$ & Correio da Bahia, Salvador, p. 3, 31 jan. 2008. \\
\hline $\begin{array}{l}\text { Descarbonizando o carnaval da Bahia } \\
\text { Saúde monitora emissão de poluentes por trios elétricos } \\
\text { durante carnaval }\end{array}$ & A TARDia, Salvador, p. 4, 15 set. 2007 \\
\hline $\begin{array}{l}\text { Bromélias vão indicar se carnaval tem poluição do Município, Salvador, } 17 \text { fev. } 2007 . \\
\text { Qualidade do ar será monitorada } 11 \text { maio } 2007\end{array}$ \\
\hline $\begin{array}{l}\text { Bioquímica vai monitorar qualidade do ar no carnaval de } \\
\text { Salvador }\end{array}$ & Folha de São Paulo, São Paulo, 18 fev. 2007. \\
\hline $\begin{array}{l}\text { Folia Baiana levanta poeira e aguça a atenção de } \\
\text { especialistas }\end{array}$ & A TARDE, Salvador, p. 5 - 5, 14 fev. 2007. \\
\hline & Correio da Bahia, Salvador, 14 fev. 2007 \\
\hline
\end{tabular}

\subsubsection{Resultados em tomada de decisão local}

A evidencia científica utilizada como suporte para a tomada de decisão foi demonstrada através da publicação do Decreto Municipal nº 20.505 - Estatuto das Festas Populares, pela Prefeitura Municipal de Salvador, em 28 de dezembro de 2009 (em anexo). Neste regulamento foi incluído o monitoramento da qualidade do ar durante o período de carnaval, de festas populares e de outros eventos que porventura necessitem do licenciamento e que estejam incluídos no calendário oficial ou privados em Salvador.

Ações de ciência e políticas públicas ocorreram durante o processo de análise de risco da poluição do ar em Salvador. Na tabela 7 está listado um paralelo destas ações entre os anos de 2005 e 2014. 
Tabela 7. Ciência e Política Pública sobre Qualidade do Ar em Salvador, BA, resultantes da Ação Intersetorial

\begin{tabular}{|c|c|c|}
\hline Data & Ciência & Política Pública \\
\hline 2005 & Inicio do Estudo Biomonitoramento usando Tillandsia usneoides & \\
\hline 2006 & I Workshop de Poluição Atmosférica e Saúde Humana & $\begin{array}{l}\text { Diálogo Intersetorial para implantação da Rede } \\
\text { de Monitoramento da Qualidade do Ar }\end{array}$ \\
\hline \multirow[t]{2}{*}{2007} & Estudo de caso no Carnaval - Fase 1-Caracterização do Risco & \\
\hline & $\begin{array}{l}\text { Conclusão do estudo Biomonitoramento usando Tillandsia } \\
\text { usneoides - Fase } 1\end{array}$ & \\
\hline 2008 & Estudo de caso no Carnaval - Fase 2 - Dose resposta & Campanha carnaval Sustentável \\
\hline \multirow[t]{2}{*}{2009} & Estudo de caso Carnaval - Fase 3 - Comunicação de Riscos & Utilização de Biodiesel pelos trios \\
\hline & & Publicação Decreto Municipal \\
\hline \multirow[t]{2}{*}{2010} & Biomonitoramento - Fase 2 & $\begin{array}{l}\text { Inicio de Instalação da Rede de Monitoramento } \\
\text { da Qualidade do Ar em Salvador }\end{array}$ \\
\hline & $\begin{array}{l}\text { Elaboração do Projeto NIQA - Núcleo Intersetorial para a } \\
\text { Qualidade do Ar - Copa }\end{array}$ & \\
\hline 2011 & II Workshop de Poluição Atmosférica e Saúde Humana & $\begin{array}{l}\text { Implementação do NIQA- Núcleo Intersetorial } \\
\text { para a Qualidade do Ar - Copa } 2014 \text { - } \\
\text { Protocolo para Rede de Pesquisa }\end{array}$ \\
\hline \multirow[t]{2}{*}{2012} & Curso Comunicação de Riscos & \\
\hline & $\begin{array}{l}\text { Estudo com PRONEX Asma } \\
\text {-Poluição do Ar e Asma Grave em Salvador: Um estudo caso } \\
\text { controle }\end{array}$ & \\
\hline 2012 & Biomonitoramento em Estações da Rede Automática de Salvador & $\begin{array}{l}\text { Elaboração do Plano de Comunicação de } \\
\text { Riscos sobre Qualidade do Ar para o Carnaval } \\
\text { de Salvador }\end{array}$ \\
\hline 2013 & $\begin{array}{l}\text { Poluição do ar, Densidade do Tráfego e áreas destinadas à } \\
\text { atividade física em Salvador: Abordagem utilizando SIG }\end{array}$ & Elaboração de Campanha Carona Solidária \\
\hline \multirow[t]{2}{*}{2014} & $\begin{array}{l}\text { Poluição do Ar e Doenças Cardiovasculares em Salvador, BA: uma } \\
\text { Análise de Serie Temporal. }\end{array}$ & $\begin{array}{l}\text {-Campanha Eu Promovo o Carnaval } \\
\text { Sustentável }\end{array}$ \\
\hline & & $\begin{array}{l}\text {-Aquisição de dois nefelômetros, } \\
\text { (equipamentos portáteis para medição de } \\
\text { material particulado) pela Vigilância em Saúde } \\
\text { Ambiental de Salvador-VIGIAR }\end{array}$ \\
\hline
\end{tabular}




\section{DISCUSSÃO}

\subsection{Estudo biomonitoramento}

O monitoramento da qualidade do ar é obrigatório em todo o mundo e têm sido feito através de diversas técnicas, sejam instrumentais ou utilizando biomonitores, considerando a disponibilidade de infra-estrutura de cada região. Países desenvolvidos, onde já existem estações de monitoramento automatizadas para o controle da qualidade do ar, têm utilizado o biomonitoramento para acompanhar a dispersão de poluentes na atmosfera, e em outras circunstâncias para observar o acúmulo destes poluentes em organismos vivos ${ }^{(111)(112)}$. Em países em desenvolvimento são escassas as estações de monitoramento mecânico. No Brasil, capitais como São Paulo e Rio de Janeiro embora já apresentem um sistema de monitoramento automatizado, também tem utilizado biomonitores como modelo de estudo para quantificação de metais adsorvidos nas

partículas atmosféricas (11)(113)(114)(115)(116). O monitoramento contínuo realizado pelo nosso estudo tem demonstrado a relevância do acompanhamento desses contaminantes na atmosfera de Salvador.

A detecção de metais no material particulado permite traçar o perfil de possíveis fontes emissoras bem como acompanhar o nível de emissão ao longo do tempo. Os nossos resultados são indicativos de contaminação e acúmulo destes elementos na atmosfera e que estes podem estar disponíveis para inalação já que os biomonitores foram instalados em altura compatível com o ar inalável por um indivíduo. 
Conhecida popularmente como "falsa barba de velho" ou "barba de bode", a Tillandsia usneoides foi o modelo de biomonitor utilizado para acessar metais no material particulado presente na atmosfera urbana de Salvador também por ser um método eficaz, de baixo custo, bem como por permitir a avaliação em diversos locais concomitantemente, sendo os resultados comparáveis ${ }^{(113)}$. Revelou ser um modelo acessível às localidades que ainda necessitam de algum dado ambiental para implementar ações de Vigilância, portanto uma ferramenta alternativa ao método mecânico na primeira etapa do processo de análise de riscos, indicando a existência do perigo.

A quantificação de metais no material particulado retido pelo biomonitor foi analisada por espectrofotomotria de absorção atômica de chama, técnica utilizada amplamente em laboratórios de análises e de pesquisas para quantificação de diversos átomos. O biomonitoramento requer um trabalho a longo prazo, já que fatores meteorológicos influenciam fortemente sobre a dispersão do material particulado. Nossos resultados obtidos em duas campanhas mostraram que as concentrações de metais sofreram variações espaciais e temporais, apresentando heterogeneidade nos locais monitorados. Os resultados de Salvador quando comparados com área controle (áreas não urbanizadas ou com baixa intensidade de tráfego), as diferenças foram claras, apontando que Salvador possui disponibilidade de metais na atmosfera. Na amostragem realizada durante o carnaval houve diferença observada quando comparadas área controle (sem trios) e área de concentração de trios. Isto reforça a utilização da técnica para detecção de elementos traços em áreas com intenso fluxo de veículos.

Até o momento não existem valores referenciais para estes metais na atmosfera ${ }^{(92)}$, exceto para o $\mathrm{Pb}$. Os nossos resultados revelando a presença de metais não são comparáveis aos padrões da qualidade do ar da legislação vigente visto que os 
resultados são expressos em massa, enquanto que os padrões adotam medidas em volume cúbico de ar. Observou-se que elementos como $\mathrm{Pb}$ ainda encontra-se espalhado pela cidade de Salvador. Gasolina aditivada com este elemento (chumbo tetraetila) não é mais utilizada no Brasil desde 1992, entretanto ainda são usados em combustíveis de aviões e helicópteros, bem como na fabricação de pneus e asfalto.

A mensuração de partículas em volume de ar $\left(\mu \mathrm{g} / \mathrm{m}^{3}\right)$ considerando o seu tamanho aerodinâmico em suspensão no ar, é geralmente realizada através de equipamentos mecânicos. Entretanto no presente estudo com a técnica de biomonitoramento e análise morfológica das partículas utilizando a microscopia eletrônica de varredura, foi possível estimar o tamanho de partículas predominantes na atmosfera urbana de Salvador. A partir da medida de partículas aderidas à superfície da planta observou-se que o material particulado das amostras analisadas apresentou $60 \%$ de partículas na faixa de 2,5 e $10 \mu \mathrm{m}$, e desta forma pôde-se estimar, que o material particulado da atmosfera urbana de Salvador está na faixa de partículas respiráveis.

$\mathrm{O} \mathrm{Pb}$ apresentou concentrações mais elevadas na Pituba em amostragem realizada no verão. Um estudo de determinação de metais em material particulado de $2,5 \mu \mathrm{m}$ realizado em Atenas, demonstrou que alguns elementos apresentam concentrações mais altas em determinada estação do ano. No referido estudo, os elementos $\mathrm{Pb}$ e $\mathrm{Ni}$ apresentaram concentrações mais elevadas na estação mais quente, sendo que o $\mathrm{Pb}$, dentre os cinco elementos estudados, foi o que apresentou um percentual maior (64\%) do $\mathrm{PM}_{2,5}$ na estação quente ${ }^{(117)}$.

Conhecer a composição química das partículas permite uma melhor investigação epidemiológica para se avaliar a real exposição ambiental e os efeitos à saúde humana. Bell e colaboradores realizou um estudo onde caracterizou a variação temporal e 
espacial na composição química do material particulado (PM 2,5) nos Estados Unidos com o objetivo de identificar os componentes para avaliação em estudos epidemiológicos futuros ${ }^{(48)}$. Os resultados apontaram para a complexidade da mistura de componentes do MP e a sua variabilidade por estação e região. Sabe-se que muitos estudos epidemiológicos têm demonstrado os efeitos do MP sobre mortalidade ${ }^{(23)}$ e sobre admissões hospitalares ${ }^{(30)}{ }^{(46)}{ }^{(118)}$. As diferenças regionais podem refletir variações na composição do MP e suas fontes de origem.

A contaminação por metais apresentou variação de acordo com o local da amostragem, entretanto os metais $\mathrm{Fe}, \mathrm{Mn}$ e $\mathrm{Zn}$ são encontrados em níveis mais elevados. No circuito do carnaval os locais que apresentaram níveis mais elevados foram Vitória, Carlos Gomes e Barra, onde havia concentração de trios. Tais resultados demonstraram a variabilidade da distribuição destes elementos no material particulado, que podem ser influenciados tanto pelas fontes emissoras, direção dos ventos, topografia e condições meteorológicas ${ }^{(119)}$.

Os metais avaliados apresentaram concentrações médias no material particulado em ordem decrescente $\mathrm{Fe}>\mathrm{Mn}>\mathrm{Zn}>\mathrm{Ni}>\mathrm{Pb}>\mathrm{Cr}>\mathrm{Cu}>\mathrm{Cd}$. O $\mathrm{Cd}$ apresentou o nível mais elevado no bairro da Barra e o $\mathrm{Pb}$ na Pituba. Resultados de estudo anterior do nosso grupo ${ }^{(11)}$ sinaliza a presença de concentrações elevadas destes metais nos mesmos locais.

Sabe-se que mesmo em baixas concentrações alguns metais podem apresentar maiores riscos à saúde humana devido ao potencial de acúmulo, a exemplo de $\mathrm{Pb}$ e $\mathrm{Cd}$. Mesmo os metais essenciais ao metabolismo humano como Fe e $\mathrm{Zn}$, quando em altas concentrações podem causar estresse oxidativo gerando radicais livres e consequentemente interferir em metabolismos celulares ${ }^{(120)}$ (Donaldson et al., 1997). 
Através da análise morfológica por microscopia eletrônica foi possível observar as características das partículas adsorvidas no biomonitor. Embora a composição química das partículas seja similar, a sua morfologia pode ser muito diferente, apresentando partículas mais irregulares ou mais esféricas. A informação obtida em relação à morfologia da partícula é importante para identificação das fontes emissoras, de abrasão mecânica ou combustão. A identificação da distribuição interna dos elementos pode ajudar a distinguir partículas originadas por diversas fontes, coletandoas, analisando-as e comparando com aquelas coletadas na atmosfera ${ }^{(54)}$.

O método de microanálise de Raios-X (EDS) permitiu analisar a composição elementar do material particulado ao estudar partículas de diâmetros menores que $10 \mu \mathrm{m}$, que são inaláveis e oferecem maior risco à saúde. A presença de metais no particulado fino merece uma atenção especial devido a possibilidade de maior penetração no organismo e elevado grau de toxicidade. Alguns elementos como $\mathrm{Cd}$ e As tem sido classificados como potencialmente carcinogênicos e suas concentrações no particulado fino são importantes para avaliação de risco. Muitos compostos de metais apresentam-se como óxidos, mais prevalentes em frações grossas. Silicatos se apresentam em abundância proveniente do solo. Estudo de análise elementar demonstrou diferentes tipos de particulados: Partículas ricas em Carbono; carbonato de $\mathrm{Ca}$ e $\mathrm{Mg}$; sulfatos de $\mathrm{Ca}$; sílica; silicatos e partículas ricas em $\mathrm{Fe}^{(121)}$. Buscamos através destas análises, estudar partículas de menor diâmetro e identificar a presença de metais. Nas amostras neste trabalho foram evidenciadas contaminação por $\mathrm{Cu}, \mathrm{Cr}, \mathrm{Zn} \mathrm{Cd}, \mathrm{Mn}, \mathrm{Ti}$ e $\mathrm{Fe}$. Um estudo de análise elementar demonstrou que elementos como $\mathrm{Cu}, \mathrm{Cr}$ e $\mathrm{Zn}$ são encontrados predominantemente em partículas $<21 \mu \mathrm{m}{ }^{(122)}$. Em outro estudo de distribuição de material particulado e sua associação com metais pesados em rodovias, 
ficou clara a relação entre o tamanho da partícula e a concentração de determinados metais. $\mathrm{Pb}, \mathrm{Cd}, \mathrm{Ni}, \mathrm{Cu}$ e $\mathrm{Mn}$ se apresentaram em partículas finas, intermediárias e grossa e o Fe foi principalmente encontrado em partículas grossas ${ }^{(123)}$.

O biomonitor foi transplantado para locais, cuja altura, as pessoas circulam e respiram. As partículas que foram retidas pela planta poderiam ter sido aspiradas pelas pessoas, já que foi demonstrado que se encontraram predominantemente na faixa dos inaláveis. Análise das concentrações e distribuição de metais no material particulado atmosférico urbano utilizando métodos instrumentais para coleta apontam para a predominância de partículas $>2,1 \mu \mathrm{m}$ na proporção de $55-64 \%$, próximo às rodovias, ${ }^{(122)}$ o que comprova a emissão de partículas finas geradas pelo tráfego de veículos.

$\mathrm{O}$ setor de transportes é o maior responsável pela geração de $\mathrm{PM}_{2,5}$, devido à exaustão veicular que emite partículas muito pequenas. Estas partículas colidem, agregam e aglomeram constituindo predominantemente a fração fina do material particulado ${ }^{(124)}$. Partículas maiores estão relacionadas com a poeira proveniente do intenso tráfego nas rodovias. Os nossos resultados apontam para a predominância de particulado fino possivelmente originado do intenso tráfego de veículos, visto que os locais monitorados foram das principais vias de trânsito da cidade e de um evento com presença intensa de caminhões e de outros geradores de energia movidos a diesel.

Existe um interesse cada vez maior em caracterizar as dimensões e formas das partículas que causam efeitos adversos ao sistema respiratório. Entretanto são ainda insuficientes estudos que relacionam a toxicidade da partícula aos eventos adversos de saúde. Conhecer a composição do material particulado que pode conter metais, compostos orgânicos, componentes biológicos, sulfatos, nitratos, acidez e presença de gases adsorvidos tais como ozônio é fundamental para o entendimento da sua toxicidade ${ }^{(125)}$. 
Alguns estudos têm associado diferentes elementos presentes no MP com mortalidade incluindo Fe, Ni e Zn ${ }^{(126)}$ nitrato de amônio, monóxido de carbono, carbono elementar e nitratos ${ }^{(127)}$.

Em Salvador não existem investigações epidemiológicas locais que relacionem a prevalência de alergias respiratórias com a poluição atmosférica, embora estudo de asma tenha revelado uma prevalência desta morbidade em $27,1 \%{ }^{(128)}$. Recursos financeiros de grande porte são alocados para controle desta doença ${ }^{(129)}$, desta forma a investigação de fatores de risco ambientais poderia ser útil para a adoção de medidas preventivas, contribuindo também para a otimização destes recursos. A carência destes estudos se deve principalmente à falta de informações ambientais, visto que, a cidade de Salvador até então, não oferecia nenhum tipo de monitoramento para avaliar a qualidade do ar.

\subsection{Estudo de caso em análise de riscos}

De acordo com a abordagem em análise de riscos proposta pela U.S. EPA ${ }^{(3)}$, o desenvolvimento de algumas etapas são essenciais para a abordagem: caracterização de risco, avaliação de risco, gerenciamento de risco e comunicação de risco, são essências para condução deste processo. O presente estudo corrobora com o desenvolvimento destas etapas no estudo de caso do evento de massa em Salvador.

A escolha deste cenário para a abordagem em análise de riscos consiste em critérios que definem um evento de massa como sendo um contexto que pelas atividades coletivas movimentem e/ou atraiam um elevado contingente de pessoas vindas de todas as partes do país e do mundo. O carnaval em Salvador, considerado o maior evento de 
massa do mundo, utiliza trios elétricos, que comandam o desfile, por onde seguem aproximadamente 2 milhões de pessoas e cerca de 170 mil trabalhadores ao longo de um circuito de $11 \mathrm{~km}{ }^{(130)}$. Estes trios elétricos utilizam óleo diesel como matriz energética. Durante 7 dias, os foliões e trabalhadores são expostos ao material particulado e gases tóxicos por até mais de 12 horas por dia. Os poluentes emitidos pela combustão do diesel pode ser um importante fator de risco também para o surgimento de doenças respiratórias e oftalmológicas, manifestações clínicas comuns no período pós carnaval. Além do desfile de trios a festa também possui estruturas de camarotes no entorno do circuito carnavalesco. Alguns destes camarotes recebem diariamente cinco mil pessoas por dia em área de dois mil e quinhentos metros quadrados. Segundo relatório da Emtursa, órgão oficial responsável pela organização do evento, a média em toda extensão da festa é de 4 pessoas por metro quadrado. Esses camarotes em sua grande parte possui áreas fechadas com sistema de ar condicionado, outras áreas com ventilação natural, além de áreas abertas bem próximas ao desfile dos trios na desfile.

Os níveis de material particulado gerado pelos trios elétricos, demonstrados na primeira fase do estudo, apresentaram níveis acima dos padrões da Organização Mundial de Saúde que preconizava médias diárias de $20 \mu \mathrm{g} / \mathrm{m}^{3}{ }^{(1)}$. Os resultados desta fase identifica a presença do perigo (contaminação) no circuito do carnaval, o que determina a necessidade de realização das etapas subsequentes para o gerenciamento de risco da população exposta.

Foi possível verificar que as técnicas para a mensuração dos poluentes, gravimetria e nefelometria utilizadas apresentaram resultados comparáveis quando observados locais "sem trio" e "concentração de trios". De acordo com a Organização Mundial de Saúde a utilização de métodos alternativos para detecção de poluentes 
devem ser estimulados em localidades onde os recursos são escassos. Os nossos resultados contribuem para a sugestão de viabilidade da técnica gravimétrica, visto que o gradiente de concentração da poeira acumulada durante o período estudado foi compatível com os níveis de material particulado medidos pelo método nefelométrico.

O presente estudo mediu os níveis de partículas no interior dos camarotes. A alta concentração de material particulado em ambientes internos verificados em ambientes climatizados nos camarotes, possivelmente não apresenta correlação com o ambiente externo. Nos ambientes fechados dos camarotes, com sistema de ar condicionado, foram encontradas fontes emissoras de poluição do ar tais como cigarro, gelo seco e produtos químicos utilizados em salões de beleza. Alguns locais foram detectados pobre ventilação, o que pode ter influenciado os altos níveis de material particulado encontrados em ambientes internos. Nossos achados corroboram com estudo realizado em ambientes internos que apresentaram níveis de particulado variando de 318 to $2000 \mu \mathrm{g} / \mathrm{m}^{3}$ (Junquer et. al., 2000).

A plausibilidade da exposição ocular à poluição atmosférica já foi reportada na literatura ${ }^{(62)}$ bem como a perda da qualidade de vida devido à doenças respiratórias e cardiovasculares associadas às diferentes concentrações de partículas inaláveis ${ }^{\left({ }^{89}\right)}$. $\mathrm{Na}$ fase 2 da abordagem metodológica (avaliação de risco) se discute a importância de um estudo que possa avaliar o impacto da exposição ambiental à saúde humana. Para esta etapa do processo vários tipos de desenho de estudo podem ser utilizados, tais como estudos epidemiológicos, toxicológicos e avaliação de dose-resposta conforme amplamente descrito na literatura ${ }^{(80)(90)(127)}$. Nosso resultado demonstrou impacto à saúde através associação entre a presença de maior quantidade de muco e concentrações de poluição ambiental. 
Considerando que este tipo de exposição pode representar riscos à saúde de foliões e trabalhadores, este diagnóstico constitui numa ferramenta importante para a tomada de decisões em políticas públicas e fiscalização eficiente das fontes poluidoras no circuito carnavalesco.

De acordo com a Organização Mundial de Saúde a comunicação de riscos é um componente necessário para os programas de gerenciamento da qualidade do ar, sobretudo pela possibilidade de encaminhamento dos resultados preliminares aos órgãos e gestores responsáveis pela tomada de decisão no controle das fontes emissoras. A comunicação de riscos deve alcançar todos os potencias stakeholders, incluindo gestores, setor privado, mídia e o público em geral. Neste estudo observamos que as informações divulgadas pela mídia facilitou o diálogo e conscientização da opinião pública. Contribuiu para a interlocução com o poder público e inclusão deste tema em agenda de governo, onde ocorreram reuniões e audiências com esferas representativas firmando a pauta de discussão na busca de soluções para a questão.

De acordo com a Instrução Normativa $n^{\circ} 1 / 2005$, do Ministério da Saúde, a parceria entre os setores de saúde, ambiente e academia para elaboração de estudos é competência da esfera federal, estadual e municipal, onde consta como atribuição do órgão de Vigilância em Saúde Ambiental promover, coordenar e executar estudos e pesquisas aplicadas na área de vigilância em saúde ambiental. Assim, através deste órgão na Secretaria Municipal de Saúde de Salvador foi iniciada a articulação intersetorial incluindo diversos saberes para a realização deste estudo. Para tanto fez-se necessário o envolvimento de stakeholders, com propósitos em comum, tais como setores de saúde, ambiente, mídia, comunidade e academia. No presente estudo a ciência foi experimentada no contexto da ação, onde buscou validar métodos e levantar 
os indicadores para subsidiar decisões locais no tocante à regulamentação das emissões atmosféricas em evento de massa em Salvador.

A participação do setor acadêmico na abordagem de avaliação de riscos é de caráter multi e interdisciplinar ${ }^{(72)}$, o que revela a necessidade de formação de rede em pesquisa para o enfrentamento das questões levantadas, com capacidade técnica e operacional para planejar o escopo da análise, definindo os métodos e técnicas a serem utilizados para as fases de caracterização, avaliação de impacto à saúde e comunicação dos riscos. Segundo Thiollent ${ }^{(131)}$ o grande desafio da pesquisa no plano da pesquisa ação, talvez seja o de unir as exigências da tomada de decisão no plano do agir, com as exigências cientificas no plano do saber.

A tomada de decisão em políticas públicas locais é o resultado esperado num processo bem sucedido de análise de análise de riscos. A articulação intersetorial prevista nesta abordagem e a fluidez de comunicação entre os setores envolvidos permitiu que os resultados apresentados sob a forma de relatórios preliminares ao órgão gestor pudessem ser incluídos na pauta de discussão de um decreto municipal acerca da organização de festas populares. Ainda em 2008, ocorreu o lançamento da campanha “Carnaval Sustentável” por iniciativa do governo e apoio da iniciativa privada, onde os trios passariam a utilizar o biodiesel. Neste primeiro ano a campanha teve fraca adesão, justificada pela dificuldade de fornecimento de combustível limpo, que pudesse atender a demanda no carnaval. Em 2009, a publicação do Decreto n $^{\mathbf{0}} 20.505 / 2009$ pela Prefeitura Municipal de Salvador, atribuiu competência para o monitoramento da qualidade do ar durante o carnaval e outros eventos de massa, ao órgão de ambiente e demais órgãos de atividades correlatas. Este fato fortaleceu as ações iniciadas voltadas ao controle das fontes emissoras no circuito, tais como campanhas para mudança de 
matriz energética utilizada pelos trios. Em 2009, a campanha para utilização de biodiesel se apresentou mais estruturada onde uma parceria público-privada garantia o fornecimento do combustível aos trios elétricos e carros de apoio no circuito. Nos anos subsequentes o poder público fez novas recomendações ao setor privado responsável pelos veículos. Em contrapartida o governo fornece um selo de qualidade aos trios que utilizam o Biodiesel. Em 2014 foi utilizado o combustível B50 em trios elétricos e carros de apoio.

Incertezas são inerentes em todos os estágios da avaliação de risco. De acordo com a Environmental Protection Agency (EPA) ${ }^{(3)}$ os critérios metodológicos devem estar claramente disponíveis para análise científica. Muitas vezes uma tomada de decisão utiliza inferências resultantes de estudos epidemiológicos. Investigações toxicológicas também são importantes para conhecer a função dose-resposta e assegurar o nível de exposição tolerável pelo organismo, quando se trata de contaminante desconhecido. Fator limitante considerado neste estudo é resultante da pesquisa no contexto da ação que apresenta peculiaridades no tempo de realização do estudo. Para a execução do protocolo exige-se habilidade da equipe no sentido de intervir e gerenciar os processos em tempo que viabilize a implementação da técnica científica. Considero também como limitação o recorte do tempo que o método foi aplicado, onde a estrutura montada para a realização do carnaval ocorre às vésperas do evento, o que não permite repetição do experimento, e assim só permitir trabalhar com as amostras factíveis de serem coletadas no evento. Estudos de impacto à saúde dos grupos vulneráveis tais como categorias de trabalhadores cordeiros e ambulantes devem ser estimulados.

De acordo com as agencias internacionais ${ }^{(1)(3)(13)}$ a comunicação de riscos é um componente necessário para os programas de gerenciamento da qualidade do ar, 
sobretudo pela possibilidade de encaminhamento dos resultados preliminares aos órgãos e gestores responsáveis pela tomada de decisão no controle das fontes emissoras. A comunicação de riscos deve alcançar todos os potencias stakeholders, incluindo gestores, setor privado, mídia e o público em geral. Um programa efetivo de comunicação de riscos pode modificar comportamentos e decisões acerca do controle e exposição das fontes emissoras ${ }^{(87)}$. Neste estudo observamos que as informações divulgadas pela mídia facilitou o diálogo e conscientização da opinião pública. Contribuiu para a interlocução com o poder público e inclusão deste tema em agenda de governo, onde ocorreram reuniões e audiências com esferas representativas firmando a pauta de discussão na busca de soluções para a questão.

\subsection{Considerações finais}

O monitoramento atmosférico constitui uma necessidade premente para a realização de diagnóstico da situação ambiental, visto que o crescimento das fontes emissoras em nossa cidade se encontra em plena expansão.

Embora Salvador apresente condições geográficas que facilitam a dispersão dos poluentes na atmosfera, a emissão gerada pelo intenso tráfego de veículos pode expor diretamente as pessoas que circulam ou residem próximas a estas vias. Partículas de menor diâmetro permanecem mais tempo suspensas no ar e apresentam maior probabilidade de penetrar nas vias aéreas.

As informações ambientais além de serem cruciais para a construção de políticas de saúde ambiental, coerentes e eficazes, são também fundamentais para o avanço em 
investigações epidemiológicas e estudos bem delineados sobre a relação entre poluição do ar e saúde.

Considerando que este tipo de exposição pode representar riscos à saúde de foliões e trabalhadores, este diagnóstico constituiu numa ferramenta importante para a tomada de decisões em políticas públicas e fiscalização eficiente das fontes poluidoras no circuito carnavalesco.

O presente estudo forneceu indicador ambiental referente à presença de metais no ar de Salvador, o qual possibilitou implementação de ações do VIGIAR. Integrou ações do Estado da Bahia e do Município de Salvador no controle e na fiscalização das fontes emissoras através de parcerias interinstitucionais, entre os órgãos de fiscalização de saúde e meio ambiente, bem como centros de pesquisa. Estabeleceu uma rede de informações para implementar as ações de fiscalização, prevenção e proteção à saúde humana atendendo à demanda de gestão interdisciplinar e intersetorial.

Além disso considero que uma das principais contribuições deste estudo, sobretudo pela necessidade de aplicação de métodos e técnicas que exigem saberes complexos em diversas disciplinas, foi a formação de uma rede temática transdisciplinar que congregou profissionais diversos que atuam em sete instituições públicas (UFBA, SMS, SMA, SEMA, USP, UFRJ, e FIOCRUZ) de três Estados brasileiros (SP, RJ e BA), que facilitou a transferência de tecnologia e conhecimento de técnicas especificas para as ações no serviço, como por exemplo análises morfológicas através de microscopia eletrônica, análise química de metais utilizando espectrofotometria de absorção atômica e outros métodos laboratoriais.

A fiscalização prévia dos trios e matriz energética no circuito do carnaval pode ser recomendada como uma ação de vigilância sanitária e ambiental, além de implementação 
de um plano de comunicação de riscos durante o evento, envolvendo a comunidade para o autogerenciamento do risco, onde o poder público possa disponibilizar informações sobre o acesso aos índices de qualidade do ar, bem como informações sobre a prevenção e gerenciamento de sintomas respiratórios.

São necessários estudos posteriores para avaliação de impacto em doenças respiratórias e ensaios toxicológicos para avaliar a cinética destes elementos no organismo humano, bem como elucidar mecanismos de biodisponibilidade destes elementos.

\subsection{Méritos e limitações}

Incertezas são inerentes em todos os estágios da análise de riscos.

O biomonitoramento não permite uma quantificação de partículas por metro cúbico de ar, o que inviabiliza estudos análise de serie temporal para elaboração de indicadores em saúde, limitando o uso desta técnica. A realização de mais campanhas ao longo do ano em mais estações aumentaria as chances de comparação entre os resultados em condições climáticas diferentes. Também permitiria um melhor acompanhamento na dispersão destes poluentes ao longo do ano. $\mathrm{O}$ monitoramento deve ser instituído de forma contínua e quanto maior o número de amostragens maior a possibilidade de interpretação dos resultados.

Para o estudo de caso do carnaval, um fator limitante foi o recorte do tempo em que o método foi aplicado, pois a estrutura do evento somente é montada às vésperas, permanecendo por curto período, o que também não permite repetição do experimento. Assim, só é possível trabalhar com as amostras factíveis de serem coletadas no próprio 
evento. Para a execução dos protocolos de pesquisa em tais condições, exige-se habilidade da equipe no sentido de intervir e gerenciar os processos de coleta, ao tempo que viabilize a implementação da técnica científica. 


\section{CONCLUSÕES}

O material particulado estudado apresentou níveis significativos de metais detectados pelo método de espectrofotometria de absorção atômica. Os elementos pesquisados $(\mathrm{Cr}, \mathrm{Cu}, \mathrm{Mn}, \mathrm{Fe}$ e $\mathrm{Zn})$ associados às partículas podem representar marcadores de tráfego de veículo na Cidade de Salvador.

A análise morfológica através da Microscopia Eletrônica de Varredura permitiu observar partículas de diferentes formas e tamanhos adsorvidas na superfície da planta, bem como verificar a predominância do particulado fino no material estudado .

A caracterização elementar realizada pelo sistema de micro-análise de raios-X acoplado ao microscópio eletrônico de varredura permitiu constatar a presença de metais em partículas de dimensões que podem alcançar o trato respiratório inferior.

O biomonitoramento, utilizando a Tillandsia usneoides para detecção de poluentes atmosféricos, representou um método de potencial aplicabilidade para a fase de identificação do perigo, em alternativa ao método mecânico.

As técnicas de mensuração de poluentes aplicados no estudo de caso no Circuito do Carnaval de Salvador demonstrou altos níveis de material particulado em ambientes externos e internos.

O estudo de avaliação da exposição em trabalhadores, segunda etapa da abordagem em análise de riscos, demonstrou uma associação entre a presença de maior 
quantidade de muco e concentrações de poluição ambiental, caracterizando assim o risco para a saúde.

A tomada de decisão em políticas públicas, etapa de gerenciamento do risco, foi demonstrada neste estudo pela publicação do decreto municipal que instituiu a fiscalização das fontes poluidoras no circuito carnavalesco.

As etapas implementadas neste estudo (identificação do perigo, avaliação de risco, comunicação do risco e gerenciamento do risco) constituíram o modelo de abordagem em análise de riscos para as ações de Vigilância em Saúde relacionada à Qualidade do Ar. 


\section{PERSPECTIVAS}

Prosseguir com os estudos abaixo listados, iniciados através de colaborações durante o período desta tese, com apoio da rede de pesquisa idealizada pelo NIQA (Núcleo Intersetorial para a Qualidade do Ar) - Copa do Mundo 2014, os quais se encontram em fase de análise dos dados:

1- Análise de serie temporal em poluição do ar, doenças respiratórias e cardiovasculares na cidade de Salvador;

2- Diagnóstico situacional sobre densidade de tráfego, poluição do ar e áreas destinadas à atividade física usando a ferramenta SIG;

3- Asma grave e poluição do ar em Salvador: Um estudo caso controle

Consolidar as publicações que poderão impulsionar novos projetos e desenvolvimento da minha carreira de Pesquisadora em Saúde Pública na Fiocruz, Bahia.

Realizar pós-doutorado para o aprendizado de modelos e métodos de análise aplicados em Epidemiologia Ambiental e Análise de Riscos. 


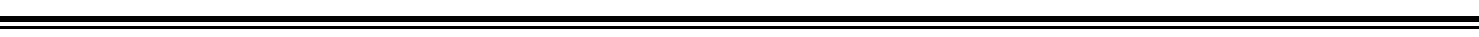




\section{Anexo 1: Carta de aprovação da CAPPesq}

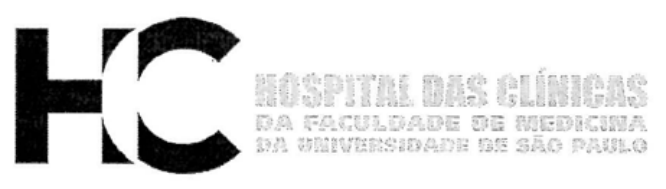

\section{APROVAÇÃO}

A Comissão de Ética para Análise de Projetos de Pesquisa CAPPesq da Diretoria Clínica do Hospital das Clínicas e da Faculdade de Medicina da Universidade de São Paulo, em sessão de 01/04/2009, APROVOU o Protocolo de Pesquisa n 0165/09, intitulado: "POLUIÇÃO ATMOSFÉRICA URBANA NA CIDADE DE SALVADOR: UMA ANÁLISE DE RISCO PARA A SAÚDE HUMANA BASEADO NAS CONCENTRAÇÕES DO MATERIAL PARTICULADO FINO" apresentado pelo Departamento de PATOLOGIA.

Cabe ao pesquisador elaborar e apresentar à CAPPesq, os relatórios parciais e final sobre a pesquisa (Resolução do Conselho Nacional de Saúde n 196, de 10/10/1996, inciso IX.2, letra "c").

Pesquisador (a) Responsável: Paulo Hilário Nascimento Saldiva

Pesquisador (a) Executante: Nelzair Araújo Vianna

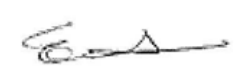

Prof. Dr. Eduardo Massad Presidente da Comissão de Ética para Análise de Projetos de Pesquisa 


\section{Anexo 2: Cartas de Anuência}

\section{Carta de Anuência}

São Paulo , 13 de agosto de 2008.

À Faculdade de Medicina da Universidade de São Paulo

Programa de Pós-graduação em Patologia

Ref. ao projeto: "Poluição atmosférica urbana em Salvador: Uma análise de risco para a saúd̄e humana baseado nas concentrações de particulado fino".

Eu, abaixo assinado, Luciana Vanni Gatti, RG $\mathrm{n}^{\circ}$, 7.561.571-X, CPF $\mathrm{n}^{\circ}$ 071.468.838-09 , Coordenadora do LABORATÓRIO DE QUÍMICA ATMOSFÉRICA do INSTITUTO DE PESQUISAS ENERGÉTICAS E NUCLEARES -IPEN, tenho pleno conhecimento do projeto proposto, submetido ao Programa de Pós-graduação em Patologia da Faculdade de Medicina da Universidade de São Paulo pelo Dr. Paulo Hilário Nascimento Saldiva, e confirmo a cooperação desta instituição no mesmo.

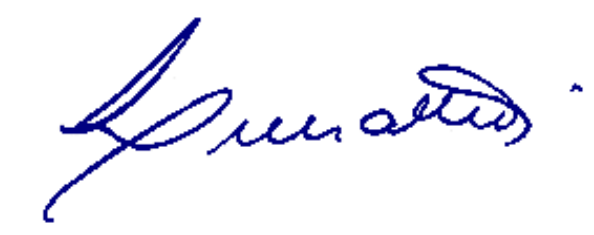

(nome completo e assinatura) 


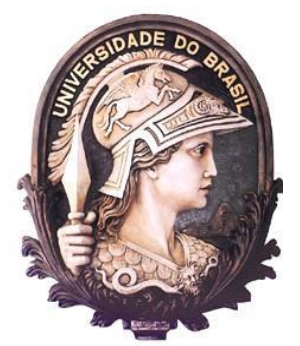

UNIVERSIDADE FEDERAL DO RIO DE JANEIRO

CENTRO DE CIÊNCIAS DA SAUDE

INSTITUTO DE CIÊNCIAS BIOMÉDICAS

Carta de Anuência

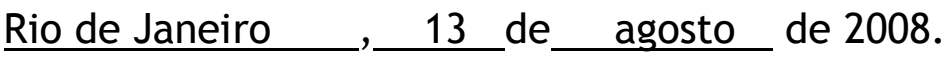

À Faculdade de Medicina da Universidade de São Paulo

Programa de Pós-graduação em Patologia

Ref. ao projeto: “'Poluição atmosférica urbana em Salvador: Uma análise de risco para a saúde humana baseado nas concentrações de particulado fino em Salvador, BA"

Eu, abaixo assinado, Leonardo Rodrigues de Andrade , RG $n^{\circ}$, 10028923-0 CPF ${ }^{\circ} \_07179860719$ Pesquisador do Laboratório de Biomineralização da Universidade Federal do Rio de Janeiro, tenho pleno conhecimento do projeto proposto, submetido ao Programa de Pósgraduação em Patologia da Faculdade de Medicina da Universidade de São Paulo pelo Dr. Paulo Hilário Nascimento Saldiva, e confirmo a cooperação desta instituição no mesmo.

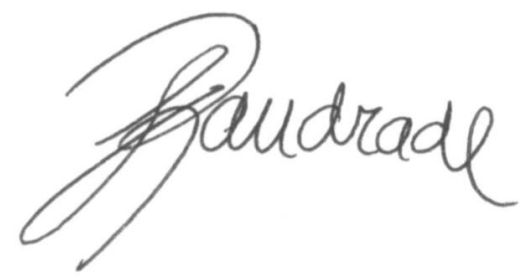

Leonardo Rodrigues de Andrade

Prof. Adjunto 


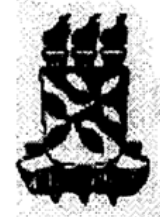

UFBA
UNIVERSIDADE FEDERAL DA BAHIA - UFBA

FACULDADE DE MEDICINA DA BAHIA

DEPARTAMENTO DE MEDICINA PREVENTIVA E SOCIAL

Av. Reitor Miguel Calmon, $\mathrm{s} / \mathrm{n}^{\circ}$ - Vale do Canela CEP 44110-100 Salvador - Bahia.

Telefones: 3283-88658884 Fax:3283.8854

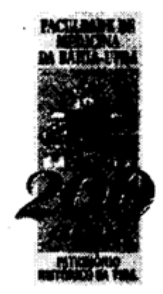

\section{Carta de Anuência}

Salvador, 13 de agosto de 2008.

À Faculdade de Medicina da Universidade de São Paulo Programa de Pós-graduação em Patologia

Ref. ao projeto:_"Poluição atmosférica urbana em Salvador: Uma análise de risco para a saúde humana baseado nas concentrações de particulado fino em Salvador, BA"

Eu, abaixo assinado, Marco Antônio Vasconcelos Rêgo, RG $n^{\circ}$ 1.097.927, CPF $n^{\circ}$ 182.847.015-53, Chefe do Departamento de Medicina Preventiva e Social da Faculdade de Medicina da Bahia da Universidade Federal da Bahia, tenho pleno conhecimento do projeto proposto, submetido ao Programa de Pós-graduação em Patologia da Faculdade de Medicina da Universidade de São Paulo por Dr. Paulo Hilário Nascimento Saldiva, e confirmo a cooperação desta instituição no mesmo.

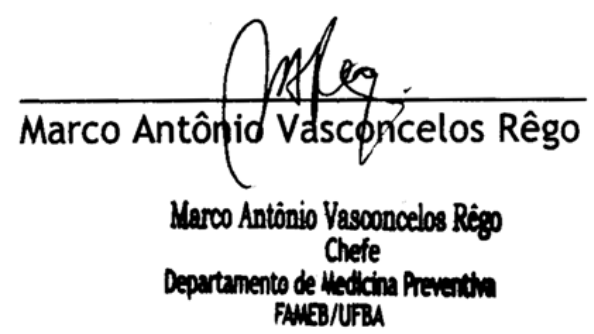




\section{Pro-AR}

Programa para o Controle da Asma e da Rinite Alérgica da Bahia

Uma Aliança entre a Faculdade de Medicina da Bahia - UFBA, a Secretaria Municipal de Saúde de Salvador, a Secretaria de Saúde de Estado da Bahia e o Ministério da Saúde do Brasil, com financiamento da FAPESB

ANEXO

Carta de Anuência

Salvador, 13 de agosto de 2008.

À Faculdade de Medicina da Universidade de São Paulo Programa de Pós-graduação em Patologia

Ref. ao projeto "Poluição atmosférica urbana em Salvador: Uma análise de risco para a saúde humana baseado nas concentrações de particulado fino em Salvador, BA"

Eu, abaixo assinado, Adelmir de Souza Machado, RG n²003993, CPF $n^{\circ} 371.201 .405-82$, coordenador pelo Programa de Controle da Asma e da Rinite Alérgica na Bahia- ProAR/ UFBA, tenho pleno conhecimento do projeto proposto, submetido ao Programa de Pósgraduação em Patologia da Faculdade de Medicina da Universidade de São Paulo por Dr. Paulo Hilário Nascimento Saldiva, e confirmo a cooperação desta instituição no mesmo.

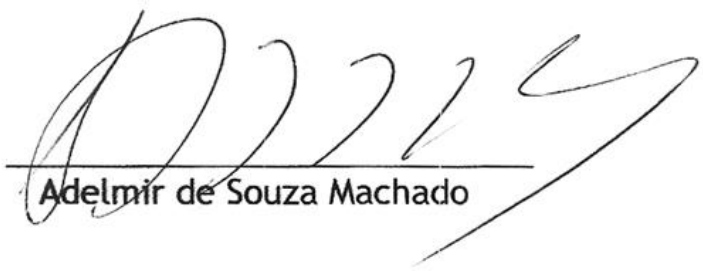




\section{Carta de Anuência}

Salvador, 14 de agosto de 2008.

À Faculdade de Medicina da Universidade de São Paulo Programa de Pós-graduação em Patologia

Ref. ao projeto: "Poluição atmosférica urbana em Salvador: Uma análise de risco para a saúde humana baseado nas concentrações de particulado fino em Salvador, BA"

Eu, abaixo assinado, JULIANO SOUSA MATOS, RG $n^{\circ} .449530973$ - SSP/BA, CPF $\mathrm{n}^{\circ}$.567.760.635-91, Secretário, pela Secretaria do Meio Ambiente do Estado da Bahia, tenho pleno conhecimento do projeto proposto, submetido ao Programa de Pósgraduação em Patologia da Faculdade de Medicina da Universidade de São Paulo por Dr. Paulo Hilário Nascimento Saldiva, e confirmo a cooperação desta Secretaria no mesmo.

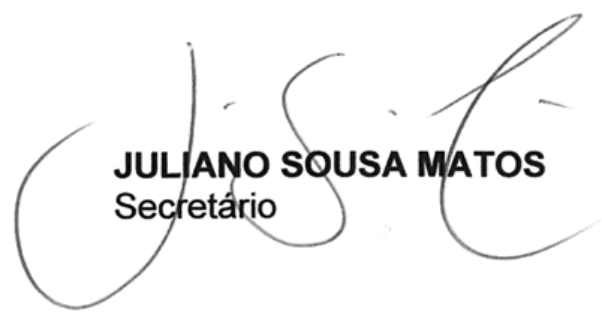



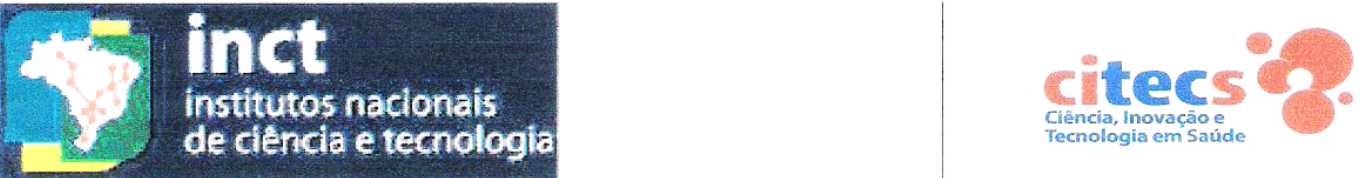

EXPRESSÃO DE INTERESSE EM DESENVOLVER PESQUISAS EM COOPERAÇÃO ENTRE OS INCT'S ABAIXO DISCRIMINADOS declarada pelos seus representantes no II Workshop de Poluição Atmosférica e Saúde Humana, nos dias 01 e 02 de dezembro de 2011 em Salvador, Bahia.

INCTs- Institutos Nacionais de Ciência e Tecnologia

-Bahia, CITECS ISC- UFBA, Prof. Dr. Sebastião Loureiro;

-São Paulo, INAIRA - Fac.Med./USP, Prof. Dr. Paulo Saldiva;

-Rio de Janeiro, INPETAM - UFRJ, Prof. Dr. Olaf Malm

As relações entre AMBIENTE, SOCIEDADE E SAÚDE DA POPULAÇÃO, nos processos de desenvolvimento, industrialização, crescimento econômico, aceleração do crescimento, já estão bem estabelecidas, no que diz respeito aos danos, os custos. Entretanto, na perspectiva do desenvolvimento de tecnologias que permitam identificar, medir, e comunicar os RISCOS AMBIENTAIS, ainda existe um longo percurso a ser trilhado pela pesquisa aplicada e pelos órgãos públicos competentes.

Neste sentido, ficou explicitado no "II Workshop Poluição Atmosférica e Saúde Humana" realizado em Salvador nos dias 01 e 02 Dezembro de 2011, não somente a necessidade, mas sobremodo a decisão de ações intersetoriais entre Universidades, Serviços, Setor Privado e grupos de pesquisa liderados pelos INCT's presentes ao evento, construírem um agenda de trabalho visando integrar recursos humanos e materiais disponíveis nestes INCTs, com ênfase num primeiro momento no tema de Poluição Atmosférica.

Esta Cooperação visa também, apoiar ações intersetoriais para dotar a Região Metropolitana de Salvador (RMS) de uma rede em Saúde Ambiental, de modo a tornar os dados e as informações acessíveis de modo continuo, não somente aos órgãos responsáveis pelo controle, bem como para a sociedade.

Assim, para fazer válido este termo de expressão de interesse, firmamos abaixo esta declaração,

Salvador, 20 de março de 2012. 
Dr. Sebastião Antonio Loureiro

Prof. Emérito da UFBA - Coordenador Executivo - INCT

CPF: 021.790.245-68

Assinatura:

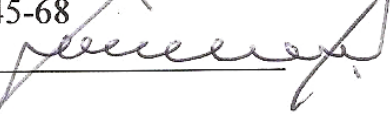

Dr. Paulo Saldivia

Prof. Titular da FMUSP - Coordenador INCT - INAIRA

CPF: 006.468.268-40

Assinatura:

Dr. Olaf Malm

Prof. Titular da UFRJ - Coordenador INCT - INPeTAm

CPF: 808.653.567-34

Assinatura:

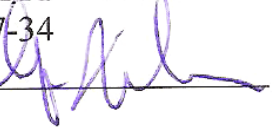




\section{Anexo 3: Lista dos resumos de trabalhos apresentados em congressos.}

\section{Apresentação Oral:}

Congresso Internacional - Environmental Health 2011, Salvador, BA fevereiro 2011

Título da Apresentação: "Caracterization of particulate matter from urban air pollution in Salvador"

\section{Posters:}

Novaes, Priscila ; Miraglia, S ; VIANNA, Nelzair Araújo . Avaliação da Exposição Ocular aos Efeitos da Poluição Atmosférica: Um Estudo De Caso Em Salvador BA. 2009. CBO, 2009.(Apresentação de Trabalho/Congresso).

VIANNA, Nelzair Araújo ; SALDIVA, P. H. N. ; Novaes, Priscila ; Gnoatto, Nelson ; ANDRADE, L. R. . Particulate matter emitted from diesel-powered vehicles during Carnival in Salvador, Bahia, Brazil: diagnosis for a risk communication management. SETAC NORTH AMERICA 2009. (Apresentação de Trabalho/Congresso).

VIANNA, Nelzair Araújo ; Gnoatto, Nelson ; SALDIVA, P. H. N. ; ANDRADE, L. R. . Indoor air monitoring of particulate matter in boxes areas along 2009 Carnival circuit in Salvador, Bahia, Brazil. 2010. AAAR San Diego, 2010 (Apresentação de Trabalho/Congresso)

VIANNA, Nelzair Araújo ; SALDIVA, P. H. N. ; Novaes, Priscila ; Gnoatto, Nelson ; ANDRADE, L. R. . Monitoramento da Poluição Atmosférica no carnaval de Salvador Uma ação de intersetorialidade. SIMBRAVISA 2008. (Apresentação de Trabalho/Simpósio).

VIANNA, Nelzair Araújo ; Gnoatto, Nelson ; ANDRADE, L. R. ; SALDIVA, P. H. N. . Indoor air monitoring in boxes areas of carnival in Salvador, BA, Brazil. 2011. ENVIRONMENTAL HEALTH 2011(Apresentação de Trabalho/Congresso).

VIANNA, Nelzair Araújo ; DOLIVEIRA JUNIOR, A. ; ANDRADE, L. R. . Caracterization of particulate matter in Salvador, BA, Brazil. 2011.ENVIRONMENTAL HEALTH 2011 (Apresentação de Trabalho/Congresso). 
N.A. Vianna O. Malm, P.H.N. Saldiva*, L.R. Andrade. University of Sao Paulo, Brazil, 2Federal University of Rio de Janeiro, Brazil. Caracterization of particulate matter from urban air pollution in Salvador, Bahia, Brazil URBAN AIR POLLUTION 2012, AMSTERDÃ, HOLANDA

N. A. Vianna ${ }^{1,2}$, P. H. N. Saldiva ${ }^{1}$, University of Sao Paulo $;{ }^{2}$ Environmental Health Surveillance of Salvador;Universidade de São Paulo; Vigilância em Saúde Ambiental de Salvador, SMS. Application of risk assessment for policy formulation in air quality, in Salvador, BA, Brazil. ENVIRONMENTAL HEALTH 2013, BOSTON, 2013.

Nelzair Araujo Vianna, Samya de Lara Lins de Araujo Pinheiro, Ademario Spinola, Sebastiao Loureiro, Federal University of Bahia, Paulo Hilario Nascimento Saldiva, University of Sao Paulo. Traffic, air quality and urban health: a proposal of intersectoral action involving stakeholders. ENVIRONMENTAL HEALTH 2013, BOSTON, EUA, 2013

N. A. Vianna ${ }^{1,2}$, P. H. N. Saldiva ${ }^{1}$, University of Sao Paulo ; ${ }^{2}$ Environmental Health Surveillance of Salvador. Application of risk assessment for policy formulation in air quality, in Salvador, BA, Brazil SOCIETY FOR RISK ANALYSIS ANNUAL MEETING, BALTIMORE, EUA, 2013

N. A. Vianna ${ }^{1,2}$, A. Lino; O. Malm; E. A. Santos; L. Campos; P. H. N. Saldiva ${ }^{1}$, University of Sao Paulo ; ${ }^{2}$ Environmental Health Surveillance of Salvador; Oswaldo Cruz Foundation; Secretaria de Educaçao da Bahia; Federal University of Rio de Janeiro; Federal University of Bahia. Elemental and Morfological Analyses of Particulate Matter in Salvador, Ba, Brazil. International Society for Environmental Epidemiology Conference, Seattle, EUA, 2014 


\section{Anexo 4: Artigo Publicado, incluindo o número DOI.}

Environ Sci Pollut Res DOI 10.1007/s11356-010-0387-y

Nelzair A. Vianna, Daniel Gonçalves, Flavia Brandão, Roberta P. de Barros, Gilberto M. Amado Filho, Rodrigo O. Meire, João Paulo M. Torres, Olaf Malm, Argemiro D’Oliveira Júnior, Leonardo R. Andrade. Assessment of heavy metals in the particulate matter of two Brazilian metropolitan areas by using Tillandsia usneoides as atmospheric biomonitor 


\title{
Anexo 5: Decreto
}

\author{
PREFEITURA MUNICIPAL DO SALVADOR - BAHIA \\ GABINETE DO PREFEITO
}

DECRETO n² 20.505 de 28 de dezembro de 2009

\begin{abstract}
Disciplina o licenciamento e a fiscalização para $\circ$ desfile de entidades carnavalescas ou folclóricas, trios elétricos e congêneres, a instalação e exploração de serviço especial, de camarote, praticável, arquibancada, palcos e similares, o nível de emissão sonora, a exibição de publicidade em geral, o disciplinamento do comércio informal, o sistema de transporte coletivo e de trânsito, a prestação do serviço de saúde, ações da vigilância sanitária, a limpeza urbana e a coleta, o tratamento e - manejo de resíduos sólidos e de qualquer natureza, durante $\circ$ período de Carnaval, de Festas Populares e de quaisquer Eventos que requeiram 0 exercício do poder de polícia, realizados e incluídos no calendário oficial ou privados na Cidade do Salvador.
\end{abstract}

O PREFEITO MUNICIPAL DA CIDADE DO SALVADOR, CAPITAL DO ESTADO DA BAHIA, no uso das atribuições que the conferem o inciso $V$ do art. 52 da Lei Orgânica do Município e tendo em vista o disposto nos artigos 94 e 328 da Lei n. 7.186, de 27 de dezembro de 2006 - Código Tributário e de Rendas do Município do Salvador,

DECRETA:

\author{
TITULO I \\ DAS DISPOSIÇÕES GERAIS \\ CAPÍTULO I \\ DAS COMPETÊNCIAS
}

Art. $1^{\circ}$ Compete à Empresa Salvador Turismo S.A. - SALTUR, vinculada ao Gabinete do Prefeito, planejar, coordenar, fomentar, produzir, contribuir e executar os festejos carnavalescos, as Festas Populares e os outros Eventos de interesse turístico no Município, inclusive adotar o procedimento necessário à comercialização dos mesmos e elaborar o calendário oficial da Cidade. 


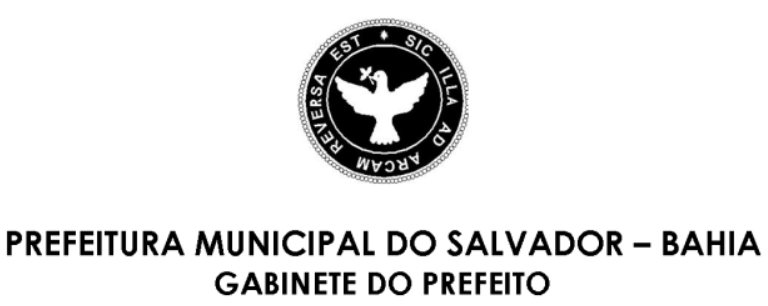

DECRETO $n^{\circ} 20.505$ de 28 de dezembro de 2009

publicidade, bem como aplicar as normas de segurança quanto ao disposto neste Decreto.

$V$ - permissão, acompanhamento e fiscalização da montagem de estruturas e de todos os equipamentos e engenhos publicitários não referidos nos itens anteriores e destinados à exploração de atividades eventuais e publicitárias exibidas, sob qualquer forma, em quaisquer áreas, ou veículos, mesmo automotores, a exemplo de trios elétricos, ou prédios, edificados ou não, públicos e privados, em qualquer período do Carnaval ou das demais Festas Populares e Eventos.

$\S 1^{\circ} \mathrm{A}$ autorização de que trata este artigo, quando não se enquadrar no uso de espaços públicos resultante de licitação, deverá ser requerida à SUCOM pela entidade realizadora das Festas Populares, dos Eventos, ou do desfile de bloco carnavalesco ou folclórico, trio elétrico e congêneres ou pela pessoa jurídica que pretender instalar e explorar serviços especiais, de camarote, praticável, arquibancada, palcos e similares, em área pública ou privada, promover veiculação sonora ou expor publicidade em logradouros, públicos ou privados, nos prazos estabelecidos na legislação.

$\S 2^{\circ}$ À SUCOM cabe, sob pena de indeferimento ou cassação de licença, a cobrança e a arrecadação dos encargos legais incidentes sobre quaisquer atividades referidas neste artigo, inclusive respeitados os parâmetros das cotas de patrocínio, quando a atividade carnavalesca representar competição com outros patrocinadores que se vincularem à forma de captação de recursos financeiros estabelecida no Edital respectivo.

Art. 12. Compete à Superintendência do Meio Ambiente - SMA, vinculada à Secretaria Municipal de Desenvolvimento Urbano, Habitação e Meio Ambiente SEDHAM, conjuntamente com os demais órgãos de atribuições correlatas:

I - fiscalizar a veiculação sonora;

II - monitorar o grau de emissão de poluição na atmosfera através do espectrofotômetro;

III - controlar e monitorar as áreas de preservação ambiental;

IV - atuar na preservação dos bens do Sítio Histórico, dos recursos naturais e paisagísticos.

Art. 13. Compete à Secretaria Municipal da Fazenda - SEFAZ, proceder, 


\section{Anexo 6: Boletim VIGIAR}

\section{Secretaria
da Saúde

BOLETIM VIGIAR - Ano I no 01 julho 2013

\section{Biomonitoramento da}

Poluição Atmosférica em

Salvador

O biomonitoramento da poluição atmosférica foi o primeiro passo para a elaboração de indicadores que pudessem auxiliar na implementação de ações do Programa VIGIAR-Vigilância em Saúde relacionada à Qualidade do $\mathrm{Ar}$, na cidade de Salvador. Este estudo foi fruto de articulação intersetorial iniciada pela Vigilância em Saúde Ambiental de Salvador, com apoio da Secretaria Municipal de Saúde e da Superintendência do Meio Ambiente. Nossa pesquisa utilizando o biomonitoramento como ferramenta de medição da poluição atmosférica foi pioneira em Salvador. Foram realizadas medidas em duas estações do ano utilizando a bromélia Tillandsia usneoides.

Fig. 1. Bromélias expostas para captura de partículas presentes no ar de Salvador, Fonte: Nelzair Vianna, 2005.

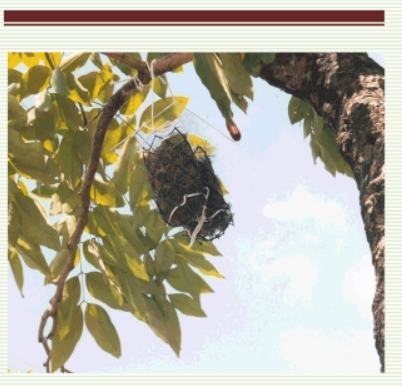

Referencia: VIANNA, Nelzair Araújo ; Daniel Gonçalves ; Flavia Brandão ; Roberta P. Barros ; Gilberto M. Amado Filho ;
Rodrigo O. Meire ; João Paulo M. Torres ; Olaf Malm; DOLIVEIRA JUNIOR, A.; ANDRADE, L. R. . Assessment of heavy metals in the particulate matter of two Brazilian metropolitan areas by using Tillandsia usneoides as atmospheric biomonitor. Environmental Science and Pollution Research International ${ }^{\text {CCR }}$, v. 17, p. 1-12, 2010.

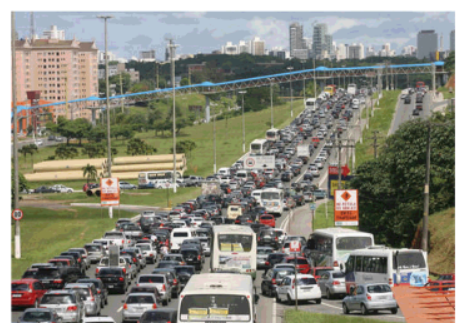

Fig.2. Congestionamento em avenidas de Salvador.

Salvador possui uma frota veicular de 783 mil veículos (2012), importante fonte de poluentes atmosféricos, e a partir de dezembro de 2011 já conta com uma rede automática da qualidade do ar.

Dentre os principais resultados desta ação, destacamos as seguintes:

-Forneceu indicador ambiental referente à presença de metais no ar de Salvador; -Integrou ações do Estado da Bahia e do Município de Salvador no despertar para o controle e fiscalização das fontes emissoras, através de parcerias interinstitucionais entre os órgãos de fiscalização de saúde, meio ambiente e centros de pesquisa, atendendo à demanda de gestão interdisciplinar e intersetorial;

-Iniciou a formação de rede para dar suporte à tomada de decisão -Promoveu comunicação de riscos, a partir da divulgação dos dados em meios de comunicação, integrando ações de órgãos ambientais e de saúde de Salvador no sentido de informar a comunidade sobre a poluição do ar e os efeitos na saúde.

Uma das principais contribuições deste estudo foi formação de uma rede temática transdisciplinar, congregando profissionais em diversas áreas do conhecimento que atuam em sete instituições públicas (SMS, UFBA, SMA, SEMA, USP, UFRJ, e FIOCRUZ) de três Estados brasileiros (SP, RJ e BA), buscando facilitar a transferência de tecnologia e conhecimen to para as ações do Sistema Único de Saúde.
Responsável: Nelzair Vianna

Quanto às vantagens na utilização do biomonitoramento com bromélias podemos destacar:

1)Este método pode ser utilizado em locais que não possuem sistema de monitoramento com equipamentos automatizados para medição de metais na atmosfera.

2)É uma forma de se conhecer ou apresentar dados iniciais, que indiquem a presença de contaminação por metais na atmosfera, ainda que não substitua em longo-prazo, um plano para aquisição de dados por estações automáticas de monitoramento. Estas possuem maior precisão de medição, não só para material particulado, mas para outros poluentes atmosféricos como ozônio, monóxido e dióxido de carbono, enxofre, etc.

3)São utilizados, mesmo em regiões que possuem rede automatizada, pois permitem a amostragem de muitos exemplares ao mesmo tempo e com isso a possibilidade de acompanhar a dispersão de poluentes na atmosfera estabelecendo gradientes de concentração para locais com maior e menor intensidade de poluição.

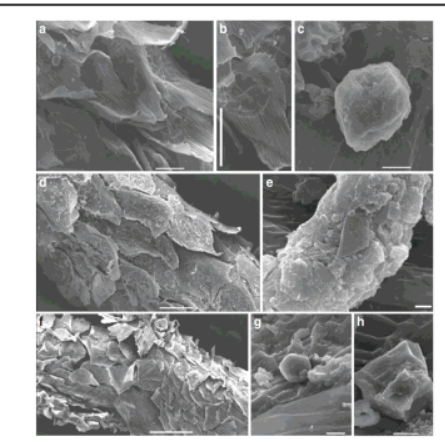

Fig. 3. Microscopia Eletrônica de Varredura de partículas do ar de Salvador retidas pelo biomonitor Tillandsia usneoides, Nelzair Vianna, 2007 


\section{Anexo 7: Setores participantes da articulação intersetorial para a abordagem em análises de riscos no estudo da poluição do ar em Salvador}

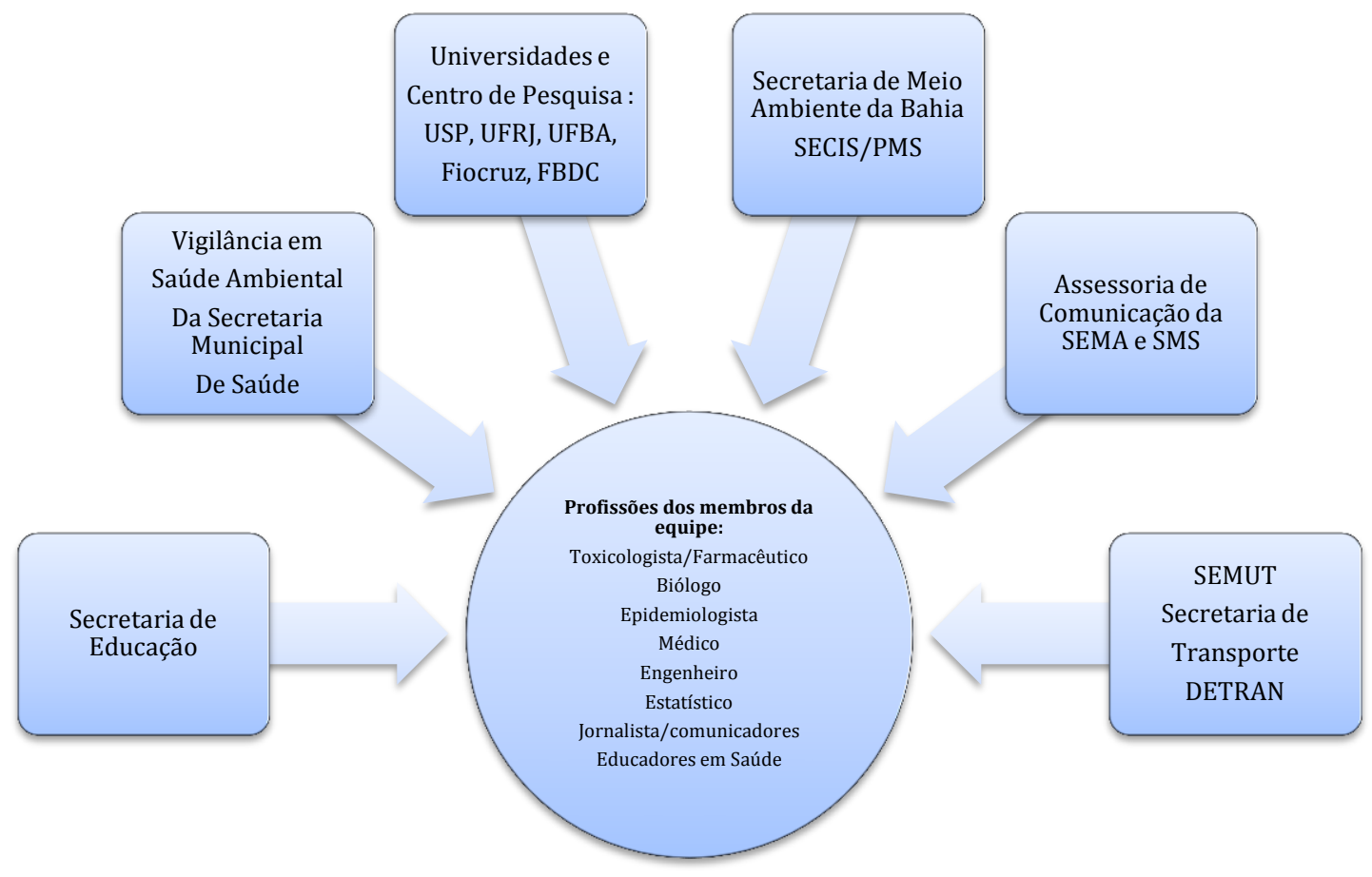




\section{REFERÊNCIAS}

1. WHO. Air Quality Guidelines - Global Update. Geneve: WHO; 2005.

2. Pope CA, Ph D. editorials Air Pollution and Health - Good News and Bad. N Engl J Med. 2004;1132-4.

3. National Research Council. Science and decisions: advancing risk assessment. [Internet]. Risk analysis : an official publication of the Society for Risk Analysis. 2009. Available from: http://www.ncbi.nlm.nih.gov/pubmed/25009905

4. Aven T, Zio E. Foundational issues in risk assessment and risk management. Risk Anal [Internet]. 2014 Jul [cited 2014 Sep 16];34(7):1164-72. Available from: http://www.ncbi.nlm.nih.gov/pubmed/24152111

5. Burns CJ, Wright JM, Pierson JB, Bateson TF, Burstyn I, Goldstein DA. Evaluating Uncertainty to Strengthen Epidemiologic Data for Use in Human Health Risk Assessments. Environ Health Perspect. 2014;1160(11):1160-5.

6. Neal Fann, Michelle L. Bell, Katy Walker and BH. Improving the Linkages between Air Pollution Epidemiology and Quantitative Risk Assessment. 2011;119(12):1671-5.

7. Armstrong B, Hajat S, Kovats S, Lloyd S, Scovronick N, Wilkinson P. Climate change: how can epidemiology best inform policy? Epidemiology [Internet]. 2012 Nov [cited 2014 Nov 16];23(6):780-4. Available from: http://www.ncbi.nlm.nih.gov/pubmed/23038105

8. Martuzzi M, Krzyzanowski M, Bertollini R. Health impact assessment of air pollution: providing further evidence for public health action. Eur Respir $\mathbf{J}$ [Internet]. 2003 May 1 [cited 2014 Sep 11];21(Supplement 40):86S-91s. Available from: http://erj.ersjournals.com/cgi/doi/10.1183/09031936.03.00403303

9. Ministério da Saúde. Instrução Normativa $n^{0} 01$, de 7 de março de 2005 (*). Brasil: Ministério da Saúde; 2005 p. 1-4.

10. ATSDR. Public Health Assessment GUIDANCE MANUAL ( Update ). Atlanta; 2005. 
11. Vianna N a, Gonçalves D, Brandão F, de Barros RP, Amado Filho GM, Meire RO, et al. Assessment of heavy metals in the particulate matter of two Brazilian metropolitan areas by using Tillandsia usneoides as atmospheric biomonitor. Environ Sci Pollut Res Int [Internet]. 2011 Mar [cited 2014 Nov 16];18(3):416-27. Available from: http://www.ncbi.nlm.nih.gov/pubmed/20798993

12. Vianna NA, Malm O, Campos L, Alves E, Lino A, Saldiva PHN. Elemental and Morphological Analysis of Particulate Matter in Salvador, BA, Brazil : Urban Air Monitoring Using Biomonitor Phase 2. 2014 International Society of Environmental Epidemiology Conference. Seattle: Environmental Health Perspectives; 2014. p. Abstract number 2537 ID P3-797.

13. ATSDR. Tools and Techniques for Effective Health Risk Communication. 2001.

14. Moreno AR. artículo original El estado del arte de la comunicación de riesgos en la región de América Latina State of the Art of Risk Communication in Latin America. 2011;1:52-68.

15. Ministerio do Meio Ambiente. Resolução do CONAMA. Brasil: CONAMAConselho Nacional do Meio Ambiente; 1990 p. 342-6.

16. Hoek G, Krishnan RM, Beelen R, Peters A, Ostro B, Brunekreef B, et al. Longterm air pollution exposure and cardio- respiratory mortality: a review. Environ Heal. 2013;12(43):2-16.

17. Beelen R, Stafoggia M, Raaschou-Nielsen O, Andersen ZJ, Xun WW, Katsouyanni $\mathrm{K}$, et al. Long-term Exposure to Air Pollution and Cardiovascular Mortality: An Analysis of 22 European Cohorts. Epidemiology [Internet]. 2014 Feb 28 [cited 2014 Mar 19];25(3):368-78. Available from: http://www.ncbi.nlm.nih.gov/pubmed/24589872

18. Brucker N, Charão MF, Moro AM, Ferrari P, Bubols G, Sauer E, et al. Atherosclerotic process in taxi drivers occupationally exposed to air pollution and co-morbidities. Environ Res [Internet]. Elsevier; 2014 Mar 14 [cited 2014 Apr 2];131C:31-8. Available from: http://www.ncbi.nlm.nih.gov/pubmed/24637182

19. Levy I, Mihele C, Lu G, Narayan J, Brook JR. Evaluating multipollutant exposure and urban air quality: pollutant interrelationships, neighborhood variability, and nitrogen dioxide as a proxy pollutant. Environ Health Perspect [Internet]. 2014 Jan;122(1):65-72. Available from: http://www.pubmedcentral.nih.gov/articlerender.fcgi? $\operatorname{artid}=3888565 \&$ tool=pmcent rez\&rendertype $=$ abstract

20. Braga ALF, Zanobetti A, Schwartz J. The Effect of Weather on Respiratory and Cardiovascular Deaths in 12 U.S. Cities. Environ Health Perspect. 2002;110(9):859-63. 
21. Atkinson RW, Kang S, Anderson HR, Mills IC, Walton H a. Epidemiological time series studies of PM2.5 and daily mortality and hospital admissions: a systematic review and meta-analysis. Thorax [Internet]. 2014 Apr 4 [cited 2014 Apr 15];1-6. Available from: http://www.ncbi.nlm.nih.gov/pubmed/24706041

22. Bell ML, Ebisu K, Leaderer BP, Gent JF, Lee HJ, Koutrakis P, et al. Associations of PM2.5 Constituents and Sources with Hospital Admissions: Analysis of Four Counties in Connecticut and Massachusetts (USA) for Persons $\geq 65$ Years of Age. Environ Health Perspect [Internet]. 2014 Feb;122(2):138-44. Available from: http://www.pubmedcentral.nih.gov/articlerender.fcgi?artid=3915260\&tool=pmcent rez\&rendertype $=$ abstract

23. Brook RD, Rajagopalan S, Iii CAP, Brook JR, Bhatnagar A, Diez-roux A V, et al. Particulate Matter Air Pollution and Cardiovascular Disease An Update to the Scientific Statement From the American. Circulation. 2010;

24. Heo J, Schauer JJ, Yi O, Paek D, Kim H, Yi S-M. Fine Particle Air Pollution and Mortality. Epidemiology [Internet]. 2014 May [cited 2014 Apr 9];25(3):379-88. Available from: http://content.wkhealth.com/linkback/openurl?sid=WKPTLP:landingpage\&an=000 01648-201405000-00009

25. Pope III CA. Lung Cancer, Cardiopulmonary Mortality, and Long-term Exposure to Fine Particulate Air Pollution. Jama [Internet]. 2002 Mar 6 [cited 2014 May 8];287(9):1132. Available from: http://jama.jamanetwork.com/article.aspx?doi=10.1001/jama.287.9.1132

26. Vieira SE, Stein RT, Ferraro A, Pastro LD, Cosme S, Lemos M, et al. Urban Air Pollutants Are Significant Risk Factors for Asthma and Pneumonia in Children: The Influence of Location on the Measurement of Pollutants \&. Arch Bronconeumol. 2012;48(11):389-95.

27. Hamra GB, Guha N, Cohen A, Laden F, Raaschou-nielsen O, Samet JM, et al. Outdoor Particulate Matter Exposure and Lung Cancer : Environ Health Perspect. 2014;(January).

28. Gouveia N, Freitas CU, Martins LC, Marcilio IO. Hospitalizações por causas respiratórias e cardiovasculares associadas à contaminação atmosférica no Município de São Paulo, Brasil. Cad Saude Publica. 2006;22(12):2669-77.

29. Arbex MA, Santos UDP, Martins LC, Hilário P, Saldiva N, Alberto L, et al. Air pollution and the respiratory system. J Bras Pneumol. 2012;38(July):643-55.

30. Braga ALF, Pereira LAA, Procópio M, André PA, Saldiva PHN. Associação entre poluição atmosférica e doenças respiratórias e cardiovasculares na cidade de Itabira , Minas Gerais , Brasil Association between air pollution and respiratory and cardiovascular diseases in Itabira, Minas Gerais. Cad Saude Publica. 2007;23(4):570-8. 
31. Arbex MA, Santos UDP, Martins LC, Saldiva PHN, Amador LAA, Braga LAF. A poluição do ar e o sistema respiratório. J Bras Pneumol. 2012;38(5):643-55.

32. Schwartz J, Morris R. Air pollution and hospital admissions for cardiovascular disease in Detroit, Michigan. Am J Epidemiol. 1995;1(142):23-35.

33. Saldiva PHN, Clarke R., Coull BA, Stearns JL, Murthy KGG, Diaz E, et al. Lung inflammation induced by concentrated ambient air particles is related to particle composition. Am J Respir Crit Care. 2002;165:1610-7.

34. Saldiva PHN, Pope III CA, Schwartz J, Dockery DW, Lichtenfels AJ, Salge JM. Air pollution and mortality in elderly people: a time-series study in Sao Paulo, Brazil. Arch Environ Heal. 1995;50(2):159-63.

35. Saldiva PHN, King M, Delmonte VLC, Macchione M, Parada MAC, Daliberto ML. Respiratory alterations due to urban air pollution an experimental study in rats. Environ Res. 1992;57:19-33.

36. Brook RD, Franklin B, Cascio W, Hong Y, Howard G, Lipsett M, et al. Air pollution and cardiovascular disease: a statement for healthcare professionals from the Expert Panel on Population and Prevention Science of the American Heart Association. Circulation [Internet]. 2004 Jun 1 [cited 2014 Nov 10];109(21):265571. Available from: http://www.ncbi.nlm.nih.gov/pubmed/15173049

37. Polosa R, Salvi S. Particulate air pollution from motor vehicles: A putative proallergic hazard? Can Respir J. 1999;6(5):2-7.

38. McCreanor J, Cullinan P, Nieuwenhuijsen MJ, Stewart-Evans J, Malliarou E, Jarup $\mathrm{L}$, et al. Respiratory effects of exposure to diesel traffic in persons with asthma. $\mathrm{N}$ Engl J Med [Internet]. 2007 Dec 6;357(23):2348-58. Available from: http://www.ncbi.nlm.nih.gov/pubmed/18057337

39. Dominici F, Peng RD, Bell ML, Pham L, McDermott A, Zeger SL. Fine particulate air pollution and hospital admission for cardiovascular and respiratory diseases. Jama. 2006;295:1127-34.

40. Donaldson K, Gilmour MI, MacNee W. Asthma and PM 10. Respir Res. 2000;1:12-5.

41. HEI Diesel Epidemiology Project. 2012 p. 2012.

42. Farhat SCL, Paulo RLP, Shimoda, T. M., Conceição GMS, Lin C, Braga ALF, Warth, M. P. N. and Saldiva P. Efecct of air pollution on pediatric respiratory emergency room visits and hospital admissions. J Med Biol Res. 2005;38:227-35.

43. Ostro B, Feng W, Broadwin R, Green S, Lipsett M. The effects of components of fine particulate air pollution on mortality in California: results from CALFINE. Environ Health Perspect. 2007;115:13-9. 
44. Laden F, Neas L, Dockery D, Schwartz J. Association of fine particulate matter from different sources with daily mortality in six U.S. cities. Environ Health Perspect. 2000;108:941-7.

45. Andre P, Veras M, Miraglia S, Saldiva P. Lean diesel technology and human health: a case study in six Brazilian metropolitan regions. Clinics [Internet]. 2012 Jun 12 [cited 2014 Nov 17];67(6):639-45. Available from: http://www.ncbi.nlm.nih.gov/pmc/articles/PMC3370317/

46. Nardocci AC, Freitas CU, Ponce de Leon ACM, Junger WL, Gouveia, Nelson C. Poluição do ar e doenças respiratórias e cardiovasculares: estudo de séries temporais em Cubatão , São Paulo , Brasil Air pollution and respiratory and cardiovascular diseases : a time series study in Cubatão, São Paulo State , Brazil La contaminación d. Cad Saude Publica. 2013;29(9):1867-76.

47. WHO. Burden of disease from Household Air Pollution for 2012 Summary of results. 2014.

48. Bell ML, Dominici FKE, Zeger, S. L., Samet JM. Spatial and Temporal Variation in PM2.5 Chemical Composition in the United States for Health Effects Studies. Environ Health Perspect. 2007;115:989-96.

49. Nandasena S, Wickremasinghe AR, Lee K, Sathiakumar N. Indoor Fine Particle (PM2.5 ) Pollution Exposure due to Secondhand Smoke in Selected Public Places of Sri Lanka Sumal. Am J Ind Med. 2013;55(12):1129-36.

50. Moja SJ, Mnisi JS, Nindi MM, Okonkwo JO. Characterization of PM10 samples from Vanderbijlpark in South Africa. J Environ Sci Health A Tox Hazard Subst Environ Eng [Internet]. Taylor \& Francis; 2013 Jan [cited 2014 Mar 15];48(1):99107. Available from: http://dx.doi.org/10.1080/10934529.2012.707859

51. Pietrodangelo A, Pareti S, Perrino C. Improved identification of transition metals in airborne aerosols by SEM-EDX combined backscattered and secondary electron microanalysis. Environ Sci Pollut Res Int [Internet]. 2014 Mar [cited 2014 Mar 15];21(6):4023-31. Available from: http://www.ncbi.nlm.nih.gov/pubmed/24194417

52. Santacatalina M, Reche C, Minguillón MC, Escrig A, Sanfelix V, Carratalá A, et al. Impact of fugitive emissions in ambient PM levels and composition: a case study in Southeast Spain. Sci Total Environ [Internet]. 2010 Oct 1 [cited 2014 Feb 25];408(21):4999-5009. Available from: http://www.sciencedirect.com/science/article/pii/S0048969710007345

53. Liati A, Brem BT, Durdina L, Vo M, Arroyo Y, Dasilva R, et al. Electron Microscopic Study of Soot Particulate Matter Emissions from Aircraft Turbine Engines. Environ Sci Technol. 2014; 
54. Kaegi R, Gasser P. Aplicattion of the focused ion beam technique in aerosol science: detailed investigation of selected, airborne particles. $\mathrm{J}$ Microsc. 2006;224:140-5.

55. Sousa SI V, Pires JCM, Martins EM, Fortes JDN, Alvim-Ferraz MCM, Martins FG. Short-term effects of air pollution on respiratory morbidity at Rio de Janeiro-PART I: Air pollution assessment. Environ Int [Internet]. Elsevier Ltd; 2012 Sep [cited 2014 Nov 17];44:18-25. Available from: http://www.ncbi.nlm.nih.gov/pubmed/22387227

56. Sousa SI V, Pires JCM, Martins EM, Fortes JDN, Alvim-Ferraz MCM, Martins FG. Short-term effects of air pollution on respiratory morbidity at Rio de Janeiro-Part II: health assessment. Environ Int [Internet]. Elsevier Ltd; 2012 Aug [cited 2014 Nov 17];43:1-5. Available from: http://www.ncbi.nlm.nih.gov/pubmed/22446713

57. Arbex MA, Martins LC, de Oliveira RC, Pereira LAA, Arbex FF, Cançado JED, et al. Air pollution from biomass burning and asthma hospital admissions in a sugar cane plantation area in Brazil. J Epidemiol Community Health [Internet]. 2007 May [cited 2014 Nov 14];61(5):395-400. Available from: http://www.pubmedcentral.nih.gov/articlerender.fcgi?artid=2465679\&tool=pmcent rez\&rendertype $=$ abstract

58. Krewski D, Burnett R, Jerrett M, Pope CA, Rainham D, Calle E, et al. Mortality and long-term exposure to ambient air pollution: ongoing analyses based on the American Cancer Society cohort. J Toxicol Environ Health A [Internet]. 2005 [cited 2014 Nov 20];68(13-14):1093-109. Available from: http://www.ncbi.nlm.nih.gov/pubmed/16024490

59. Ishii H, Hayashi S, Hogg $\mathrm{CH}$, Fujii $\mathrm{T}$, Goto $\mathrm{Y}$, Sakamoto $\mathrm{N}$, et al. Alveolar macrophage-epithelial cell interaction following exposure to atmospheric particles induces the release of mediators involved in monocyte mobilization and recruitment. Respir Res. 2005;6:87-98.

60. Nazariah SSN, Juliana J, Abdah $\mathrm{M}$ a. Interleukin-6 via sputum induction as biomarker of inflammation for indoor particulate matter among primary school children in Klang Valley, Malaysia. Glob J Health Sci [Internet]. 2013 Jul [cited 2014 Sep 25];5(4):93-105. Available from: http://www.ncbi.nlm.nih.gov/pubmed/23777726

61. Gibbs AR, Pooley FD. Analysis and interpretation of inorganic mineral particles in “lung" tissues. Thorax. 1996;51:327-34.

62. Novaes P, do Nascimento Saldiva PH, Kara-José N, Macchione M, Matsuda M, Racca L, et al. Ambient levels of air pollution induce goblet-cell hyperplasia in human conjunctival epithelium. Environ Health Perspect [Internet]. 2007 Dec [cited 2014 Mar 9];115(12):1753-6. Available from: http://www.pubmedcentral.nih.gov/articlerender.fcgi?artid=2137119\&tool=pmcent rez\&rendertype $=$ abstract 
63. Torriceli AAM, Novaes P, Matsuda M, Alves MiR, Monteiro MLR. Ocular surface adverse effects of ambient levels of air pollution Efeitos adversos na superfície ocular relacionados à poluição ambiental. Arq Bras Oftalmol. 2011;74(5):377-82.

64. Chang C-J, Yang H-H, Chang C-A, Tsai H-Y. Relationship between air pollution and outpatient visits for nonspecific conjunctivitis. Invest Ophthalmol Vis Sci [Internet]. 2012 Jan [cited 2014 Nov 24];53(1):429-33. Available from: http://www.ncbi.nlm.nih.gov/pubmed/22205603

65. Saha a, Kulkarni PK, Shah a, Patel M, Saiyed HN. Ocular morbidity and fuel use: an experience from India. Occup Environ Med [Internet]. 2005 Jan [cited 2014 Nov 24];62(1):66-9. Available from: http://www.pubmedcentral.nih.gov/articlerender.fcgi?artid=1740843\&tool=pmcent rez\&rendertype $=$ abstract

66. WHO. Global surveillance, prevention and control of chronic respiratory diseases : a comprehensive approach. Geneve; 2007 May p. 490.

67. Schluger NW, Koppaka R. Lung disease in a global context. A call for public health action. Ann Am Thorac Soc [Internet]. 2014 Mar [cited 2014 Oct 28];11(3):407-16. Available from: http://www.ncbi.nlm.nih.gov/pubmed/24673697

68. Gratt LB. Glossary of Risk Analysis Terms Risk Analysis Glossary: A - Z [Internet]. Society for Risk Analysis; Available from: http://www.sra.org/sites/default/files/docs/SRA_Glossary.pdf

69. Tinker TL, Collins CM, King HS, Hoover MD. Assessing risk communication effectiveness: perspectives of agency practitioners. J Hazard Mater. 2000;B73:117-27.

70. Freitas CM De. Avaliação de Riscos como Ferramenta para a Vigilância Ambiental em Saúde. Inf Epidemiológico do SUS. 2002;11:227-39.

71. Barbosa EM. Avaliação de Impacto à Saúde como Instrumento para o Licenciamento Ambiental na Indústria de Petróleo. ENSP, FIOCRUZ; 2010.

72. Cox T, Lowrie K, Avens T, Guikema S. Foundational issues in risk analysis. Risk Anal [Internet]. 2014 Jul [cited 2014 Oct 8];34(7):1161-3. Available from: http://www.ncbi.nlm.nih.gov/pubmed/25074020

73. Lavis JN, Boyko J, Oxman AD, Lewin S, Fretheim A. 14 . Organizar e utilizar os diálogos da política para apoiar a política de saúde baseadas em evidências. $2009 ; 1-19$.

74. Panisset U, Koehlmoos TP, Alkhatib AH, Pantoja T, Singh P, Kengey-Kayondo J, et al. Implementation research evidence uptake and use for policy-making. Health Res Policy Syst [Internet]. 2012 Jan [cited 2014 Oct 13];10:20. Available from: http://www.pubmedcentral.nih.gov/articlerender.fcgi? artid=3443065\&tool=pmcent rez\&rendertype $=$ abstract 
75. Lavis JN, Oxman AD, Lewin S, Fretheim A. Introdução. Heal Res Policy Syst. 2009;7(1):1478-4505.

76. Beck U. Sociedade de Risco - Rumo a uma outra modernidade. 10th ed. Editora 34, editor. 2010.

77. Ribeiro JUR. O correto uso do papel higienico. Salvador; 2014 Jul 19;1. Available from: www.atarde.com.br

78. Frieden TR. Government's Role in Protecting Health and Safety. N Engl J Med. 2013;April, 18:1-4.

79. Almeida-Filho N De, Coutinho D. Causalidade, contingência, complexidade: o futuro do conceito de risco. Physis Rev Saúde Coletiva [Internet]. 2007 Apr;17(1):95-137. Available from: http://www.scielo.br/scielo.php?script=sci_arttext\&pid=S0103$73312007000100007 \& \operatorname{lng}=$ pt\&nrm=iso\&tlng=pt

80. Johns DO, Stanek LW, Walker K, Benromdhane S, Hubbell B, Ross M, et al. Review Practical Advancement of Multipollutant Scientific and Risk Assessment Approaches for Ambient Air Pollution. 2012;(9):1238-42.

81. Kioumourtzoglou M-A, Coull B a, Dominici F, Koutrakis P, Schwartz J, Suh H. The impact of source contribution uncertainty on the effects of source-specific PM2.5 on hospital admissions: a case study in Boston, MA. J Expo Sci Environ Epidemiol [Internet]. Nature Publishing Group; 2014 Jul [cited 2014 Nov 10];24(4):365-71. Available from: http://www.pubmedcentral.nih.gov/articlerender.fcgi?artid=4063325\&tool=pmcent rez\&rendertype $=$ abstract

82. Eftim SE, Samet JM, Janes H, McDermott A, Dominici F. Fine particulate matter and mortality: a comparison of the six cities and American Cancer Society cohorts with a medicare cohort. Epidemiology [Internet]. 2008 Mar [cited 2014 Nov 17];19(2):209-16. Available from: http://www.ncbi.nlm.nih.gov/pubmed/18223484

83. Chess C, Salomone KL, Sandman PM. Risk communication activities of state health agencies. Am J Public Health [Internet]. 1991 Apr;81(4):489-91. Available from: http://ajph.aphapublications.org/doi/abs/10.2105/AJPH.81.4.489

84. Society AC. Understanding Risk Analysis. Society AC, editor. Internet Edition; 1998.

85. Ministério da Saúde. Avaliação de Risco por Resíduos Perigosos no condomínio Barão de Mauá , Município de Mauá / SP. Revista de saúde pública. 2002.

86. Wachinger G, Renn O, Begg C, Kuhlicke C. The risk perception paradox-implications for governance and communication of natural hazards. Risk Anal [Internet]. 2013 Jun [cited 2014 Apr 4];33(6):1049-65. Available from: http://www.ncbi.nlm.nih.gov/pubmed/23278120 
87. United States Environmental Protection Agency U. Urban Sprawl Modeling, Air Quality Monitoring, and Risk Communication : The Northeast Ohio Project. 2002.

88. Miraglia SGEK, Gouveia N. Custos da poluição atmosférica nas regiões metropolitanas brasileiras. Cien Saude Colet [Internet]. 2014 Oct [cited 2014 Nov 18];19(10):4141-7. Available from: http://www.scielo.br/scielo.php?script=sci_arttext\&pid=S1413$81232014001004141 \& \operatorname{lng}=$ pt\&nrm=iso\&tlng=en

89. Miraglia S, Saldiva P, Böhm G. An evaluation of air pollution health impacts and costs in São Paulo, Brazil. Env Manag. 2005;35(5):667-76.

90. Fátima B, Oliveira A De, Ignotti E, Artaxo P, Hilário P, Junger WL, et al. Risk assessment of PM 2. 5 to child residents in Brazilian Amazon region with biofuel production. Environ Heal. 2012;11:64:1-11.

91. Hammond D, Conlon K, Barzyk T, Chahine T, Zartarian V, Schultz B. Assessment and application of national environmental databases and mapping tools at the local level to two community case studies. Risk Anal [Internet]. 2011 Mar [cited 2014 Nov 21];31(3):475-87. Available from: http://www.ncbi.nlm.nih.gov/pubmed/21077925

92. Esworthy R. Air Quality: EPA's 2013 Changes to the Particulate Matter ( PM ) Standard. 2013.

93. EPA. Policy Assessment for the Review of the Particulate Matter National Ambient Air Quality Standards. 2011.

94. Ministério do Meio Ambiente. Padrões nacionais de qualidade do ar - Resolução CONAMA. Brasil; 1990 p. 1990.

95. Estado de São Paulo. Decreto $\mathrm{N}^{\mathrm{o}}$ 59.113, de 23 de abril 2013. Brasil; 2013.

96. Indices da Qualidade do Ar [Internet]. Cetrel. 2014 [cited 2014 Nov 18]. Available from: http://www.cetrel.com.br/entendendoAQualidadeDoAr.aspx

97. Gold DR, Samet JM, Pollution A, Disease H. Air Pollution, Climate, and Heart Disease. Circulation. 2013;

98. Olmo NRS, Saldiva PHDN, Braga ALF, Lin CA, Santos UDP, Pereira LAA. A review of low-level air pollution and adverse effects on human health: implications for epidemiological studies and public policy. Clinics [Internet]. 2011 [cited 2014 Oct 21];66(4):681-90. Available from: http://www.scielo.br/scielo.php?script=sci_arttext\&pid=S1807$59322011000400025 \& \operatorname{lng}=$ en\&nrm=iso\&tlng=en

99. Brilhante OM, Caldas LQ de A. Gestão e avaliação de risco em saúde ambiental Ogenis Magno Brilhante. 2004. 
100. Vianna NA, Andrade LR De, Souza-machado A, Saldiva PHN. Uma proposta de intersetorialidade para investigar poluição atmosférica e doenças respiratórias. Gaz Medica da Bahia. 2008;78 (suplem:86-92.

101. Barcellos C, Quitério LAD. Vigilância ambiental em saúde e sua implantação no Sistema Único de Saúde. Rev Saude Publica. 2006;40(1).

102. Briggs D, Corvalan C, Nurminen M. Linkage methods for enviroment and health analysis - General Guidelines. 1996.

103. Wotzasek J, Villardi R, Cristina L, Bueno PC, Zaitune MP, Rodrigues JC, et al. Vigilância em saúde ambiental de populações expostas à poluição atmosférica no Brasil - um modelo em construção. 2011;19(4).

104. Ministério da Saúde V. Manual de Instruções - Unidade Sentinela - 2013. 2013.

105. Han X, Naeher PL. A review of traffic-related air pollution exposure assessment studies in the developing world. Environ Int. 2005;37:1-15.

106. Lyra DGP. Modelo Integrado de Gestão da Qualidade do Ar da Região Metropolitana. Universidade Estadual de Campinas - UNICAMP; 2008.

107. IBGE. Instituto Brasileiro de Geografia e Estatística. PNUD [Internet]. 2014 [cited 2014 Nov 12]. Available from:

http://cidades.ibge.gov.br/xtras/perfil.php?codmun=292740

108. PNUD. IDH Indice de Desenvolvimento Humano. 2000. p. 0-2.

109. DETRAN BAHIA. Sistema Renavam / Módulo Veículos [Internet]. Salvador; 2014. Available from: www.detran.detran.ba.gov.br/documents/

110. Schiffman RM, Christianson MD, Jacobsen G, Hirsch JD, Reis BL. Reliability and Validity of the Ocular Surface Disease Index. Arch Ophthalmol. 2000;118(May):615-21.

111. Husk GI, Weishampel, J. F., Schlesinger WH. Mineral dynamics in Spanish moss, Tillandsia usneoides L (Bromeliaceae) from Central Flórida, USA. Sci Total Environ. 2003;321:165-72.

112. Brighigna L, Papini A, Most S, Cornia A, Bocchini P, Galleti G. The use of tropical bromeliads (Tillandsia spp) for monithoring atmospheric pollution in the town of Florence, Italy. Rev Biol Trop. 2002;50:574-84.

113. Amado Filho, M. G, Andrade LR, Farina M, Malm O. Hg localization in Tillandsia usneoides L. (Bromeliaceae), an atmospheric biomonitor. Atmos Environ. 2001;36:881-7. 
114. Calasans CF, Malm O. Elemental mercury contamination survey in a chlor-alkali plant by the use of transplanted Spanish moss, Tillandsia usneoides ( L .). Sci Total Environ. 1997;208:165-77.

115. Sumita NM, Mendes ME, Macchione M, Guimarães, E. T., Lichtenfels, A. J. F. C., Lobo DA, Saldiva PHN. Tradescantia pallida cv. purpurea boom in the characterization of air pollution by accumulation of trace elements. J Air Waste Manag. 2003;53:574-9.

116. Figueiredo AMG, Nogueira $S^{\text {a }}$, Saiki M, Milian FMD. Assesment of atmospheric metallic pollution in the metropolitan region of São Paulo, Brazil, employing Tillandsia usneoides L. as biomonitor. Environ Pollut. 2007;145:279-92.

117. Vasilakos C, Pateraki S, Veros D, Maggos T, Michopoulos J, Saraga D, et al. Temporal determination of heavy metals in PM2,5 aerosols in a suburban site of Athens, Greece. J Atmos Chem. 2007;57:1-17.

118. Hacon SDS, Artaxo P, Carlos A, Ponce M. Air pollution and hospital admissions for respiratory diseases in the subequatorial Amazon : a time series approach Poluição do ar e admissões hospitalares por doenças respiratórias na Amazônia subequatorial : abordagem de séries temporais. Cad Saude Publica. 2010;26(4):747-61.

119. Seed L, Wolseley P, Gosling L, Davies L, Power S a. Modelling relationships between lichen bioindicators, air quality and climate on a national scale: results from the UK OPAL air survey. Environ Pollut [Internet]. Elsevier Ltd; 2013 Nov [cited 2014 Apr 24];182:437-47. Available from: http://www.ncbi.nlm.nih.gov/pubmed/23992684

120. Carreras H a, Wannaz ED, Pignata ML. Assessment of human health risk related to metals by the use of biomonitors in the province of Córdoba, Argentina. Environ Pollut [Internet]. 2009 Jan [cited 2014 Nov 17];157(1):117-22. Available from: http://www.ncbi.nlm.nih.gov/pubmed/18771831

121. Paoletti L, Berardis BDE, Arrizza L. Inquinamento da polveri e da particolato fino in siti con differenti caratteristiche ambientali. Ann Ist Super Sanità. 2003;39(3):381-5.

122. Zereini F, Alt F, Messerschmidt, J., Wiseman C, Feldmann I, Bohlen A V., Müller $\mathrm{J}$, et al. Concentration and distribution of heavy metals in urban airborne particulate matter in Frankfurt am Main, Germany. Environ Sci. 2005;39:2983-9.

123. Thomaidis S, Bakeas E, Siskos P. Characterization of lead, cadmium, arsenic and nickel in $\mathrm{PM}(2.5)$ particles in the Athens atmosphere, Greece. Chemosphere. 2003;52(6):959-66. 
124. Amato F, Cassee FR, Denier van der Gon H a C, Gehrig R, Gustafsson M, Hafner $\mathrm{W}$, et al. Urban air quality: The challenge of traffic non-exhaust emissions. $\mathbf{J}$ Hazard Mater [Internet]. Elsevier B.V.; 2014 Apr 29 [cited 2014 May 27];275C:31-6. Available from: http://www.ncbi.nlm.nih.gov/pubmed/24837462

125. Bailar JC, Safety O, Agency I. Diesel Emissions and Lung Cancer: Epidemiology and Quantitative Risk Assessment [Internet]. New directions for youth development. USA; 2013 Dec p. 5-8. Available from: http://www.ncbi.nlm.nih.gov/pubmed/24589852

126. Burnett R, Brook J, Dann T, Delocla C, Philips O, Cakmak S. Association between particulate- and gasphase components of urban air pollution and daily mortality in eight Canadian cities. Inhal Toxicol. 2000;12(S):15-39.

127. Lim SS, Vos T, Flaxman AD, Danaei G, Shibuya K, Adair-Rohani H, et al. A comparative risk assessment of burden of disease and injury attributable to 67 risk factors and risk factor clusters in 21 regions, 1990-2010: a systematic analysis for the Global Burden of Disease Study 2010. Lancet [Internet]. 2012 Dec 15 [cited 2014 Jul 10];380(9859):2224-60. Available from: http://www.ncbi.nlm.nih.gov/pubmed/23245609

128. Solé D, Camelo-Nunes, I, Wandalsen GF, Mallozi MC. A asma na criança e no adolescente brasileiro : contribuição do International Study of Asthma and Allergies in Childhood ( ISAAC ). Rev Paul Pediatr. 2014;32(1):114-25.

129. Franco R, Santos AC, do Nascimento HF, Souza-Machado C, Ponte E, SouzaMachado A, et al. Cost-effectiveness analysis of a state funded programme for control of severe asthma. BMC Public Health [Internet]. 2007 Jan [cited 2014 Nov 21];7:1-8. Available from: http://www.pubmedcentral.nih.gov/articlerender.fcgi?artid=1896159\&tool=pmcen trez\&rendertype $=$ abstract

130. Prefeitura Municipal de Salvador. EMTURSA Indicadores do Carnaval 2007. Salvador; 2007 p. 28.

131. Thiollent M, Silva GO. Metodologia de pesquisa-ação na área de gestão de problemas ambientais. R Eletr Com Inf Inov Saúde. 2007;93-100. 


\section{APENDICES}

Matérias de jornais e noticias 


\section{Estudo aponta bairro do Comércio como mais poluído de Salvador}

Um estudo realizado por pesquisadores da Universidade Federal da Bahia (Ufba) revelou que o bairro do Comércio é o bairro que tem o ar mais poluído em Salvador, de acordo com informações da Agência de Notícias Ciência e Cultura da Ufba. A pesquisa, feita também na Universidade Federal do Rio de Janeiro (UFRJ,) propôs detectar a presença de metais pesados nas partículas que circulam no ar da capital baiana e fluminense. Coordenado em Salvador pela farmacêutica Nelzair Vianna, da Secretaria Municipal de Saúde, em parceira com professor do Instituto de Ciências Biomédicas da UFRJ, Leonardo de Andrade, o biomonitoramento utilizou a bromélia conhecida como barba-de-velho para verificar a concentração de chumbo, cromo, cádmio, cobre e zinco. As plantas ficaram expostas durante 90 dias por ano, entre 2006 e 2008, divididas nas estações verão e inverno, geralmente, a 2,5 m de altura, para absorver os componentes que poderiam ser inalados pelas pessoas. Foram monitoradas sete regiões de Salvador (Subúrbio Ferroviário, Comércio, Brotas, Dique, Pituba, Barra e Stella Maris). As concentrações de chumbo mais acentuadas foram encontradas na Pituba durante o verão. Apesar de ser considerado o ar menos poluído das regiões pesquisadas, Stella Maris apresentou elevadas concentrações de cádmio juntamente com a Barra. "Nos surpreendeu. É uma área com trafego menos intenso, no entanto poderia estar relacionado com a proximidade ao aeroporto, já que o combustível utilizado pelas aeronaves contém cádmio na sua composição", explica Nelzair. Neste ano, foi instalada em Salvador uma rede de monitoramento do ar com dez estações em funcionamento, sistema exigido para todas as cidades-sede da Copa do Mundo de 2014. 
Carnaval Sustentável

Ônibus rodarão com B5 no Carnaval

Todo o sistema de ônibus de Salvador vai funcionar no Carnaval com cinco por cento de biodiesel (B5) misturado ao diesel derivado do petróleo, em vez dos dois por cento já utilizados atualmente, o B2.

O fornecimento do produto para o transporte coletivo no período da festa foi garantido pela Petrobrás à Secretaria de Meio Ambiente do Estado, às Superintendências de Meio Ambiente e de Transporte Público da Prefeitura e ao Sindicato das Empresas de Transporte de Passageiros de Salvador.

A iniciativa constitui um avanço importante em relação ao ano passado, quando os trios elétricos e carros de apoio já funcionaram com o B5, e integra o esforço dos governos estadual e municipal para realizar um Carnaval sustentável em termos ambientais. Com 2.600 veículos, a frota de ônibus da capital baiana consome um total de 1,5 milhão de litros de combustível no período carnavalesco.

Como parte do programa implementado para tornar o Carnaval baiano sustentável, 33 mil mudas de árvores já em estágio de desenvolvimento serão plantadas em parques públicos e na área da Refinaria Landulpho Alves. O material será financiado pela Petrobrás e pela Secretaria de Meio Ambiente do Estado e o plantio ocorrerá antes mesmo da festa.

\section{Monitoramento}

Especialistas no assunto afirmam que, enquanto o biodiesel reduz as emissões de monóxido de carbono, as árvores contribuem para neutralizar os efeitos do material que ainda chega à atmosfera.

O professor Paulo Saldívar, da Universidade de São Paulo (USP), considerado uma das maiores autoridades do País em poluição atmosférica, calcula que uma hora de exposição atrás de um trio elétrico equivale a um dia inteiro de exposição à poluição de São Paulo.

No ano passado, ele trabalhou no Carnaval de Salvador com uma equipe da USP, Universidade Federal do Rio de Janeiro (UFRJ) e da Fiocruz e está voltando este ano para monitorar as emissões nos principais circuitos da festa.

O monitoramento é feito, por um lado, com a exposição de bromélias, plantas que funcionam como um "filtro" de ar, retendo o material particulado, e, por outro, pela utilização de nefelômetros, que são aparelhos que detectam a quantidade de partículas presentes no ar, em dimensões suficientes para serem absorvidas pelo sistema respiratório humano.

A idéia é repetir esse trabalho ano a ano, a fim de produzir uma série histórica que permita chegar a conclusões. Os resultados, porém, podem ser sentidos mais cedo, com a redução das doenças respiratórias registradas pós-Carnaval e do fluxo de pessoas que procuram os postos de saúde e os serviços de emergência dos hospitais. Um ganho em todos os sentidos, inclusive para os cofres públicos. 


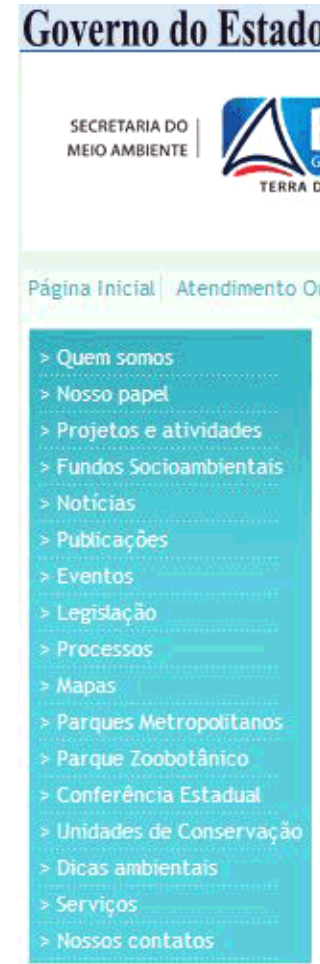

\section{Notícias}

\section{Métodos de monitoramento do ar no Carnaval serão apresentados amanhã}

O novo método para monitorar a qualidade do ar nos circuitos do Carnaval de Salvador 2008 será conhecido amanhã (dia 30 ), às 17 horas, no Auditório do Restaurante Aice Zushi, na Av. Paulo VI (Pituba). A novidade será apresentada pelo pesquisador da Universidade de São Paulo (USP), o patologista Paulo Saldiva, pela bioquímica Nelzair Vianna e pelo secretário de Meio Ambiente e Recursos Hídricos do Estado (Semarh), Juliano Matos.

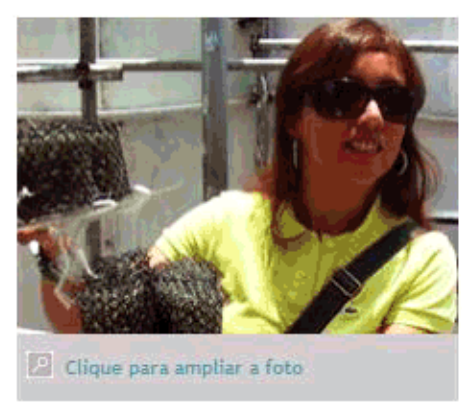

o dispositivo de tubo passivo é um monitor individual capaz de identificar a quantidade de dióxido de nitrogênio (NO2), gás emitido na atmosfera por meio da combustão do diesel, utilizado nos trios elétricos, carros de apoio, caminhões de lixo, ônibus urbanos e outros veículos nos circuitos da Folia.

Além desse, será apresentado ainda o aparelho mecânico nefelômetro, cedido pelo Laboratório de Poluição Atmosférica da USP, que faz a monitoração contínua de concentração de material particulado (poeira em suspensào), com capacidade para detectar o tamanho mínimo capaz de penetrar no trato respiratório.

As bromélias Tillandsia Usneoides, que também são utilizadas em técnicas de biomonitoramento do ar, serão trazidas do Jardim Botânico do Rio de Janeiro, pelo biólogo Leonardo Andrade, do Departamento de Histologia e Embriologia da Universidade Federal do Rio de Janeiro (UFRJ). As plantas, também conhecidas como barba-de-velho, retém em sua superfície escamosa partículas microscópicas de metais pesados e poluentes, capazes de afetar a saúde humana.

A pesquisa de monitoramento do ar durante o Carnaval de Salvador é uma ação pioneira da Secretaria de Meio Ambiente e Recursos Hídricos do Estado (Semarh), e pretende identificar 05 metais pesados e gases tóxicos na atmosfera da festa, ao longo de 25 quilômetros de vias, em trechos com pouca ventilação e muita queima de combustivel.

Ascom/Semarh - (71)3115-6289/3836

\section{$=-\triangle$ Bahia}

SEMA - Secretaria do Meio Ambiente - Governo do Estado da Bahia

Avenida Luís Viana Fitho, $3^{2}$ Avenida, $n^{\circ} 390$ - Plataforma IV - Ala Norte - CEP: 41.745-005 I Centro Administrativo da Bahia Salvador - Bahia - Brasil CNPJ: 05.467.476/0001-50 | Tel: 55 (Oxo71) 31156288 Fax.: 55 (Oxox71) 31153808 unw. meioambiente. ba.gov. br - Todos direitos reservados 


\section{- Revista de Pesquisa da FAPESP, Barba de velho mede poluição, maio 2011}

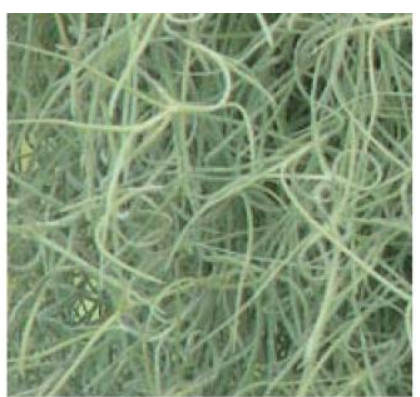

\section{Barba-de-velho mede poluição}

\section{Espécie de bromélia é usada para captar metais pesados no ar}

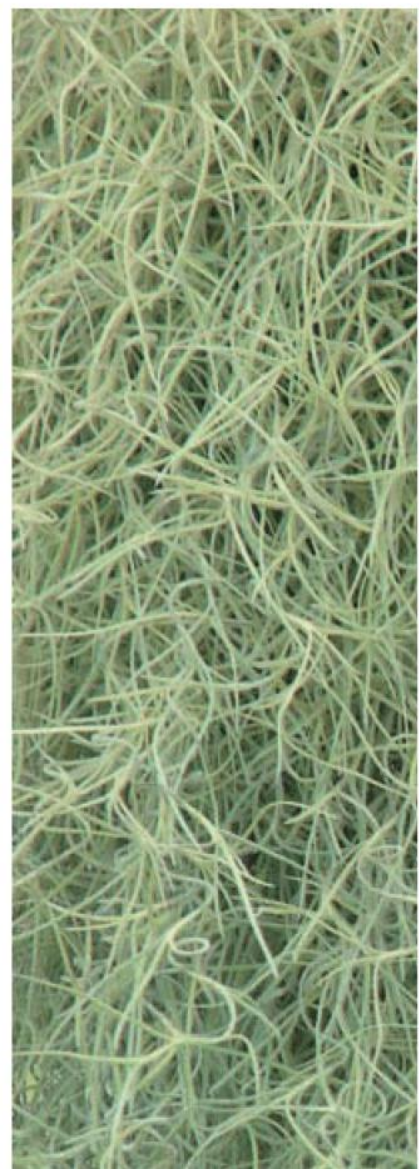

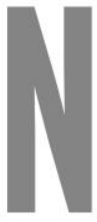

as grandes cidades há algo no ar além do oxigênio que respiramos. É o chamado material particulado, composto por minúsculos fragmentos de elementos químicos carregados principalmente de metais pesados causadores de estragos consideráveis à saúde, seja em problemas gastrointestinais, pulmonares ou hematológicos. Na tentativa de identificar essas partículas de forma barata e como alternativa aos equipamentos convencionais de monitoramento do ar, pesquisadores das universidades federais do Rio de Janeiro (UFRJ) e da Bahia (Ufba) usaram a bromélia conhecida como barba-de-velho (Tillandsia usneoides), espécie presente nas matas brasileiras, para estudar as concentrações de metais pesados no ar das cidades de Salvador e do Rio de Janeiro. A técnica, chamada de biomonitoramento atmosférico, ainda é experimental em centros de pesquisa de vários países. O estudo nas duas capitais brasileiras - coordenado pelo biólogo Leonardo Rodrigues de Andrade, professor do Instituto de Ciências Biomédicas da UFRJ, e pela farmacêutica Nelzair Araújo Vianna, da Secretaria Municipal de Saúde de Salvador provou que o material particulado atmosférico inalado pelas pessoas contém elementos tóxicos para a saúde humana nas duas cidades.

"Mostramos também que a Tillandsia usneoides indica a concentração de metais que estão presentes na fração do material particulado mais perigoso para a saúde", diz Andrade, que atualmente faz um pós-doutorado no National Institutes of Health (NIH), nos Estados Unidos. "Concluímos ainda que a principal fonte desses elementos nos locais estudados relaciona-se à poluição causada por veículos automotores." Segundo o pesquisador, antes do estudo realizado por eles não se sabia nada sobre a presença e concentrações de metais pesados nos locais estudados, principalmente em Salvador. "De certa forma, foi o nosso trabalho o primeiro a quantificar as concentrações de metais na atmosfera nos pontos pesquisados", assegura. "No Rio existe um monitoramento do material particulado nos locais que estudamos, mas não de metais pesados." 


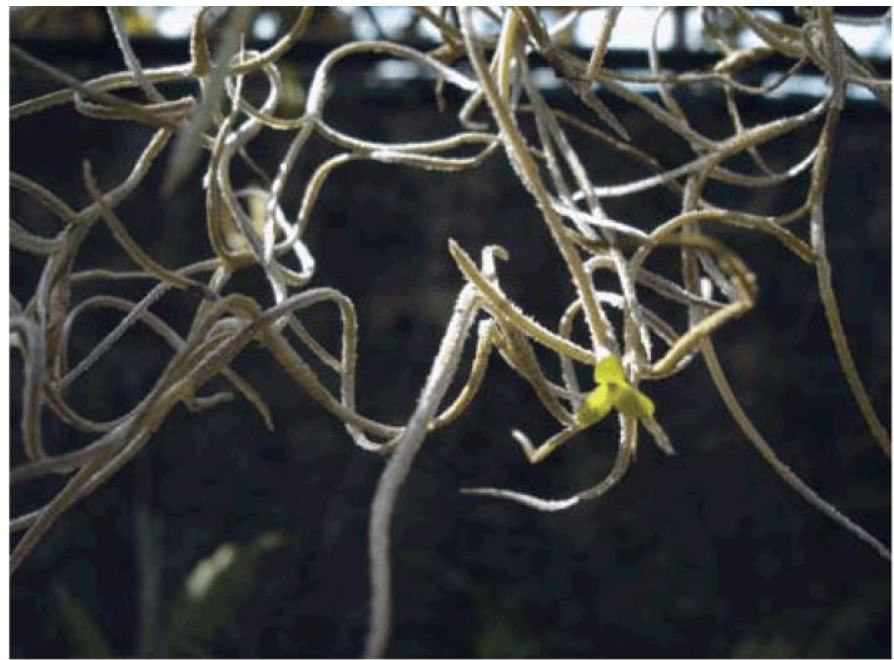

A Tillandsia adere ou fica pendurada em outras plantas, mas não é um parasita
Os pesquisadores usaram a bromélia Tillandsia usneoides para quantificar a presença de cinco elementos considerados extremamente tóxicos - cobre, cromo, cádmio, zinco e chumbo - em cinco locais distribuídos no estado do Rio de Janeiro, sendo três na capital, e em sete pontos na cidade de Salvador. Foram monitorados ainda dois locais sem poluição, para funcionar como controle de comparação: o Parque Nacional do Itatiaia (RJ) e a cidade de Cordeiro, na região serrana do Rio de Janeiro. "Escolhemos esses metais por serem encontrados em regiões consideradas poluídas", conta Andrade. Depois de 45 dias de exposição nos locais escolhidos, os pesquisadores recolheram amostras da barba-de-velho e as levaram para o laboratório. Lá, pedacinhos da planta foram analisados com técnicas de espectrofotometria de absorção atômica, microscopia eletrônica de varredura e microanálise de raios $\mathrm{X}$.

A equipe escolheu a bromélia barba-de-velho para os experimentos porque é uma espécie com fisiologia adaptada para sobreviver em ambientes quentes e secos e que já foi usada em alguns estudos na Argentina, na Itália, no estado da Flórida, nos Estados Unidos, e na Alemanha. No Brasil também foi utilizada na análise do ar de São Paulo, no início dos anos 2000, pela equipe da professora Mitiko Saiki, do Instituto de Pesquisas Energéticas e Nucleares (Ipen) (ver Pesquisa FAPESP $n^{\circ}$ 104). A bromélia é uma epífita que vive aderida ou pendurada em outras plantas, mas não como um parasita. Como não possui raízes de- senvolvidas, absorve água e nutrientes diretamente da atmosfera por meio de estruturas chamadas escamas, que recobrem todo seu corpo. "Essas escamas possuem grande habilidade de atrair e reter líquido", explica Andrade. O material particulado fica retido nas escamas $\mathrm{e}$ se acumula proporcionalmente ao tempo que a planta fica exposta ao ar.

No Rio de Janeiro foram encontrados índices de cromo, chumbo, cobre e zinco muito maiores nos pontos biomonitorados do que nos locais controles, onde o ar é limpo. O cádmio só foi mais elevado nas localidades de Jacarepaguá e São Gonçalo. Destaque para o zinco, que teve em São Gonçalo valores até 17 vezes maiores em relação a Itatiaia e a Cordeiro. Em Salvador, o panorama não foi diferente. Embora os valores de cádmio, cromo e chumbo tenham sido semelhantes nas duas cidades, os índices de zinco e cobre foram mais elevados no Rio."Um desdobramento de nossa pesquisa em Salvador foi a utilização dos dados como base científica para justificar o investimento financeiro na instalação de miniestações de monitoramento do ar como preparação para a Copa do Mundo de 2014", revela Nelzair. De acordo com ela, isso é consequência do pioneirismo do trabalho deles na capital baiana, que mobilizou os meios de comunicação e os órgãos ambientais. "Até então Salvador não possuía nenhum dado relativo às condições do ar nos locais estudados." A Secretaria de Saúde do município implantou o Núcleo Intersetorial para Qualidade do $\mathrm{Ar}$, coordenado por Nelzair, e recomenda para os órgãos ambientais a utilização da Tillandsia usneoides no monitoramento do ar. De acordo com os pesquisadores, o método testado por eles não deve substituir estações de monitoramento que possuem maior precisão de medição não só para material particulado, mas também para outros poluentes.

Evanildo Da Silveira

Artigo científico

VIANNA, N.A.; ANDRADE, L.R. et al Assessment of heavy metals in the particulate matter of two Brazilian metropolitan areas

by using Tillandsia usneoidesas atmospheric biomonitor. Environmental Science and Pollution Research. v.18, n.3, p. 416-27. 2011. 


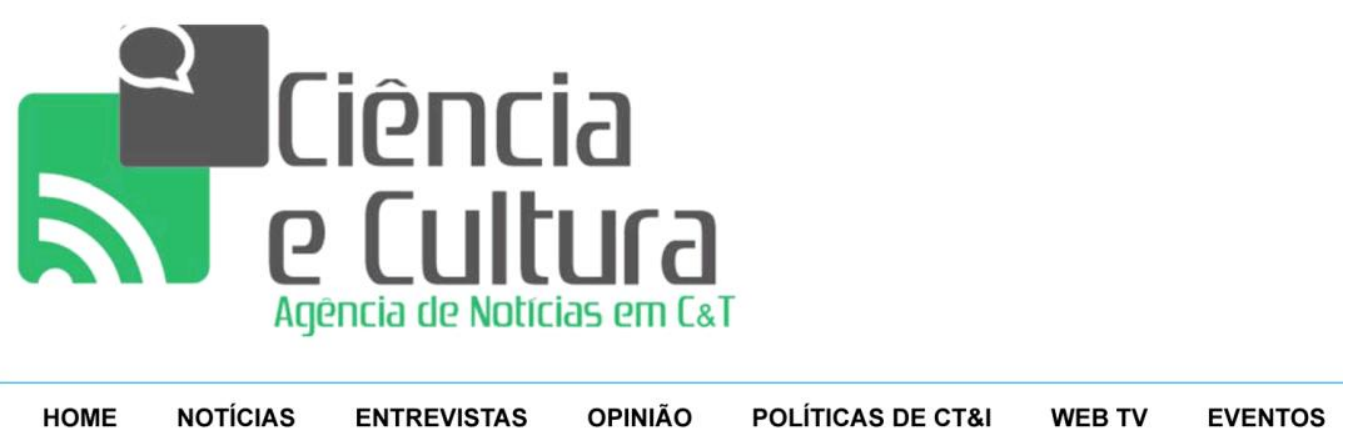

Home $>$ Notícias

atualizado em 22 de outubro de 2011 ás 15:06

\section{Bromélias detectam metais pesados no ar de Salvador e Rio de Janeiro}

Estudo pioneiro da Ufba e UFRJ revela concentração de chumbo, cádmio e cobre nas duas capitais. Em Salvador, bairro do Comércio tem o ar mais poluído

\section{Por Raiza Tourinho*}

raizatourinho@yahoo.com.br

$\triangle \quad$ Curtir 48

Buzinas, congestionamento, carros. Além do barulho e do estresse que as dezenas de quilômetros de veículos enfileirados causam aos condutores e passageiros, nas grandes cidades os automóveis são responsáveis por um perigo quase invisível: a poluição atmosférica. Foi essa a conclusão de um estudo, que visa detectar a presença de metais pesados nas partículas que circulam no ar da capital baiana e fluminense, realizado por pesquisadores das universidades federais da Bahia (Ufba) e do Rio de Janeiro (UFRJ), que revelou ainda que o Comércio é o bairro que tem o ar mais poluído em Salvador.

Coordenado em Salvador pela farmacêutica Nelzair Vianna, da Secretaria Municipal de Saúde, em parceira com professor do Instituto de Ciências Biomédicas da UFRJ, Leonardo de Andrade, o biomonitoramento constatou que $\circ$ ar que se respira contém elementos tóxicos para a saúde humana nas duas cidades.

Os pesquisadores utilizaram a bromélia conhecida como barba-de-velho (Tillandsia usneoides), espécie presente nas matas brasileiras, para realizar o biomonitoramento do ar, verificando a concentração de cinco elementos considerados extremamente tóxicos chumbo, cromo, cádmio, cobre e zinco. A planta foi escolhida devido às características que favorecem sua implantação para este fim: com uma raiz que serve apenas para fixar-se no solo, a espécie retira todos os nutrientes que necessita do ar, através das escamas que 
Bromélias detectam metais pesados no ar de Salvador e Rio de Janeiro ... http://www.cienciaecultura.ufba.br/agenciadenoticias/noticias/destaque...

recobrem seu corpo, além de se adaptar bem a condições climáticas extremas. O método é considerado eficiente e de baixo custo.

Pioneiro em Salvador, o estudo gerou resultados concretos que já podem ser visualizados nas avenidas da capital: as miniestações de monitoramento do ar. "A intenção não era mostrar somente um retrato da cidade, mas fornecer dados para políticas públicas que mitiguem de alguma forma esse impacto", afirma Nelzair. Apesar de satisfeita com o passo que foi dado devido à sua pesquisa, a farmacêutica alerta para a necessidade de mudanças mais efetivas. "Não é só melhorar o combustível utilizado, mas também o transporte público. Nós esperamos que a poluição seja vigiada pelo poder público", diz.

Poluição - As bromélias ficaram expostas durante 90 dias por ano, entre 2006 e 2008, divididas nas estações verão e inverno. As plantas ficaram, geralmente, a 2,5 metros de altura, para absorver os componentes que poderiam ser inalados pelas pessoas. Foram monitoradas sete regiões de Salvador (Subúrbio Ferroviário, Comércio, Brotas, Dique, Pituba, Barra e Stella Maris) e cinco locais no Rio. Para servir de comparação, as amostras foram transplantadas de dois locais sem poluição: o Parque Nacional do Itatiaia (RJ) e a cidade de Cordeiro, na região serrana do Rio de Janeiro.

Foram encontradas concentrações prejudiciais semelhantes de chumbo, cádmio e cobre nas duas cidades, sendo que o zinco e o cobre tiveram concentrações mais elevadas no Rio. Um relatório divulgado no final de setembro pela Organização Mundial de Saúde (OMS) apontou que o nível de poluição atmosférica da Região Metropolitana do Rio de 
Bromélias detectam metais pesados no ar de Salvador e Rio de Janeiro ... http://www.cienciaecultura.ufba.br/agenciadenoticias/noticias/destaque..

Janeiro é quase duas vezes maior ao da Região Metropolitana de São Paulo e ainda supera metrópoles como Nova York, Londres e Paris.

Na Bahia, as concentrações de chumbo mais acentuadas foram encontradas no bairro da Pituba durante o verão. Apesar de ser considerado o ar menos poluído das regiões pesquisadas, o bairro de Stella Maris apresentou elevadas concentrações de cádmio juntamente com a Barra. "Nos surpreendeu. É uma área com trafego menos intenso, no entanto poderia estar relacionado com a proximidade ao aeroporto, já que o combustível utilizado pelas aeronaves contém cádmio na sua composição", explica Nelzair, indicando uma associação provável entre o elemento e o bairro, próximo ao aeroporto. No entanto, na balança dos níveis das substâncias nenhum bairro foi mais impactado pela poluição do que o Comércio.

Comércio - O cenário defronte à minúscula barraca que o chaveiro Olímpio Soares trabalha há 30 anos, pouco mudou: carros, pessoas, navios, paredões de edifícios, apesar de mais modernos, continuam regendo o ritmo agitado no dia a dia do bairro Comércio. Apesar de nunca ter sofrido com problemas respiratórios, Soares teve a audição prejudicada pelo barulho dos motores. Ele não acredita que o ar do Comércio seja mais poluído do que o restante da cidade. "Só sinto o ar melhor mesmo quando vou para o interior. Aqui está pior e vai piorar cada dia mais", dispara. Os motivos para tal crença está no próprio caminho entre o trabalho e sua casa: o trajeto de 11 quilômetros entre o bairro de Tancredo Neves e o do Comércio chega a durar duas horas. Quatro das 24 horas do dia perdidas em engarrafamentos. "Daqui a cinco anos vai ser pior".

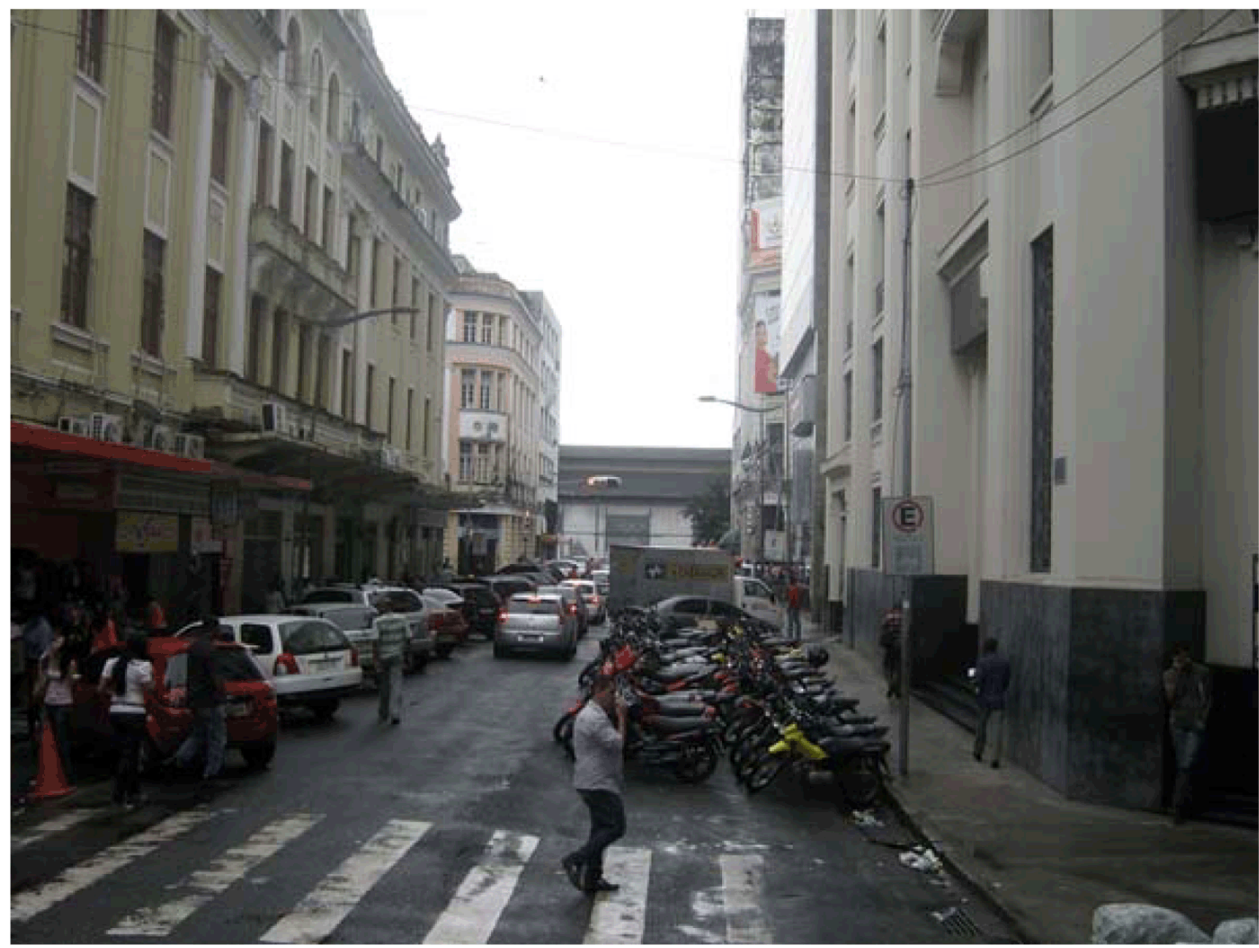

Número de veículos e grande concentração de prédios dá ao Comécio o título de bairro mais poluido 
Bromélias detectam metais pesados no ar de Salvador e Rio de Janeiro ... http://www.cienciaecultura.ufba.br/agenciadenoticias/noticias/destaque..

De acordo com a pesquisadora da Ufba, o intenso tráfego de veículos, o porto de Salvador e a topografia de paredões de prédio facilita o título de bairro que concentra mais o ar mais poluído. Até mesmo porque essas partículas viajam centenas de quilômetros. "Não existe delimitação geográfica. Estudos já revelaram que partículas da Floresta Amazônica chegam a São Paulo e da costa da África em Arembepe", conta Nelzair.

Assim, somente como políticas públicas locais talvez não seja possível evitar a globalização da poluição atmosférica, mas a farmacêutica explica que ações locais podem minimizar o impacto da poluição mais direta e concentrada, que atinge as pessoas próximas.

O próximo passo da pesquisa, aliás, é avaliar o risco para as pessoas, relacionando os danos à saúde provocados por esses elementos e a população soteropolitana. A ciência já sabe que os malefícios à saúde humana provocados pelos metais particulados são muitos. O chumbo, por exemplo, traz complicações renais, anemia crônica e déficit cognitivos. 0 cádmio geralmente se deposita nas células dos ossos e próstata, podendo causar danos a esses órgãos. Em excesso, mesmo o zinco, considerado essencial ao organismo humano, provoca danos como o estresse oxidativo. "Às vezes a brisa do mar nos passa a sensação que estarmos protegidos, mas não estamos", enfatiza Nelzair.

*Estudande de Jornalismo da Faculdade de Comunicação da Ufba - Facom

\section{Notícias relacionadas}

Seminário discute metas para cidade sustentável

\section{Um comentário a Bromélias detectam metais pesados no ar de Salvador e Rio de Janeiro}

alvaro figueiredo disse:

excelente pauta para a mídia ambiental e cddadã_grato pelo tema e abordagem

\section{Deixe um comentário}

O seu endereço de email não será publicado Campos obrigatórios são marcados *
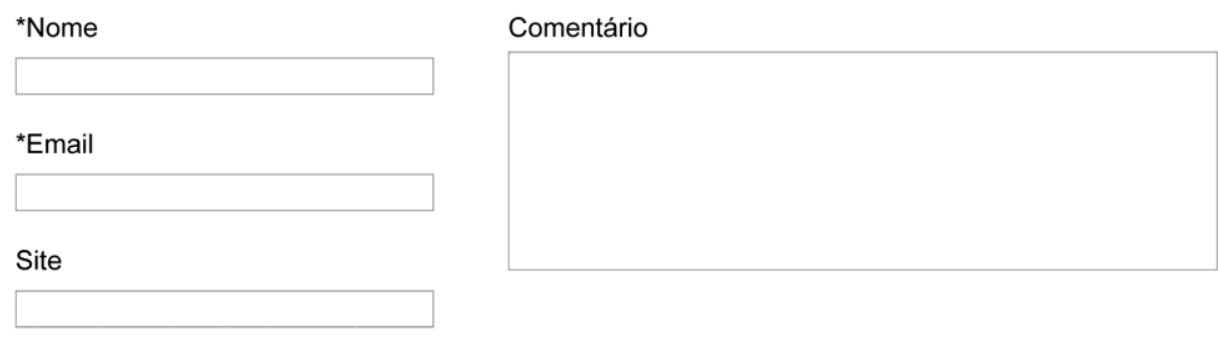
Bromélias detectam metais pesados no ar de Salvador e Rio de Janeiro ... http://www.cienciaecultura.ufba.br/agenciadenoticias/noticias/destaque...

Realização

Parceria

\section{周 facom}
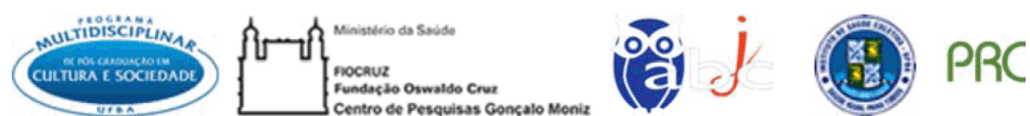

Ciência e Cultura - Agência de Notícias em CT\&I da Bahia - Copyright $\odot 2011$ - Todos os direitos reservados

Faculdade de Comunicação - Universidade Federal da Bahia

Rua Barão de Geremoabo, s/n, Ondina, Salvador, Bahia, Brasil. Tel: (71) 3283-6174, 3283-6177 Fax: (71) 3283-6197 


\section{- Jornal A TARDE}

MEEı AMBBIEnTrE I Medições das partículas lançadas por carretas e caminhões apontaram índices muito acima do recomendado

\section{Ar fica mais poluído no Carnaval}

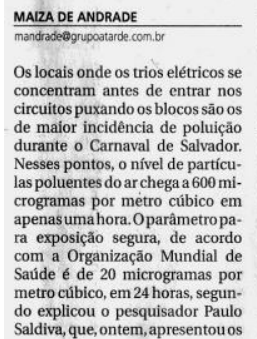

resultados do monitoramento da qualidade do ar

Carnaval de 2007. Segundo o pesquisador, as pecorre minhōes com motores velhos us. dos para carregar os equipametos de somede suportedos blocos.

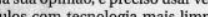
para evitar que a festa, "que é pan celebrar a alegria, se torne motivo de prejuízo para a saúde". Elecom parou a exposiçáo à poluiçáo ro a cada hora. "Ninguém cai duro

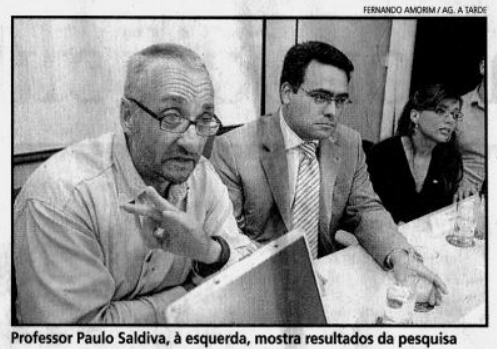

ter aumentado o risco de contrair Municipal de Meio Ambient uma asma agravada, ou de ter gri- ram utiliza pe com mais facilidade, observou melias por terem a capacidade d

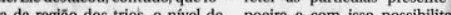
particulas em suspensio produzi- pontise a dos na combustão veicular estava Oseeretário de Meio Ambiente
dentro dos padrōes da OMS. ção do governo é a de criar norn do ar no Carnaval foi feito por pes- regras para os veículos usados

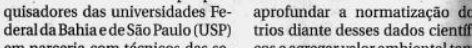

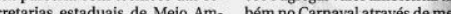
cretarlas estaduals de Melo $\mathrm{Am}$ bém no Carnaval através de medi Saúde, além da Superintendéncia a dascomo ous

Salvador não tem rede de monitoramento do ar

O monitoramento da qualidade do ar de Salvador nâ é feito de Cristina Semotora Maria forma regular. Antes do

feita foi $\mathrm{em} 2006$, em pesquisa da bioquímica Nelzair Vianna, de Meio Ambiente (SMA). Segundo a pesquisadora. estudo foi apontada a presenç de metais pesados, como chumbo, no ar da Pituba, en nivels acsultado das primeira pesquisas levou o Ministério Público a abrir inquéritos nas promotorias de saude publica de políticas públicas ara medir a qualidade do ar. públicos açóes neste sentido, $j$ que a qualidade do ar afeta

0 secretario estadual de

Meio Ambiente e Recurso Hídricos, Juliano Matos, disse resolver essa questão seráa a extensãosa para Salvador da rede de monitoramento da 
- Jornal A TARDE - 31.10.11

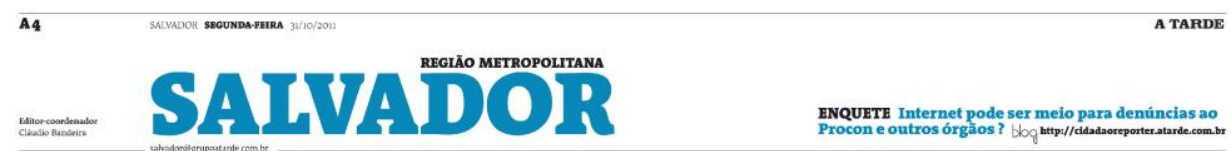

SAÚDE Pesquisa mostra que bairros apresentam altos índices de contaminação por metais pesados no ar atmosférico Barra, Pituba e Comércio lideram poluição

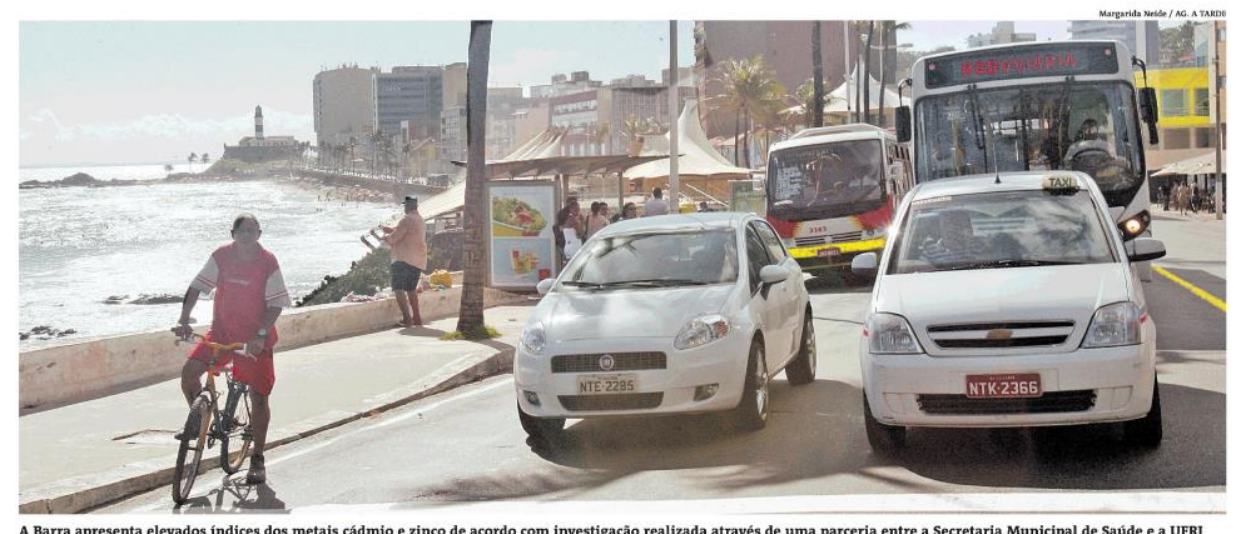

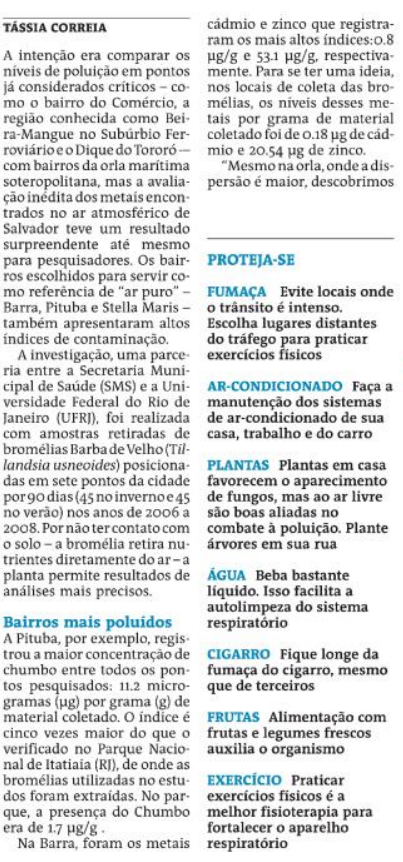

Metais podem duplicar efeitos negativos da poluição na saúde
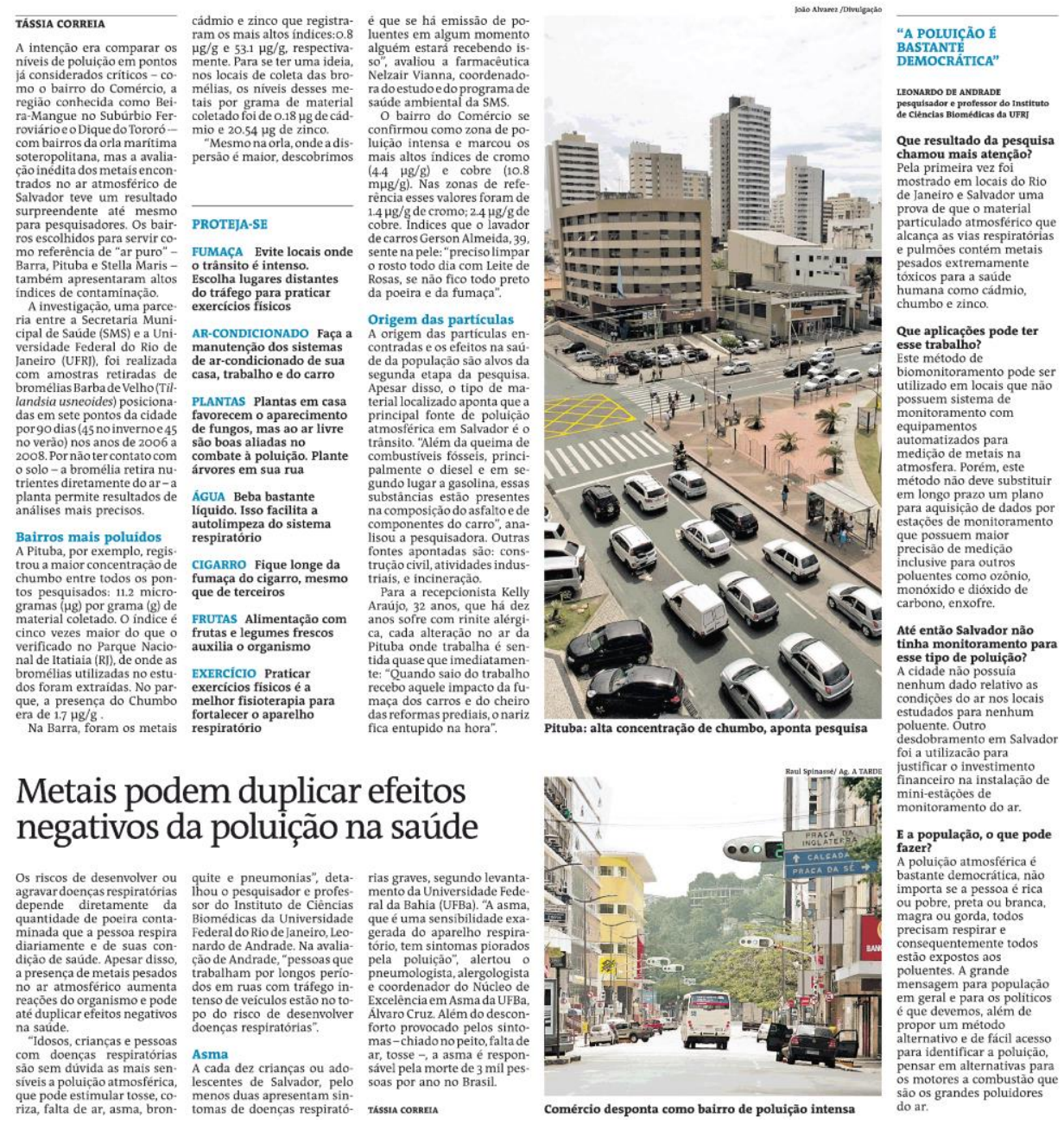
- Jornal A TARDE - 27.10.10

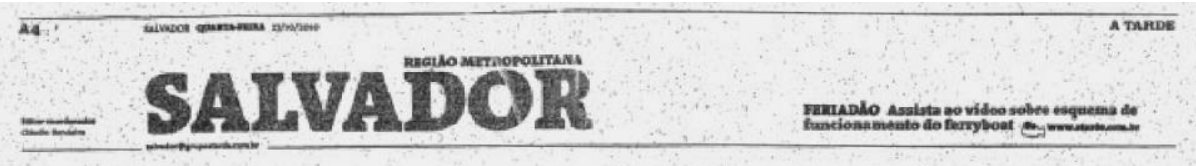

SAUUDE Apesar da exigência em cidades com mais de 500 mil habitantes, poluiçăo atmosférica não é monitorada em Salvador Capital não tem controle da qualidade do
ar, contrariando uma determinação legal
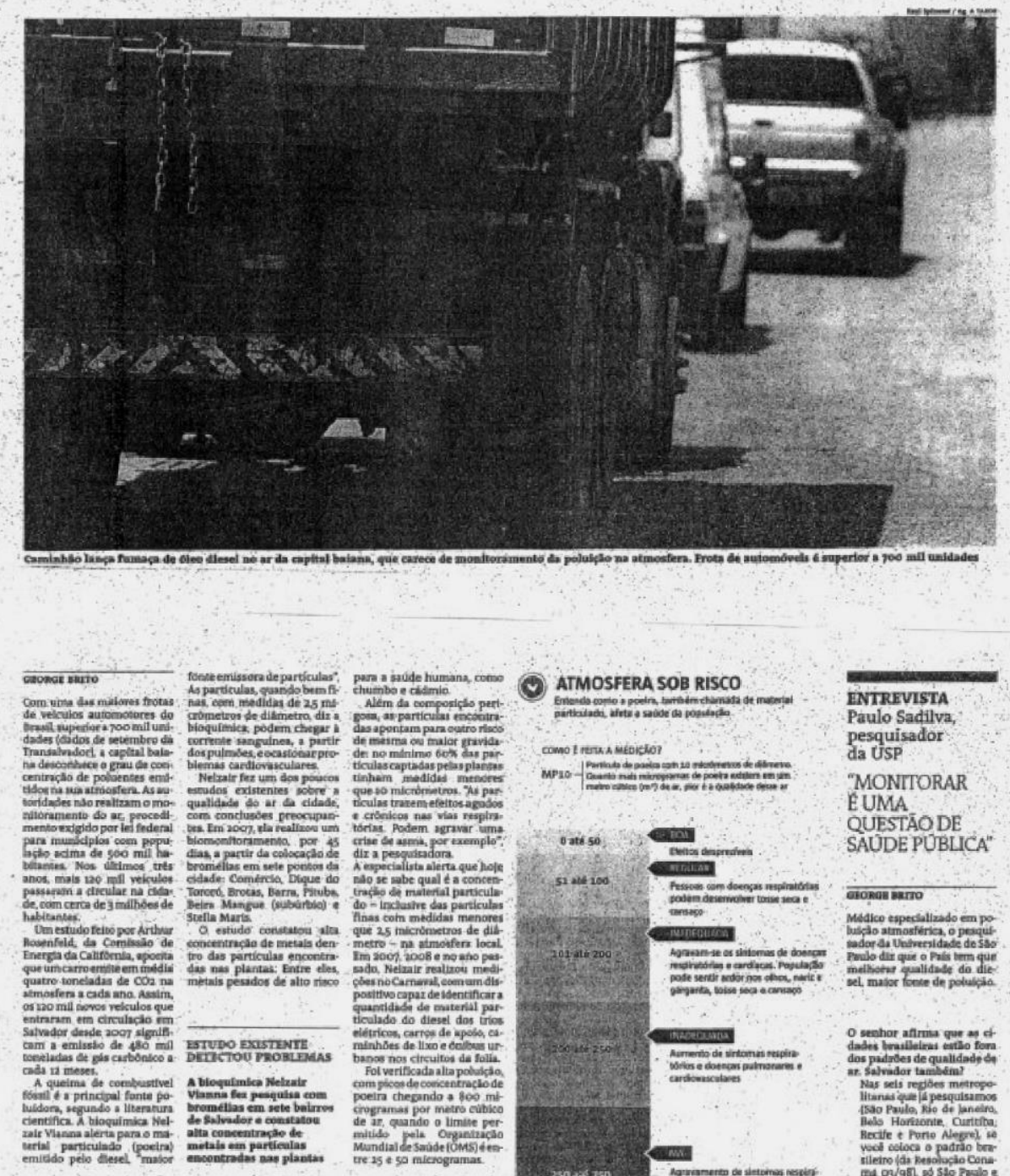

Iniciativas começam a tomar corpo em função da Copa 2014

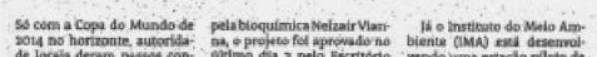

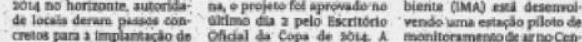

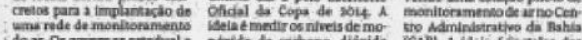

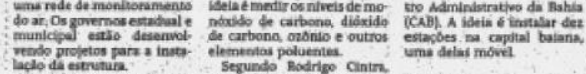

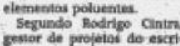

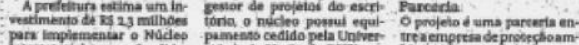

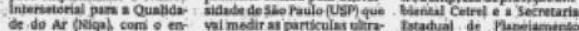

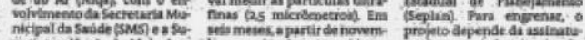

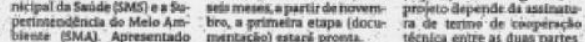

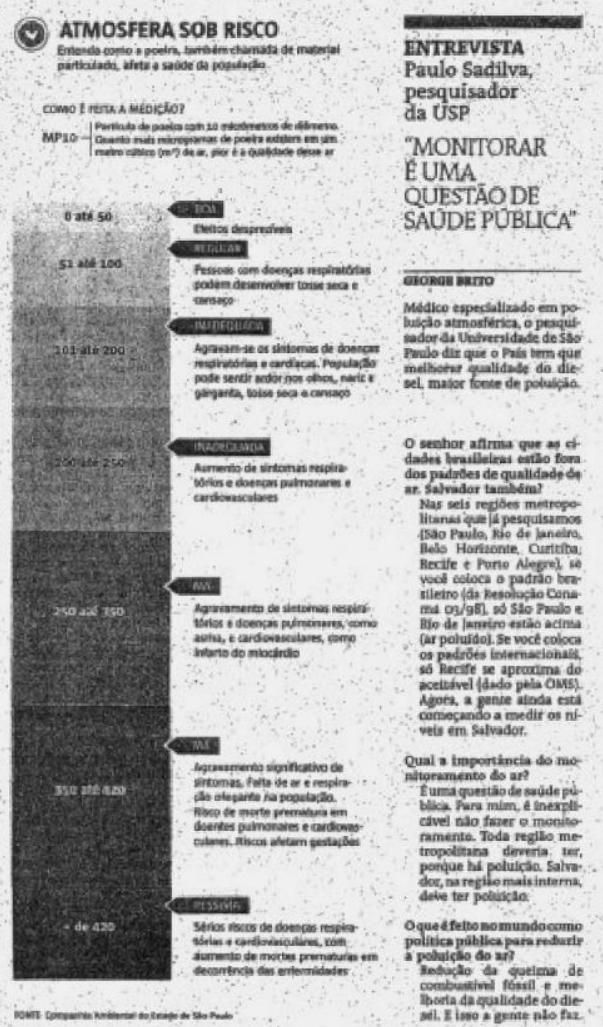


- Jornal A TARDE - Dia do meio ambiente 05.06.2009

DIA DO MIEIO AMiBRENTE I Os baianos do interior e da capital praticamente não têm o que celebrar na data

Menos verde, mais carros e muito pouco lixo reciclado

"Nós não temos a opção de deixar de respirar"

Nelzair Vianna | farmacêutica bioquímica e pesquisadora da USP

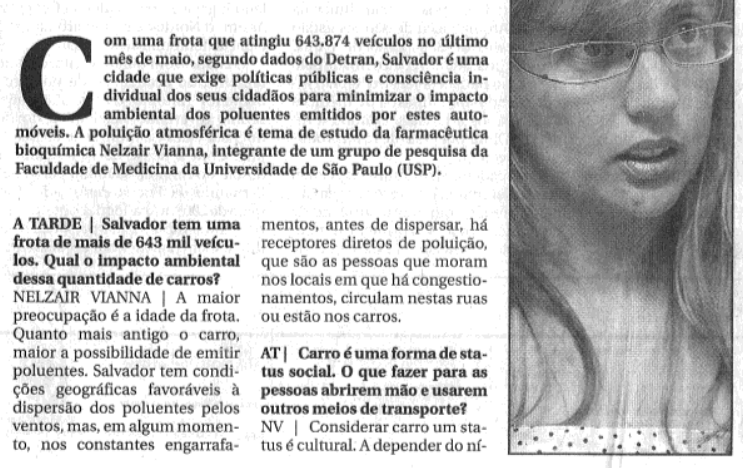

\section{vel de consciéncia ambiental da} pessade ela pode se sentir coin
mais status em uma bicicleta

ATI O que pode ser feito para minimizar esse impacto? NV I Mudança da matriz ener.
getica. por exemplo. Hámedida gética, por exemplo. Hámedidas
que podem ser adotadas pelo poder público, comomelhoraro sistema de transporte público,
estimular o uso de bicicletas a construçá de cicloviase

É inadmissivel que o poder público permita circularem veícuIs soltando fumaça negra. Salmento da qualidade do ars

ATI Mesmo quem anda decar-
ro pode contribuir de alguma orma para reduzir a poluluç̧̃ó

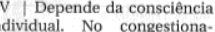
nento, a pessoa pode acelerar

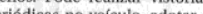

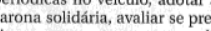
isa mesmousar o carro oupodo utilizar outro meio de locomo
cio. Pode escolher o tipo çäo. Pode ess
combustivel.

\section{"É}

Pode exarcebar os sintom

inadmissivel

público

publico

permita

circularem

veículos

fumaça

negra.

preciso

monitorar o

ar"

crise de asma e outras dor

gulabilidade do sangue provocar conjuntivite, contato com o poluente mucosa e facilita a entrac cronicas temosocectincer, d bios nervosos e hormona sordem do sistema reprodi Tudo decorrente da toxici partículas mais finas ina chegam à corrente sanguif se depositam nas células. AT | Como vocé avalia as ticas pút

AT | Qual o melhor combustível, omenos poluente?

$90 \%$ do material particulad que é aquele associado a efeitos à sád́de e, por isso, mais preocu-
pante, é emitido por vécullos que usam diesel. O Oálcool é o o

AT] Quals problemas esse ma dade do Pais e temos um cl
d mento acelerado. As po
públicas, não sei por não acompanham. certamente, haverá cobì
da sociedade. Dife de nis retermos a respirar. Entāo, acredito 
- Jornal A TARDE - 18.10.05

Bromélias indicarão qualidade do ar"
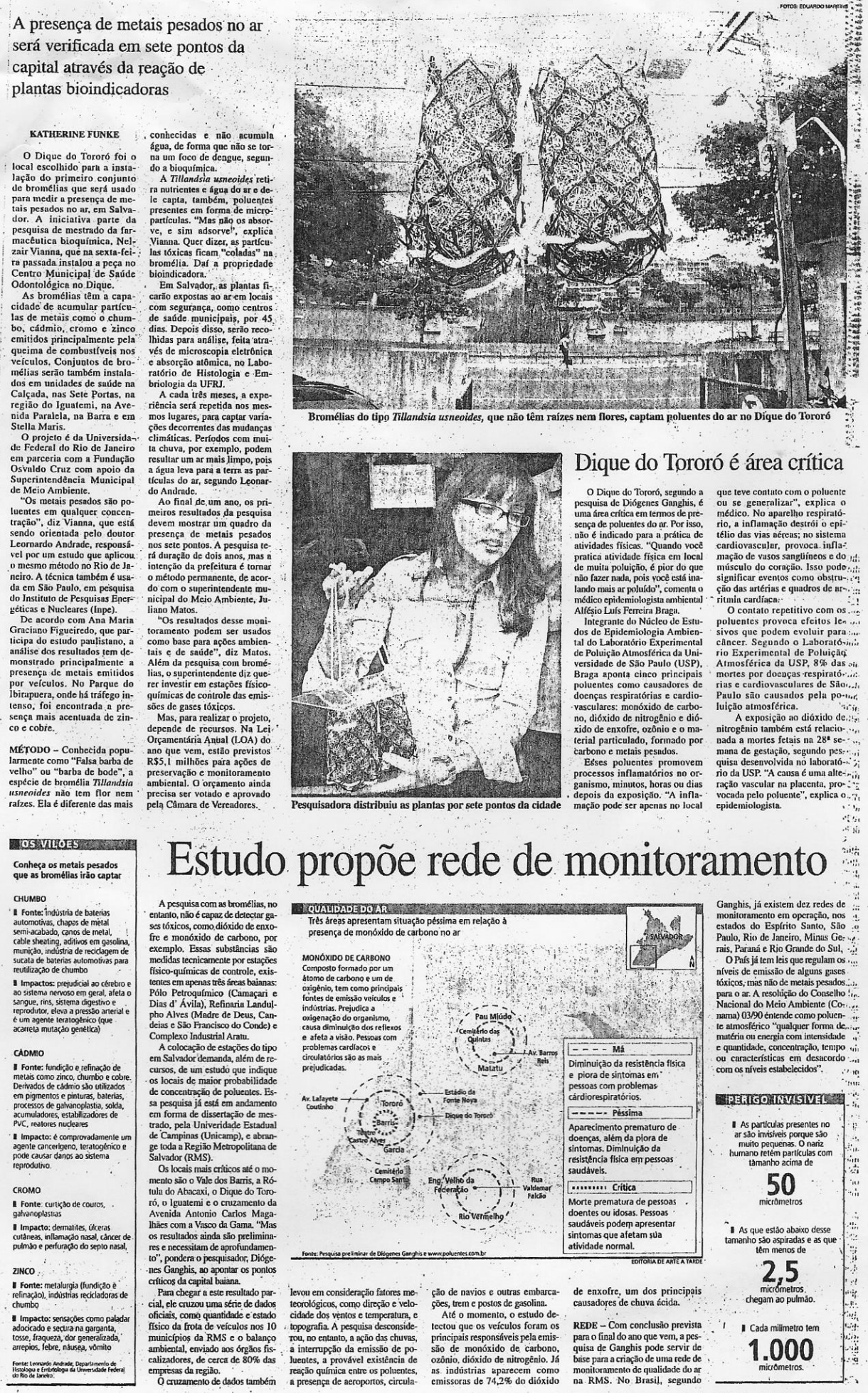


\title{
aratuonline
}

$30 / 01 / 2008-06 h 45$

\section{Métodos de monitoramento do ar no Carnaval serão apresentados hoje}

\begin{abstract}
O novo método para monitorar a qualidade do ar nos circuitos do Carnaval de Salvador 2008 será conhecido hoje (30), às $17 \mathrm{~h}$, no Auditório do Restaurante Aice Zushi, na Av. Paulo VI (Pituba). A novidade será apresentada pelo pesquisador da Universidade de São Paulo (USP), o patologista Paulo Saldiva, pela bioquímica Nelzair Vianna e pelo secretário de Meio Ambiente e Recursos Hídricos do Estado (Semarh), Juliano Matos.
\end{abstract}

O dispositivo de tubo passivo é um monitor individual capaz de identificar a quantidade de dióxido de nitrogênio (NO2), gás emitido na atmosfera por meio da combustão do diesel, utilizado nos trios elétricos, carros de apoio, caminhões de lixo, ônibus urbanos e outros veículos nos circuitos da Folia.

Além desse, será apresentado ainda o aparelho mecânico nefelômetro, cedido pelo Laboratório de Poluição Atmosférica da USP, que faz a monitoração contínua de concentração de material particulado (poeira em suspensão), com capacidade para detectar o tamanho mínimo capaz de penetrar no trato respiratório.

As bromélias Tillandsia Usneoides, que também são utilizadas em técnicas de biomonitoramento do ar, serão trazidas do Jardim Botânico do Rio de Janeiro, pelo biólogo Leonardo Andrade, do Departamento de Histologia e Embriologia da Universidade Federal do Rio de Janeiro (UFRJ). As plantas, também conhecidas como barba-develho, retém em sua superfície escamosa partículas microscópicas de metais pesados e poluentes, capazes de afetar a saúde humana.

A pesquisa de monitoramento do ar durante o Carnaval de Salvador é uma ação pioneira da Secretaria de Meio Ambiente e Recursos Hídricos do Estado (Semarh), e pretende identificar os metais pesados e gases tóxicos na atmosfera da festa, ao longo de 25 quilômetros de vias, em trechos com pouca ventilação e muita queima de combustivel. 


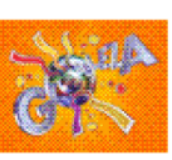

www.globo.com/carnaval

CARNAVAL 2008

$\underline{\text { imprimir }}$

21/01/2008-11h06

\section{Qualidade do ar de Salvador será monitorada durante o carnaval}

Pesquisa vai identificar metais pesados e gases tóxicos presentes na atmosfera.

Este ano, monitoramento também avalia quantidade de dióxido de nitrogênio.

Do G1, em São Paulo, com informações doiBahia.com

A qualidade do ar que abastece os foliões durante o carnaval de Salvador será monitorada novamente este ano. A pesquisa, realizada ao longo de 25 quilômetros de vias, vai identificar os metais pesados e os gases tóxicos na atmosfera da festa em trechos com pouca ventilação e muita queima de combustível.

O projeto é promovido pela Secretaria Estadual de Meio Ambiente e Recursos Hídricos (Semarh), em parceria com departamentos de pesquisa ambiental das universidades de São Paulo (USP) e do Rio de Janeiro (UFRJ).

A bioquímica e pesquisadora Nelzair Vianna informou que os locais com maior incidência de poluição durante o Carnaval de Salvador são o Campo Grande e o Farol da Barra, com as concentrações dos trios elétricos. O nível de partículas poluentes do ar nesses locais chega a 600 microgramas por metro cúbico, em apenas uma hora. De acordo com a Organização Mundial de Saúde (OMS), uma exposição segura é de 20 microgramas por metro cúbico, no período de 24 horas.

\section{Novidade}

A novidade do monitoramento deste ano é um dispositivo de tubo passivo, um monitor capaz de identificar a quantidade de dióxido de nitrogênio, gás emitido na atmosfera por meio da combustão do diesel utilizado nos trios elétricos, carros de apoio, caminhões de lixo, ônibus urbanos e outros veículos nos circuitos da folia.

URL:http://g1.globo.com/Carnaval2008/o,,MUL267649-9772,oo.html 


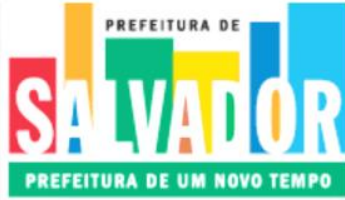

Pesquisar

Mude o Tamanho da Letra A+ A-
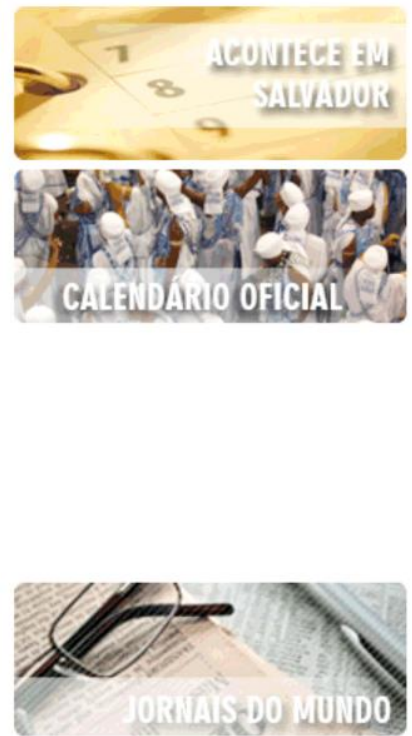

\section{ENQUETE}

Para reduzir os danos causados pela incidência das fortes chuvas é importante:

Processos continuos de educação ambiental e de conscientização voltadas para a população:

A realização de açōes conjuntas preventivas pelos governos municipal e estadual e federal

Cooperação entre cidadãos e poderes públicos:

Ações de urbanização e de

saneamento básico são

suficientes.

Votar Resultado

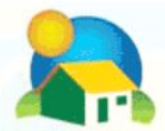

Minha Casa

Minha Vida

\section{CADASTRE - SE AQUI}

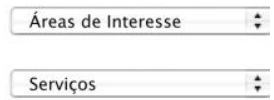

Principal + Notícias + Qualidade do ar fica comprometida no Carnava

\section{Qualidade do ar fica comprometida no Carnaval}

A) (2) D

\section{1/05/2007 16:43}

Foi apresentado ontem (dia 10), à tarde, durante coletiva na Secretaria de Meio Ambiente e Recursos Hídricos do Estado da Bahia (Semarh), no Centro Administrativo da Bahia, o resultado dos estudos de biomonitoramento da qualidade do ar do percurso do Carnaval de Salvador de 2007. A pesquisa de campo comprovou que atrás de um trio elétrico a concentração de substâncias tóxicas chega a 400 microgramas $/ \mathrm{m}^{3}$ em uma hora de exposição, sendo que pelos padrões da Organização Mundial de Saúde o normal é 20 microgramas $/ \mathrm{m}^{3}$ em 24 horas de exposição.

Para fazer tal avaliação foi utilizado o nefelômetro, um aparelho que mede, instantaneamente, a quantidade de concentração de substâncias nocivas à saúde, tais como metais pesados e hidrocarbonetos (hidrogênio + carbono). "Uma hora atrás de um trio elétrico velho corresponde a 24 horas de exposição numa cidade como São Paulo em um dia de poluição elevada", compara o professor Paulo Saldiva, da Universidade de São Paulo, que completa na tentativa de amenizar a situaçăo: "Como são poucos dias de festa, o risco apresentado, felizmente, não é tão acentuado".

O que pode acontecer, segundo o professor, é o agravamento de uma sinusite, de asma ou o risco de uma gripe mais agressiva. O encontro na Semarh concluiu que é possivel fazer uma festa "mais limpa", agregando valores ambientais a um evento tão importante como o Carnaval.

"A festa por si só já tem uma tradição de avaliar o que não foi positivo para que não se repita e o resultado desse estudo nos possibilita melhorar a qualidade do ar da maior festa de rua do planeta" avalia o superintendente do Meio Ambiente, Ary da Mata, que se comprometeu em encaminhar ao Conselho Municipal do Carnaval os resultados do monitoramento e as possiveis soluções para o problema.
Providências

Aprofundar as normatizações relacionadas à questão, promover a descarbonização e a mudança da matriz energética dos trios elétricos do Carnaval de Salvador são algumas medidas mencionadas no encontro com o intuito de amenizar o indice de poluiçăo. "Nosso trabalho agora será o de estabelecer padrões aos trios que agreguem valor ambiental e os que não atingirem tais padrões vão ter de se qualificar", alertou Juliano Matos, secretário estadual do Meio Ambiente, acrescentando: "Já iremos trabalhar pensando no Carnaval de 2008, sem esquecer também dos trios que fazem parte das micaretas em outros municipios".

A coletiva contou com a presença de autoridades ligadas ao tema, como a bioquimica e pesquisadora Nelzair Vianna, o biólogo do Departamento de Histologia e Embriologia da Universidade Federal do Rio de Janeiro, Leonardo Andrade, e o pesquisador da Fiocruz, Marcos Vannier.

[ Voltar ] 